\title{
Evolutionary Cell Biology of Proteins from Protists to Humans and Plants
}

\author{
Helmut Plattner (iD) \\ Department of Biology, University of Konstanz, P. O. Box M625, Konstanz 78457, Germany
}

\author{
Keywords \\ Cell function; eukaryote; evolution; molecu- \\ lar biology; protozoa; ultrastructure.

\section{Correspondence} \\ H. Plattner, Department of Biology, Univer- \\ sity of Konstanz, P. O. Box M625, Konstanz \\ 78457, Germany \\ Telephone number: +49 7531-88-2228; \\ FAX: +49-7531-88-2168; \\ e-mail: helmut.plattner@uni-konstanz.de
}

\begin{abstract}
During evolution, the cell as a fine-tuned machine had to undergo permanent adjustments to match changes in its environment, while "closed for repair work" was not possible. Evolution from protists (protozoa and unicellular algae) to multicellular organisms may have occurred in basically two lineages, Unikonta and Bikonta, culminating in mammals and angiosperms (flowering plants), respectively. Unicellular models for unikont evolution are myxamoebae (Dictyostelium) and increasingly also choanoflagellates, whereas for bikonts, ciliates are preferred models. Information accumulating from combined molecular database search and experimental verification allows new insights into evolutionary diversification and maintenance of genes/proteins from protozoa on, eventually with orthologs in bacteria. However, proteins have rarely been followed up systematically for maintenance or change of function or intracellular localization, acquirement of new domains, partial deletion (e.g. of subunits), and refunctionalization, etc. These aspects are discussed in this review, envisaging "evolutionary cell biology." Protozoan heritage is found for most important cellular structures and functions up to humans and flowering plants. Examples discussed include refunctionalization of voltage-dependent $\mathrm{Ca}^{2+}$ channels in cilia and replacement by other types during evolution. Altogether components serving $\mathrm{Ca}^{2+}$ signaling are very flexible throughout evolution, calmodulin being a most conservative example, in contrast to calcineurin whose catalytic subunit is lost in plants, whereas both subunits are maintained up to mammals for complex functions (immune defense and learning). Domain structure of R-type SNAREs differs in mono- and bikonta, as do $\mathrm{Ca}^{2+}$-dependent protein kinases. Unprecedented selective expansion of the subunit a which connects multimeric base piece and head parts (VO, V1) of $\mathrm{H}^{+}$-ATPase/ pump may well reflect the intriguing vesicle trafficking system in ciliates, specifically in Paramecium. One of the most flexible proteins is centrin when its intracellular localization and function throughout evolution is traced. There are many more examples documenting evolutionary flexibility of translation products depending on requirements and potential for implantation within the actual cellular context at different levels of evolution. From estimates of gene and protein numbers per organism, it appears that much of the basic inventory of protozoan precursors could be transmitted to highest eukaryotic levels, with some losses and also with important additional "inventions."
\end{abstract}

\section{BASIC PRINCIPLES}

For the evolution of complex eukaryotic cells, increase of genetic information and its sequestration into a nucleus was a prerequisite. This, paralleled by increased cytoplasmic complexity, has been facilitated by increased energy supply enabled by symbiotic nidation of endocytosed bacteria performing oxidative phosphorylation (Hedges 2002). Although Llynch and Marinov (2016) recently argued that acquirement of mitochondria did not 
Table 1. Changes of defined proteins and/or reassignment to variable functions during evolution

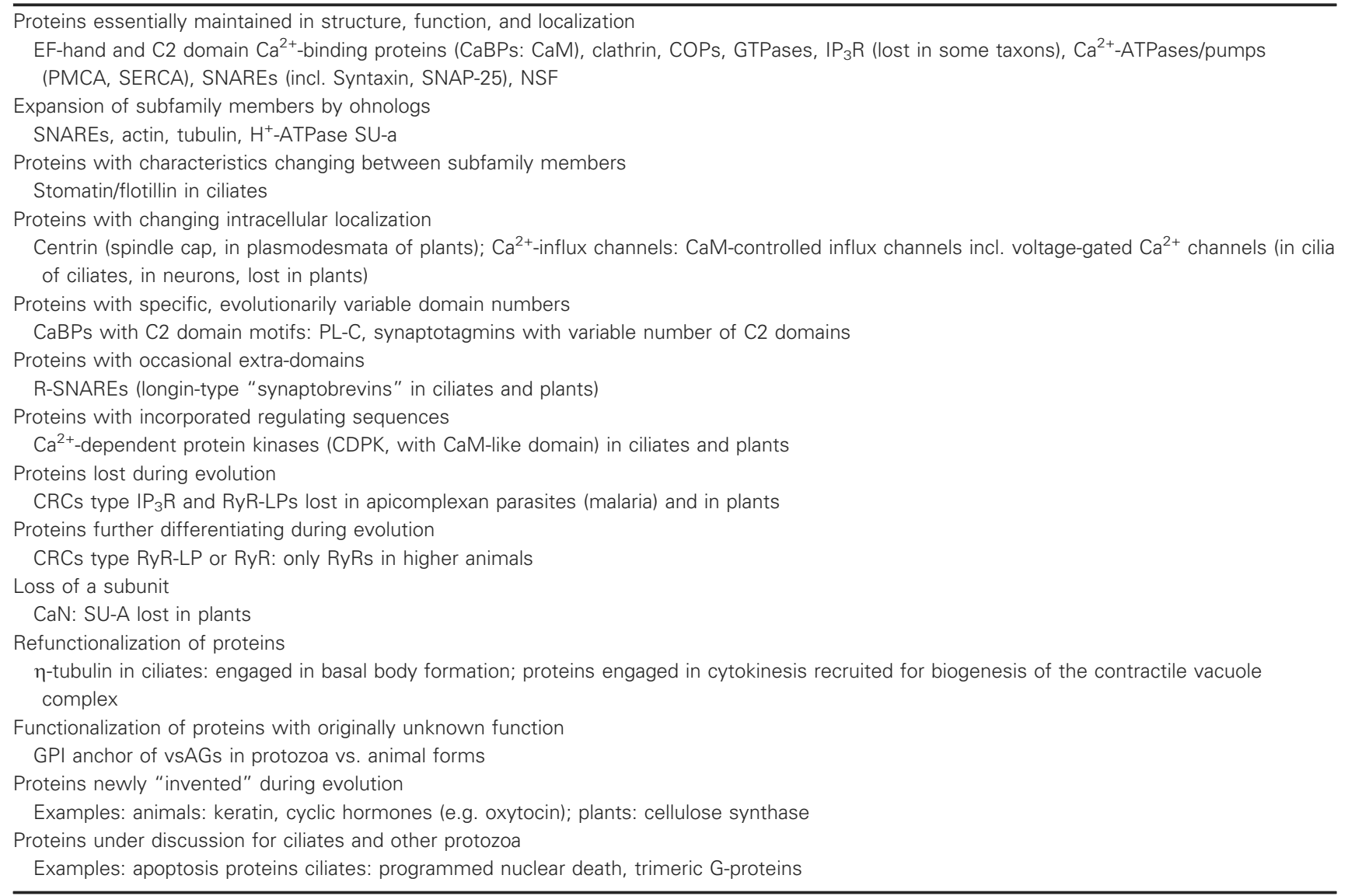

Note that indications given do not reflect all details which are to be retrieved from the text.

boost biogenetic capacity in eukaryotic cells, the advantage may have been the provision of ATP at defined intracellular sites near mitochondria, just as discussed for the involvement of $\mathrm{Ca}^{2+}$ signaling also in early eukaryotic evolution (below). This was paralleled by efficient phagocytosis of nutrient bacteria for intracellular digestion. Archaea, particularly of the "TACK" superphylum (Lokiarchaeota), recently come into the limelight of eukaryote evolution, since they share important molecules with eukaryotes (Guy and Ettema 2011; Koonin and Yutin 2014) and anticipated the following aspects: protein-bound DNA (nucleosomes), provision of cytoskeletal elements, protein modifications, and endo-/phagocytosis capability (Ammar et al. 2012; Spang et al. 2015). Such archaebacteria may have provided a "mother-cell" for endocytotic uptake and symbiotic integration of specific eubacteria, together with uptake of specific eubacterial genes. The most essential components of the cytoskeleton, actin, and tubulin in polymerizable form are thought to originate from stages preceding the last common eukaryotic ancestor (Koonin and Yutin 2014), followed by accessory and regulatory proteins (Wickstead and Gull 2011). Partial compartmentalization is observed already in multiple prokaryotic lineages (Diekmann and Pereira-Leal 2013), as are some prokaryote cell fusions (Martijn and
Ettema 2013) and extensive lateral gene transfer (Abby et al. 2012; Katz 2012), to mention just some aspects of most likely importance for early eukaryote evolution.

With increasing complexity, this prokaryote-to-eukaryote transition required control by a plethora of key molecules some of which are addressed in this review. Some concern $\mathrm{Ca}^{2+}$ which steadily leaks into cells and is transformed from toxic agent into a useful second messenger. The cell has to remain flexible, as a fine-tuned machine, under steadily changing conditions. Each cell may be optimally organized in the respective environment, as pointed out for organismic life by environmentalist Jakob von Uexküll already in the 19th century. Nevertheless, terms such as "lower" and "higher" eukaryotes may be used to indicate evolutionary successions. However, "low" does not necessarily mean primitive; for this, we will find ample testimony when we trace the "evolutionary career" of individual proteins. As summarized in the Tables 1, 2, we see proteins maintained throughout evolution, but often with more or less changes in structure, function, and intracellular localization. In this sense, "evolutionary cell biology" a term propagated by Lynch et al. (2014) should follow the key goal to provide cell biology with an evolutionary perspective. This is the perspective of this article. 
Table 2. Similarity (of molecular structure) and comparison of intracellular localization of selected proteins in Monokonta and Bikonta

\begin{tabular}{|c|c|c|c|c|}
\hline \multirow[b]{2}{*}{ Molecule } & \multicolumn{2}{|c|}{ Occurrence in } & \multicolumn{2}{|c|}{ Comparison Mono-/Bikonta } \\
\hline & Monokonta & Bikonta & Similarity & Localization \\
\hline CaM & + & + & Yes & Variable \\
\hline $\mathrm{CaN}$ & $+(\mathrm{SU}-\mathrm{A}$ and SU-B) & $\begin{array}{l}\text { + (Paramecium tetraurelia) } \\
\text { - Plants: SU-B only }\end{array}$ & Yes & Variable \\
\hline GTPases & + & + & Yes & Comparable \\
\hline Q-SNARES & + & + & Yes & Identical \\
\hline \multicolumn{5}{|l|}{ R-SNARES } \\
\hline "Brevins" & + & - (P. tetraurelia) & na & na \\
\hline Longins & +/- (Rare in mammals) & $+P$. tetraurelia, plants & Mostly diff. & na \\
\hline Synaptotagmin & + & + Plants (not in P.t.) & Yes & na (plants) \\
\hline eSyntag & $\begin{array}{l}\text { + Monosiga brevicollis } \\
+ \text { Mammals (rare) }\end{array}$ & $+P$. tetraurelia & Variable & Unknown \\
\hline PMCA & + & + & Yes & Identical \\
\hline SERCA & + & + & Yes & Identical \\
\hline Flotillin/Reggie & + & + & Variable & Variable \\
\hline Centrin & + & + & Yes & Different \\
\hline Actin & + & + & Yes & Variable \\
\hline Tubulin & + & + & Yes & Similar \\
\hline CDPK & - & + Ciliates, plants & Different & Unknown \\
\hline V-dep.Ca ${ }^{2+}$ channels & + & $\begin{array}{l}+ \text { P. tetraurelia } \\
+ \text { Chlamydomonas } \\
- \text { Plants }\end{array}$ & $\begin{array}{l}\text { Identical? } \\
\text { na } \\
\text { na }\end{array}$ & $\begin{array}{l}\text { Different } \\
\text { Identical } \\
\text { na }\end{array}$ \\
\hline TRP channels & + & $\begin{array}{l}\text { - Ciliates } \\
+ \text { Chlamydomonas }\end{array}$ & na & na \\
\hline $\mathrm{IP}_{3} \mathrm{R}$ & + & $\begin{array}{l}+P . \text { tetraurelia } \\
\text { - Plants }\end{array}$ & $\begin{array}{l}\text { Yes } \\
\text { na }\end{array}$ & Similar \\
\hline GPI proteins & + & + & Similar anchor & Different \\
\hline
\end{tabular}

Note that this table gives only a gross outline; for details, see text.

n.an/na $=$ not analyzed/not applicable or not analyzed; P.t. $=$ Paramecium tetraurelia.

\section{There is a common molecular heritage}

Widely different genes from different bacteria must have been collected by early eukaryotes; in the end (archae)bacterial genes contribute by $\sim 37 \%$ to mammalian gene sequences (McFall-Ngai et al. 2013). Moreover, gene transfer occurs frequently between different levels of evolution (Soucy et al. 2015), and this is an ongoing process up to vertebrates (Crisp et al. 2015). Altogether $\sim 28 \%$ of genes are all-eukaryotic (McFall-Ngai et al. 2013). This makes this review feasible. It starts at the level of protists (and occasionally of bacteria), meaning mainly protozoa and fewer taxons of algae, the green counterparts.

Protozoa already contain a considerable inventory of genes/proteins and protein assemblies which can be followed up to multicellular organisms. There are reasons to assume that the last eukaryotic common ancestor already possessed such organelles (Brooks and Wallingford 2014). Two main evolutionary lineages are frequently envisaged; depending on the occurrence of single cilia (or flagella) or of ciliary (flagellar) pairs, organisms are subdivided-whether right or wrong remaining debatable-into mono- or bikonta. On this basis, one can ask-beyond genomics-two fundamental questions. First, which changes in function and localization may have occurred during evolution? Second, are there consistent differences between the main lineages of eukaryote evolution, such as mono- and bikonts? As summarized in Table 1, widely different mechanisms result in changes during evolution. According to Table 2, about two-thirds of the molecules analyzed look rather similar the two lineages, only about one-third being considerably different, but with considerable changes in intracellular localization.

Proteins mandatory for basic eukaryotic functions are in particular focus. Cytoskeletal elements, like microtubules and microfilaments, have been inherited from prokaryotes (Pilhofer et al. 2011), to which, in eukaryotes, accessory proteins and motor proteins have been adopted (Wickstead and Gull 2011). This was required for intracellular transport, together with motor proteins whose number is identical in Tetrahymena thermophila and in Homo sapiens (Eisen et al. 2006). This was complemented by molecules for vesicle budding and other proteins mediating specificity of membrane-to-membrane interactions, docking, and final fusion. All this is mediated essentially by coatomer proteins (COPs), SNARE proteins (soluble $\mathrm{N}$ ethylmaleimide-sensitive factor attachment protein receptors) and GTPases (monomeric low-molecular weight GTP-binding/GTP hydrolyzing proteins) (Bonifacino and 
Glick 2004; Grosshans et al. 2006; Mizuno-Yamasaki et al. 2012; Rothman 2014; Südhof 2014).

SNAREs are integrated in membranes by a single carboxy-terminal hydrophobic stretch (Rothman 2014; Südhof 2014). They contain a SNARE domain around central layer of a typical aminoacids, Arg and GIn, and, therefore, are called, R- and Q-SNAREs, respectively. This R/Q situation, however, is not fully maintained, from Paramecium on up to highest species (Plattner 2010a). GTPase effects are regulated by proteins with antagonistic, activating, and inhibiting effects still to be studied in protists.

Establishment of a simple intracellular trafficking system is considered an early achievement of eukaryote evolution (Dacks and Field 2007), and this may have included SNAREs and GTPases. Remarkably, for early eukaryotes a set of 20 SNAREs has been extrapolated (Kloepper et al. 2008). Although this is well below values found in protists and in any other organism (Plattner 2010a), this may have allowed for increased energy input by phagocytosis, as found already in Archaeota (Koonin and Yutin 2014) and further differentiation of lytic compartments and recycling vesicles. In addition, $\mathrm{H}^{+}$-ATPase/pumps and $\mathrm{Ca}^{2+}$-regulating proteins had to be established, as to be demonstrated. Some of these components have been available already in bacteria. Since the eukaryotic cell, therefore, had not to start from zero, but from a collection of prokaryotic capabilities, emerging eukaryotic complexity is not a problem of a square-the-circle; rather, evolution of early eukaryotic cells may largely have profited from the accumulation of genes from bacteria encoding some putative precursors/ homologs. Gene duplication, as seen in Paramecium (Arnaiz et al. 2007), and diversification have been an additional driving force.

Most salient features of endocytosis are the eventual use of clathrin, together with adaptor proteins, as a molecular filter which also causes bulging of a vesicle domain to be internalized, in conjunction with dynamina member of a GTPase superfamily - that helps pinch off a vesicle (Hinshaw 2000; Rothman 2014). Such components occur already in protozoa, specifically in Tetrahymena (Briguglio et al. 2013; Elde et al. 2005). Surprisingly dynamin has precursors in bacteria (Bramkamp 2012). Also unexpectedly, coated pits in Paramecium are sites of constitutive internalization of glycosyphosphatidylinositol (GPI)-anchored proteins (Flötenmeyer et al. 1999), just as in mammalian cells (Langhorst et al. 2008; Veith et al. 2009).

In summary, key players in early eukaryotic cell activity most likely must have included cytoskeletal elements and motor proteins, SNAREs, GTPases (monomeric GTPbinding/hydrolyzing proteins), and their modulators, as well as key elements required for endocytosis. SNAREs serve for attachment and final fusion of distinct organelles (Rothman 2014; Südhof 2014) specified by organelle-specific Rho-type GTPases (Mizuno-Yamasaki et al. 2012). Together with components mandatory for endocytosis, also available at the protozoan level, this appears as a basic heritage transmitted from early to most recent eukaryotes. They all serve for increasing complexity of vesicle trafficking up to mammalian and plant cells.

\section{The time frame available for changes during eukaryote evolution}

Some molecular phylogeny studies support the subdivision of multicellular organisms into two main branches (Hedges 2002) which, by most researchers, are called monokonts and bikonts, respectively. Among monokonts, choanoflagellates are rather close to the roots of animals, to which myxamoebae, like Dictyostelium, are less close (Katz 2012). Unfortunately, still now much less experimental and molecular data are available for choanoflagellates than for myxamoebae. Among bikonts, we find Alveolata, including ciliates. Both lineages appear approximately of the same age, with common ancestors $\sim 1.5$ billion years ago (Hedges 2002). As evidenced also in this review, there are not only some specific differences in molecules between unikonts and bikonts, but also some common features are observed at the molecular level, thus potentially reflecting their common origin. Further on, some proteins or protein subunits may have been lost in specific unikonts or bikonts, respectively.

Frequently, proteins are predicted by database mining, as is currently intensified with choanoflagellates (Cai et al. 2015; King et al. 2008). Together with myxamoebae (Dictyostelium discoideum), choanoflagellates (e.g. Monosiga brevicollis) play a pivotal role, as testimony for metazoan evolution along the unikont lineage, from Porifera (sponges) up to man (Carr et al. 2008; King et al. 2008; Ruiz-Trillo et al. 2007). There is some consent that myxamoebae have evolved before divergence of animals (Williams 2010; Williams et al. 2005). For the bikont lineage, ciliates are frequently considered a model. Species mainly used experimentally are Paramecium tetraurelia, T. thermophila, and Tetrahymena pyriformis. Bikont evolution is thought to have proceeded from green flagellates, such as Chlamydomonas reinhardtii (Jékeley 2007), and further on via complex Charophyta-related algae (McCourt et al. 2004; Úmen 2014) to angiosperms (flowering plants) (Magallón et al. 2013). Recall that protozoa and the unicellular algae under consideration here are jointly called "protists."

It appears, however, that the evolutionary scale envisaged up to now may possibly have been underestimated, since recent estimates based on the constantly low mutagenesis rate in $P$. tetraurelia argue for much older origin of ciliates, that is, $1,500 \mathrm{Myr}$ (McGrath et al. 2014). Remarkably this is also the time range assumed for formation of multicellular organisms (Alegado and King 2014) and even for mono-/bikont separation (Hedges 2002). These remarkable discrepancies and uncertainties justify to have another look at the problem, and analysis of closest living relatives is the only chance to have a glance at a likely molecular inventory of progenitors under discussion. 


\section{Questions envisaged in this review}

This situation implies several major aspects: On one hand, there is sufficient capacity to maintain a substantial percentage of the old genetic inheritance, including functionally most important functions, and on the other hand, innovation could take place. This includes increasing epigenetic control, including tissue- and stage-specific expression profiles, the latter also in protists (considering, e.g. cell duplication and nuclear death). During evolution, new domains may be included in proteins, domains may be rearranged or transferred, translation products can be modified and targeted to other sites of the cell, etc. Whenever function and localization is scrutinized, the question emerges whether the respective gene products have maintained their basic molecular structure and function as well as intracellular localization up to the highest levels of eukaryotes. This question is the hard core of this review which is mainly based on the authors experience with Paramecium and on work with mammalian cells. As far as data are available, this question is pursued from low up to highest levels of evolution. Many other teams have substantially contributed to cell biology and evolutionary aspects of protists, with widely scattered literature, which called for an overview.

\section{SPECIFIC CONSERVATION AND CHANGES DURING EVOLUTION}

Among others, the following examples are discussed in this review, as summarized in Tables 1, 2: (i) Some proteins maintain function and intracellular localization from low to high levels of eukaryotic evolution. Examples of considerable conservation are GTPases, calmodulin (CaM), PMCA-type $\mathrm{Ca}^{2+}$-ATPase/pumps (maintenance during evolution, with a PMCA precursor in bacteria), and SERCAtype $\mathrm{Ca}^{2+}$ pumps. (ii) Some proteins eventually change their intracellular position, for example, voltage-dependent $\mathrm{Ca}^{2+}$-influx channels in cilia of ciliates, but presence in neurons and absence in mammalian cilia and in plant cells. (iii) Some genes/proteins undergo an unprecedented expansion of paralogs/ohnologs, as occurring in Paramecium with actin and with the a-subunit (SU-a) of $\mathrm{H}^{+}$ATPase. (iv) A domain may be added to a protein, for example, integration of a (longin-) domain in ciliates and plant R-SNAREs. Another example is the integration of a CaM sequence in " $\mathrm{Ca}^{2+}$-dependent protein kinases" (CDPK) in ciliates and in plants; here, CDPKs substitute for $\mathrm{Ca}^{2+} / \mathrm{CaM}$-activated protein kinase ("CaM-kinase"). (v) A protein subunit (SU-A) may be lost, accompanied by refunctionalization of SU-B of phosphatase 2B (calcineurin, CaN). Both SUs occur in ciliates, but SU-A is lost in plants where a SU-B derivative is refunctionalized to cope with ionic stress. (vi) Some molecules are lost, as seen with $\mathrm{Ca}^{2+}$-release channels, type $\mathrm{IP}_{3}$ receptor; these are maintained from mono- and bikont protozoa up to man, but lost in plants. (vii) Ryanodine receptor-type $\mathrm{Ca}^{2+}$ channels (RyR) have bona fide precursors in ciliates (RyR-like proteins, RyR-LP), although with lower molecular weight. (viii) Altogether many new types of ion channels emerge during evolution. (ix) Members of the SPFH (stomatin, prohibitin, flotillin, bacterial $\mathrm{HfIK/C)}$ superfamily are engaged in scaffolding membrane microdomain with specific proteins. HfIK precursors occur in bacteria, and SPFH members can vary during evolution, with either stomatin- or flotillin/reggie-related characteristics dominating in closely related ciliates. More definded orthologs are found up to man and angiosperms. (x) A variety of proteins are newly generated as evolution goes on.

These examples stand for many others to be discussed. In summary, during evolution only part of the proteins analyzed in some detail remain unchanged in structure, function, subcellular localization (Tables 1, 2), and interaction with partner proteins. Beyond this, also some considerable differences in the evolutionary development may be noticed between protozoans, metazoans, and plants.

\section{Conservation of structure, function, and localization}

To summarize, there is a variety of proteins which essentially maintain their basic structure during evolution. Among them are some of the CaBPs, specifically those with $\mathrm{C} 2$ domains (synaptotagmin, PL-C) and EF-handmotifs (CaM), together with some proteins containing an additional part with acidic aminoacids (e.g. centrin). The $\mathrm{Ca}^{2+}$-ATPases/pumps (PMCA, SERCA) and $I P_{3} \mathrm{R}$ are other examples. The group of essentially conserved proteins also encompasses proteins that are more directly involved in vesicle trafficking, such as clathrin and adaptor proteins (APs) together with coatomer proteins (COPs), all required for vesicle budding, furthermore, GTPases, most SNAREs including syntaxins, SNAP-25 and synaptobrevins (aside from "longin"-types), as well as the SNARE-specific chaperone, NSF. CaN is widely conserved from some protozoa to mammals, but undergoes considerable change in plants, to mention just one example of severe changes.

\section{$\mathrm{Ca}^{2+}$-ATPases/pumps}

$\mathrm{Ca}^{2+}$-ATPases/pumps have evolved in two forms, that is, PMCA and SERCA, both with 10 transmembrane domains and formation of a phospho-intermediate (P-type ATPases) during their primary active $\mathrm{Ca}^{2+}$ transport activity (Brini and Carafoli 2009; Bublitz et al. 2011; Palmgren and Nissen 2011). PMCAs have a precursor in bacteria to counteract the permanent leakage of $\mathrm{Ca}^{2+}$ from the outside (Domínguez et al. 2015). Generally, they bear a carboxyterminal autoinhibitory $\mathrm{Ca}^{2+} / \mathrm{CaM}-$ binding domain, as demonstrated in mammals (Carafoli 1994; Lopreiato et al. 2014). This exhibits only small variability, when ciliates, myxamoebae, and plants are compared with mammals.

In Dictyostelium, both PMCA and SERCA are described as regulators of $\left[\mathrm{Ca}^{2+}\right]_{i}$ (Schlatterer et al. 2004). In Paramecium, these pumps would be too sluggish to mediate rapid $\mathrm{Ca}^{2+}$ downregulation, for example, after massive exocytosis stimulation, thus stressing the importance of $\mathrm{Ca}^{2+}$ binding to high-capacity CaBPs (Plattner 2017a,b).

Since PMCA's working kinetics is rather sluggish, as found also in mammalian cells, PMCA was considered to 
serve mainly for household activity (Brini and Carafoli 2011). In Paramecium, balance calculations suggest that both P-types pumps can regulate $\left[\mathrm{Ca}^{2+}\right]$ at best on a 60 min time scale (Plattner 2017a,b). This makes both CaBPs and antiporter systems important for rapid $\left[\mathrm{Ca}^{2+}\right]_{i}$ downregulation after stimulation. In line with this, more recent considerations addressing mammalian systems stress the relevance of PMCA for local $\left[\mathrm{Ca}^{2+}\right]_{i}$ fine-tuning in subplasmalemmal microdomains (Lopreiato et al. 2014).

In contrast to the PMCA, the SERCA pump has no CaM-binding domain; it serves for the refilling of the $E R$, the main $\mathrm{Ca}^{2+}$ store in animal (Vandecaetsbeek et al. 2011) and plant cells (Liang and Sze 1998). A SERCAtype activity has been recorded in Dictyostelium (Schlatterer et al. 2004). Thus, D. discoideum is endowed with both types of $\mathrm{Ca}^{2+}$ pumps, SERCA and PMCA (Wilczynska et al. 2005). Similarly both pumps occur in $P$. tetraurelia (SERCA [Hauser et al. 1998, 2000; Kissmehl et al. 1998], PMCA [Elwess and Van Houten 1997]). In Paramecium, SERCA occurs in the ER from where it is also exported to alveolar sacs (Hauser et al. 1998, 2000), the cortical $\mathrm{Ca}^{2+}$ stores (Länge et al. 1995; Stelly et al. 1991) from where $\mathrm{Ca}^{2+}$ is released during exocytosis stimulation (Hardt and Plattner 2000). This situation strongly recalls the sarcoplasmic reticulum of muscle cells.

In summary, the basic aspects of PMCA and SERCA function appear rather strictly maintained throughout evolution in both mono- and bikonts.

\section{CaBPs}

Let us anticipate some general aspects of CaBPs. About 3,500 CaBPs are known from animals and $\sim 800$ from plants (Morgan et al. 2004; Williams 2006). Among CaBPs, there are some with high-affinity/low-capacity characteristics, for example, with EF-hand domains (CaM, centrin, calcineurin B) and some with C2 domains (PL-C, synaptotagmin, copines). CaM possesses four EF-hand domains and is highly conserved, with a homolog already in some bacteria (Swan et al. 1987). There are 68 CaBPs in eubacteria, an unknown number in protozoa, and finally 2,540 in animals and 499 in plants (Morgan et al. 2004; Williams 2006). C2 domains mediate $\mathrm{Ca}^{2+}$-dependent binding of the respective $\mathrm{CaBP}$, or rather of the respective $\mathrm{C} 2$ -domain, to membranes (Südhof 2013). The number of C2-type CaBPs, which are not known from bacteria (Domínguez et al. 2015), has been reported as 242 in plants and 762 in animals (Morgan et al. 2004; Williams 2006).

Other CaBPs are devoid of such specific domains; rather, they contain acidic stretches serving for rapid binding of $\mathrm{Ca}^{2+}$ with low affinity but high capacity. This applies to luminal $\mathrm{CaBPs}$ contained in $\mathrm{Ca}^{2+}$ stores, with lectin (sugar binding) functions, such as calreticulin and calnexin (Zhou et al. 2013). Both these CaBPs have been identified in Dictyostelium (Fajardo et al. 2004; Müller-Taubenberger et al. 2001) and in Monosiga (Cai 2008), whereas information from P. tetraurelia is preliminary (Plattner et al. 1997b). An additional group of CaBPs of ciliates contains high-affinity sites together with low-affinity binding sites (Gogendeau et al. 2008; Kim et al. 2002). This combination of low-affinity and high-affinity binding is also a feature of centrin, also in ciliates (Kim et al. 2002).

In summary, CaBPs diversified enormously during evolution, but functionally important domains are retained.

\section{CaM}

CaM with its 4 EF-hand $\mathrm{Ca}^{2+}$-binding motifs serves for widely different functions not only in man (Chin and Means 2000) and plants (Poovaiah et al. 2013) but also down to protozoa (Saimi and Kung 2002) including choanoflagellates (Cai 2008). CaM modulates several cation influx channels from ciliates (Brehm and Eckert 1978; Preston et al. 1991; Saimi and Kung 2002) to human brain (Findeisen et al. 2013; Levitan 1999). In both these cases, $\mathrm{Ca}^{2+}$-influx channels are first activated and then rapidly deactivated by the forming $\mathrm{Ca}^{2+} / \mathrm{CaM}$ complex. CaM can thus be considered a flexible channel subunit (Saimi and Kung 2002). The role of these $\mathrm{Ca}^{2+}$ channels has been documented primarily by electrophysiology (Saimi and Kung 2002) and most recently been supported by molecular biology (Lodh et al. 2016).

A conserved function of $\mathrm{CaM}$ is its participation in the assembly of docking/fusion sites for dense core-secretory vesicles at the cell membrane in Paramecium (Kerboeuf et al. 1993), that is, at sites where CaM is enriched according to immune labeling (Momayezi et al. 1986). Similarly, by binding to synaptobrevin, CaM is essential for the assembly of neurotransmitter release sites in mammalian neurons (Quetglas et al. 2002).

$\mathrm{CaM}$ is an activator of CaN, not only in higher eukaryotes but also in ciliates (Kissmehl et al. 1997) and in myxamoebae (Aichem and Mutzel 2001; Hellstern et al. 1997). Already in protozoa, the CaN-A subunit contains a CaMbinding domain. This ensemble, together with the modulating effect of CaM on cation influx channels (Saimi and Kung 2002), therefore, may represent an old functional heritage of eukaryotic cells, yet executed at different sites of the cell. Another conserved function of $\mathrm{CaM}$ is the regulation of the PMCA-type $\mathrm{Ca}^{2+}$-ATPase/pump. For CaN, see below, for synaptotagmin.

So far, in choanoflagellates, EF-hand CaBPs are known only from genomic analyses (Burkhardt 2015). Beyond CaM, mammalian cells possess additional high-affinity/ low-capacity CaBPs with four EF-hands. Also the myxamoeba, D. discoideum expresses not only calmodulin (André et al. 1996) but also some other developmentally regulated forms of CaBPs (Loomis 2014; Sakamoto et al. 2003). From lower eukaryotes on, cells contain CaM-binding proteins. This holds for Dictyostelium (Catalano and O'Day 2008), Tetrahymena (Gonda et al. 2000; Nagao and Nozawa 1985), and Paramecium (Chan et al. 1999) and is continued up to plants (Bouché et al. 2005) and mammals (Bhattacharya et al. 2004)

All this forms part of an extensive $\mathrm{Ca}^{2+}$-based signal transmission machinery occurring, with variations on the basic theme, from bottom-to-top of eukaryote evolution. Thereby, CaM is one of the most important $\mathrm{Ca}^{2+}$. 
dependent regulatory proteins with high conservation throughout evolution. Its effects are achieved by conformational change which alters the characteristics of binding to target molecules.

\section{CaN}

Such conservation is only partially observed with $\mathrm{CaN}$ (protein phosphatase 2B, PP2B). CaN is a dimeric Ser/Thr phosphatase of little substrate specificity (Klee et al. 1998; Rusnak and Mertz 2000) and accordingly with widely different functions, as outlined by Fraga et al. (2010). CaN consists of a catalytic SU-A (CaN-A) and a smaller regulatory SU-B which possesses four EF-hand $\mathrm{Ca}^{2+}$-binding motifs (Guerini 1997). Both subunits have been identified in P. tetraurelia (Fraga et al. 2010; Kissmehl et al. 1997). Fourteen isoforms of the catalytic SU-A are encoded by seven subfamily genes, each with two rather similar members, that is, ohnologs (Fraga et al. 2010). This is a most convincing example of ohnolog formation. In contrast, only two very similar genes are found for SU-B which-rather surprisingly-encode an identical protein. Also the binding site for SU-B in SU-A is very similar in the paralogs/ohnologs. This is an extreme example of selective restriction of variability of one SU of a protein complex. In contrast to the situation in Paramecium, Dictyostelium expresses two distinct forms of CaN-B (Aichem and Mutzel 2001).

In Paramecium, CaN exerts an effect on stimulated exocytosis (Momayezi et al. 1987), probably by affecting $\mathrm{Ca}^{2+}$ dynamics (Fraga et al. 2010). Its effect on exocytosis performance has been repeatedly documented also in metazoan cells (Sim et al. 2003). This includes regulation of ion channels in mammalian cells (Herzig and Neumann 2000). Remarkably, in immunogold labeling experiments with P. tetraurelia, coated pits ("parasomal sacs") are heavily labeled with gold particles (Momayezi et al. 2000). These findings agree with observations, in neuronal cells, that CaN/PP2B activates retrieval of synaptic vesicle membranes by dephosphorylation of dynamin (Lai et al. 1999; Marks and McMahon 1998) which once had been called a "pinchase." We expect many more functions for CaN also in Paramecium, possibly including regulation of cation influx channels, as amply documented for CaN in metazoan cells (Herzig and Neumann 2000; Rusnak and Mertz 2000). In Dictyostelium, its presence (Dammann et al. 1996) and widely diversified functions (Weissenmayer et al. 2005) suggest that dimeric CaN can be considered an old heritage. Remarkably, SU-A is lost in plants.

\section{Copines}

These are a family of $\mathrm{Ca}^{2+}$-dependent membrane binding proteins endowed with a C2 domain (Tomsig and Creutz 2002). They have been detected not only in Paramecium (Creutz et al. 1998) and in Dictyostelium (Damer et al. 2005), but they also occur in plants (Arabidopsis) and in animals up to mammalians (Creutz et al. 1998; Tomsig and Creutz 2002). In Dictyostelium, they are localized to the plasma membrane as well as to endocytotic and phagocytotic membranes, in addition to the contractile vacuole system. Downregulation of one of the six copine genes affected biogenesis and function of the contractile vacuole (Damer et al. 2007), whereas the function of copines in other systems is not established.

\section{The tandem of GTPases and SNARES}

When the (ultra)structural appearance of ciliate and mammalian dense core-secretory systems is compared, they evidently look very different (see below). GTPases are monomeric GTP-BPs, activated by GTP hydrolysis. For membrane trafficking, Rab-type GTPases are in focus. These are required for binding organelle-specific antigens. Thus, in cooperation with SNAREs, GTPases mediate specific vesicle/membrane interactions (Grosshans et al. 2006; Stenmark 2012). For instance, early endosome antigen EEA1 binds a Rab-type GTPase designated as Rab5. Other textbook examples include Rab7 for late endosomes and Rab11 for recycling endosomes. This situation has allowed one to address the specific functional topologies of different GTPases with green fluorescent protein (GFP) fusion proteins in T. thermophila and P. tetraurelia (Bright et al. 2010). Only a few lineage-specific paralogs have evolved for use in special organelles, such as the contractile vacuole complex of ciliates. Remarkably, GTPases are abundant already in the Lokiarchaeota-type archaebacteria (Spang et al. 2015), where they contribute to the genome by $1.7 \%$, as compared with $1.2 \%$ in D. discoideum, $0.6 \%$ in $H$. sapiens, $0.55 \%$ in $T$. thermophila, and $0.3 \%$ in Arabidopsis thaliana.

SNAREs and GTPases have been identified, localized, and eventually functionally probed in different protozoa. This includes SNAREs (Plattner 2010a,b) and GTPases in Paramecium (Peterson 1991; Saito-Nakano et al. 2010) as well as GTPases in Tetrahymena (Bright et al. 2010). The number of SNAREs identified by genomic analysis in T. thermophila and P. tetraurelia, 88 and 229 (SaitoNakano et al. 2010), respectively, may well reflect the whole genome duplications in $P$. tetraurelia (Aury et al. 2006) which can serve for amplification effects, rather than for refinement in signaling. The number of Rab-type GTPases is generally said to increase with organismal complexity, culminating with 36 members in $A$. thaliana and 67 in H. sapiens (Rojas et al. 2012). However, according to Bright et al. (2010), the numbers reported for T. thermophila are 56, 54 for D. discoideum, 57 for A. thaliana, and 63 for $H$. sapiens. Thus, molecules directing vesicle trafficking seem to have been diversified already at an early stage.

Remarkably, GTPases are encoded already by a number of bacteria where they participate in the regulation of protein and DNA synthesis and also of fine-tuned different pathways, depending on the cell's energy status (Kint et al. 2014). Some pathogenic bacteria are able to inject GTPases into host cells, thus manipulating trafficking and overall function (Ham et al. 2011). An alternative pathogenic strategy aiming at inhibiting fusion with phagolysosomes is the expression of inhibitory SNARE-like proteins by the bacterial invaders (Shi et al. 2016; Wesolowski and Paumet 2010). 
Database analysis of choanoflagellates and related filasterians has revealed a variety of molecules essential for neurotransmission in metazoans (Burkhardt 2015; Burkhardt et al. 2014). This includes R-and Q-SNAREs (e.g. synaptobrevin, syntaxin, SNAP-25 [Cai 2008]) and SNARE assembly proteins (e.g. Munc18 and complexin) as well as Homer (able to bind to cortical $\mathrm{Ca}^{2+}$ stores). One of the rare experimental analyses with choanoflagellates has applied fluorescence anisotropy, calorimetric, and crystallographic analyses for verifying the interaction of SNARE with Munc proteins (Burkhardt et al. 2011).

More intensive experimental and domain analysis of SNAREs and associated proteins in $P$. tetraurelia has revealed 26 syntaxin isoforms with differential localization comparable to mammalian cells (Kissmehl et al. 2007), together with the SNARE chaperone, NSF (Froissard et al. 2002; Kissmehl et al. 2002), and SNAP-25 (Schilde et al. 2008). All representatives of the synaptobrevin family were found to be of the "longin" type, that is, with a longin domain distal to the SNARE domain (Schilde et al. 2006). This corresponds to the situation in plants where all R-SNAREs then known were "longins" (Lipka et al. 2007; Uemura et al. 2005). In contrast, R-SNAREs of choanoflagellates are of the conventional type (Cai 2008). In summary, there are specific differences maintained in the mono- and bikont lineage, respectively.

R- and Q-SNAREs have been found in different eukaryotic phyla. Essentially, the inventory of SNAREs is high already in unicellular ("lower") eukaryotes, not only in ciliates (Plattner 2010a,b) but also in myxamoebae and chlorophyceae (Sanderfoot 2007). This abundance not only with SNAREs (including those involved in the secretory pathway) but also with GTPases (Bright et al. 2010; Guerrier et al. 2017).

In the myxamoeba Dictyostelium (Kienle et al. 2009) and in various unicellular organisms, SNAREs have been characterized on an informatic level, with the result that their number is only slightly higher in "higher" than in "lower" eukaryotes (Sanderfoot 2007), including Dictyostelium and Chlamydomonas. It is feasible to assume that $\mathrm{Ca}^{2+}$-driven, SNARE-mediated membrane fusion also occurs in choanoflagellates inferred from the presence of complexin (Yang et al. 2015). This molecule binds to the SNARE complex like a clamp which is overridden when $\mathrm{Ca}^{2+}$ binds to synaptotagmin after stimulation (Martin et al. 2011). Accordingly, SNAREs and a synaptotagmin-LP should be found in these cells and, in fact, stochastic data on SNAREs can be retrieved from the databases of choanoflagellates (Burkhardt 2015; Burkhardt et al. 2011, 2014; Kienle et al. 2009). SNARE proteins have been analyzed for structure, function, and localization in more detail up to mammalians (Rothman 2014; Südhof 2014) and flowering plants (Lipka et al. 2007; Sanderfoot 2007; Sansebastiano and Piro 2014; Uemura et al. 2004; Vedovato et al. 2009). Disregarding closely similar ohnologs within subfamilies, the number of SNAREs in P. tetraurelia is comparable to that in
H. sapiens (Plattner 2010a) and in A. thaliana (Lipka et al. 2007).

In conclusion, SNAREs belong to the protein repertoire of all eukaryotes.

\section{Examples of minor changes of proteins during evolution}

Proteins combining characteristics of different subfamilies

Members of the stomatin-prohibitin-flotillin (reggie)-HfIK bacterial protein (SPFH) superfamily form microdomains in different membranes of multicellular animals (Browman et al. 2007; Lapatsina et al. 2012) as well as in angiosperms (Daněk et al. 2016). Their occurrence in low evolutionary levels is surprising, as the prototype, reggie (flotillin) has been detected by upregulation during neuronal regeneration, as reviewed by Stuermer (2010). There are homologs in different animal phyla (Rivera-Milla et al. 2006) and even in bacteria (Hinderhofer et al. 2009). When we analyzed the possible occurrence of members of the SPFH superfamily in ciliates, we realized that they may be closer to stomatin in $P$. tetraurelia, but closer to reggie/ flotllin in T. pyriformis (Reuter et al. 2013). Occurrence of flotillin 1 (reggie 2) and of flotillin 2 (reggie 1) is reported from database search in choanoflagellates (Burkhardt 2015; Burkhardt et al. 2014), thus suggesting a widespread presence in eukaryotes.

\section{Proteins with specific, but quantitatively variable functional domains}

In contrast to EF-hand CaBPs, C2 domain containing CaBPs are not known from bacteria (Domínguez et al. 2015; Morgan et al. 2004; Williams 2006), but they have been identified from protozoa on. A C2 motif is a $\beta$-barrel

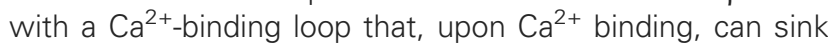
into a lipid bilayer. This takes place with synaptotagmin, for example, during membrane fusion which is, thus, enabled (Rizo et al. 2006; Südhof 2013, 2014). However, the number of $\mathrm{C} 2$ domains per synaptotagmin molecule may differ, as found in multicellular organisms and in ciliates. Most mammalian synaptotagmin species have two C2 domains (Rizo et al. 2006), as do plants (Craxton 2004, 2007), but exceptions with four such domains have been described as "enhanced Syntags" (eSyntag) (Martens and McMahon 2008; Min et al. 2007). No synaptotagmin or related proteins have been found in the $D$. discoideum genome (Barber et al. 2009), in contrast to a more recent report (Zhang et al. 2011) although this refers to abortive literature citations. Only eSyntag-like genes have been found in the genomes of $M$. brevicollis (Barber et al. 2009) and of P. tetraurelia (R. Kissmehl and H. Plattner, unpubl. observ.; Plattner 2010b)_functional verification still to be accomplished. These phenomena may be paradigmatic for domain shuffling - an important mechanism of evolution (Di Roberto and Peisajovich 2014; Marsh and Teichmann 2010). There is no mono-/bikont consistency in C2 domain bearing synaptotagmin and related proteins. 


\section{$\mathrm{Ca}^{2+}$ signaling, a revolution in early eukaryote evolution, required new "inventions"}

During evolution of the eukaryotic cell, two basic revolutions came into play. One was the well-known exploitation of $\mathrm{O}_{2}$ for energy conservation. Another one-although less reflected-was the recruitment of $\mathrm{Ca}^{2+}$ as a universal second messenger (Berridge 2006; Berridge et al. 2003; Clapham 2007) and a mandatory factor specifically for membrane-to-membrane interactions (Carafoli and Krebs 2016; Marchadier et al. 2016; Plattner and Verkhratsky $2015,2016)$. Here, the crucial problem was the antagonism between ATP-based energetics and the low solubility of $\mathrm{Ca}^{2+}$ phosphates. Thus, the given establishment of ATP as universal energy carrier has forced cells to keep $\left[\mathrm{Ca}^{2+}\right]_{\text {I }}$ low. While this is true already of bacteria (Domínguez et al. 2015), evolution of large eukaryotic cells required small, short signals strictly restricted in time and in space to strategic sites. This has the favorable side-effect of low-energy expenditure of ATP-based regulation (Plattner and Verkhratsky 2016). To achieve this, $\mathrm{Ca}^{2+}$-release channels (CRCs) had to be "invented," which had to be locally restricted to strategic sites, in order to produce short and site-specific signals. This, together with $\mathrm{Ca}^{2+}{ }_{-}$influx channels in the plasmamembrane and $\mathrm{Ca}^{2+}$-binding proteins (CaBPs) of different kinetics at specific sites in the cytosol can not only effectuate efficient local signaling, but it can also facilitate $\left[\mathrm{Ca}^{2+}\right]_{i}$ downregulation with little energy consumption (Plattner and Verkhratsky 2016). Signaling can be executed by high-affinity/low-capacity CaBPs (Zhou et al. 2013). For instance, calmodulin (CaM), endowed with four EF-hands along a central $\alpha$-helical link, performs a conformational change when activated by $\mathrm{Ca}^{2+}$, and after binding to a target molecule, initiates a site-specific effect (Fernandes and Oliveira-Brett 2017; Park et al. 2008). By the same token, low-affinity/high-capacity CaBPs can serve as immobile $\mathrm{Ca}^{2+}$ buffers by inactivating $\mathrm{Ca}^{2+}$ signals which, thus, become even more topologically restricted. The intracellular contribution of different CaBPs is particularly well analyzed in some nerve terminals (McMahon et al. 2016), but much less in protozoa (Plattner 2014, 2015b; Plattner and Verkhratsky 2015).

Clearly, in principle, proteins engaged in $\mathrm{Ca}^{2+}$ signaling occur in all eukaryotes, but with considerable variability. This is particularly true of CRCs, as summarized recently (Plattner and Verkhratsky 2015, 2016).

\section{Change of localization and function of proteins during evolution}

Three examples are selected for a discussion about proteins whose intracellular localization changes during evolution, that is, centrin, voltage-gated $\mathrm{Ca}^{2+}$ channels and SNAREs (with a side glace at calmodulin).

\section{Centrin}

Centrin is a good example of topological variability. Centrin is the name-giving component of the centrosome of the mammalian cytospindle. This molecule also occurs, although at different sites, in ciliates, choanoflagellates, and all animal phyla, but not in angiosperms (Hodges et al. 2010). It is found in the centrosomes of green algae, such as Chlamydomonas (Azimzadeh 2014). In myxamoebae (Dictyostelium), centrin is represented by two centrin-related paralogs (Mana-Capelli et al. 2009) without stringent association with the centrosome (Levy et al. 1996). Altogether the occurrence of centrioles/centrosomes is quite variable during evolution (Azimzadeh 2014; Hodges et al. 2010). Centrin molecules are able of self-assembly (Yang et al. 2006) and formation of filamentous aggregates which can also result in binding specific proteins (Martinez-Sanz and Assairi 2016). In Paramecium, centrin makes an elaborate cortical contractile network, called the "infraciliary lattice" (Beisson et al. 2001; Gogendeau et al. 2008), whose negative charges enable centrin to act as an immobile $\mathrm{Ca}^{2+}$ buffer (Sehring et al. 2009). Alternatively, it builds a $\mathrm{Ca}^{2+}$ sensitive contractile stalk in the ciliate Vorticella (Buhse et al. 2011; Levy et al. 1996). Due to its high $\mathrm{Ca}^{2+}$-binding capacity, this "infraciliary network" acts as a powerful immobile $\mathrm{Ca}^{2+}$ buffer when cells are flushed with $\mathrm{Ca}^{2+}$ (Sehring et al. 2009), with the result of strong contraction. In fact, the availability of dual, widely different $\mathrm{Ca}^{2+}$-binding constants of centrin in different organisms including protists (Levy et al. 1996; Zhang and He 2012) enables centrin to act as a high-sensitivity/low-capacity as well as a low-sensitivity/high-capacity CaBP.

In higher plants, in the absence of a centriole/centrosome, centrin is not detectable in the spindle poles (Del Vecchio et al. 1997). However, centrin occurs in plasmodesmata where it may regulate permeability (Blackman et al. 1999). This can be considered an alternative to the $\mathrm{Ca}^{2+}$-sensitive open/closed state of metazoan gap junctions - a pathway of intercellular communication (Zhou and Jiang 2014).

In many organisms, uni- or multicellular, centrin also forms part of ciliary and flagellar basal bodies (CarvalhoSantos et al. 2011), which evidently is not the case in organisms lacking such structures (Dictyostelium and angiosperms). Quite in contrast to this, in mammalian cells centrin is required for centriole duplication (Salisbury et al. 2002) and, thus, exerts a vital function.

To sum up, the distribution of centrin in different organisms and within different cell types varies widely (Bhattacharya et al. 1993). Evidently this variability does not follow a clear monokont/bikont scheme, although centrin is substituted for by related proteins with cytoskeletal functions.

Centrin is present in basal bodies and in centrosomes of animals (Vonderfecht et al. 2012), thus reflecting the ability of their interconversion (Bornens and Azimzadeh 2007; Wang et al. 2011) that had been recognized already more than a century ago (Henneguy-Lenhossék theory). Several groups of unicellular eukaryotes do not form a centriole/centrosome, including some Alveolata (Tetrahymena, Paramecium, Apicomplexa) and green flagellates (Chlamydomonas) (Azimzadeh 2014; Hodges et al. 2010; Zhang and He 2012), although they possess centrin 
(Hodges et al. 2010). In Dictyostelium, a quite unusual centrin with low sequence homology is associated with the nucleus in an unusual form (Gräf et al. 2004). Strikingly, there is no centrosome in choanoflagellates, and the flagellar basal bodies serve as microtubule organizing centers during nuclear division (Karpov 2016).

The situation with centrin is particularly diverse when cytospindles in animal cells, from ciliates up to mammals, are compared with those in plant cells. To comprehend this, one has to recall again the similarity of ciliary/flagellar basal bodies and centrioles_-both structures being absent from plant cells. In ciliates, centrin is required for basal body formation (Stemm-Wolf et al. 2005), as reviewed by Pearson and Winey (2009), just as in metazoans (Salisbury et al. 2002; Tassin et al. 2016). Nevertheless, in ciliates, the alter ego of basal bodies, the centriole, does not contain any centrin (Hodges et al. 2010). In the present context, one should recall that centrin in ciliates additionally forms an extensive contractile cortical filament network (Beisson et al. 2001), intermingled with actin (Kissmehl et al. 2004). The situation in choanoflagellates is like in metazoans (Hodges et al. 2010). In angiosperms, the microtubule organizing centers of spindle pole caps are devoid of centrin (Hodges et al. 2010). Rather, centrin in plants is enriched in the cell plate during cell division (Del Vecchio et al. 1997).

Besides this gross line of evolutionary development, centrosomes exhibit considerable inconsistency with regard to their name-giving molecular constituent, centrin. As a nucleator for microtubules in centrioles, pole caps, and ciliary/flagellar basal bodies, the widely distributed tubulin isoform, $\gamma$-tubulin, is a much more wide-spread determinant (Firat-Karalar and Stearns 2014). This also holds for a variety of protists (Klotz et al. 2003).

Another interesting aspect is the similarity of the immune synapse of lymphocytes and the docking sites of trichocysts in Paramecium cells (Griffiths et al. 2010). Here, microtubules serve for transport of trichocysts (Platther et al. 1982) and of lytic granules, respectively, to the cell membrane. For the formation of microtubule organizing centers in lymphocytes, centrin is transported along the cell membrane (Yuseff et al. 2011). In contrast, centrin is present at the self-assembly sites of this microtubule subpopulation in Paramecium, that is, the ciliary basal bodies (Beisson et al. 2001). In both cases, secretory vesicle transport takes place in the plus-to-minus direction of microtubules, whereas in most secretory cells, this transport starts at microtubules emanating from a centrosome located at the cytocenter and, thus, goes in opposite direction.

In summary, apart from centrin, there is hardly any other protein with comparable variability in localization and function during evolution.

Voltage-dependent $\mathrm{Ca}^{2+}$ channels for ciliary activity In ciliates, voltage-dependent $\mathrm{Ca}^{2+}$-influx channels are restricted to the ciliary membrane where they are activated upon depolarization to induce ciliary reversal, as outlined in Fig. 1. This is no more so in metazoan cilia which have acquired other types of ciliary channels which even may not be important for the modification of ciliary activity (Malicki and Johnson 2017); see Fig. 2, 3. In vertebrates, voltage-gated $\mathrm{Ca}^{2+}$ channels are transferred to motor endplates and to synaptic membranes of neurons of the central nervous system (Atlas 2013; Yamashita 2012). Partial sequencing in Paramecium revealed sequence homology (Yano et al. 2013), albeit full sequencing, eventual subtyping, and reconstitution studies are still missing.

In cilia of unicellular organisms, some basic $\left[\mathrm{Ca}^{2+}\right]$ in cilia is required for normal activity which increases severalfold during stimulation (Salathe 2007). In ciliates, mechanical stimulation generates an action potential by activation of mechanosensitive $\mathrm{Ca}^{2+}$ channels in the somatic (nonciliary) cell membrane and a receptor potential by activation of voltage-gated $\mathrm{Ca}^{2+}$ channels (Naitoh and Eckert 1969). Insight into their localization has been achieved by comparative electrophysiology of Paramecium cells before and after deciliation (Dunlap 1977; Machemer and Ogura 1979), as well as by proteomic analysis of purified ciliary membranes (Yano et al. 2013) and by partial gene sequencing and cloning (Lodh et al. 2016). Localization and basic mechanism appear similar for flagella of Chlamydomonas (Beck and Uhl 1994; Fujiu et al. 2009) and for cilia in ctenophores, the comb jellies (Tamm 2014). Consequently, upon depolarization, ciliates and ctenophores perform ciliary beat reversal, whereas Chlamydomonas responds by changing wave form of the flagellar beat (Fujiu et al. 2009). Detailed molecular characterization of voltage-dependent $\mathrm{Ca}^{2+}$ channels in cilia and flagella of lower eukaryotes still awaits scrutiny. Remarkably, these channels are inactivated by formation of a $\mathrm{Ca}^{2+} / \mathrm{CaM}$ complex in both Paramecium (Saimi and Kung 2002) and neurons of the human brain (Findeisen et al. 2013; Levitan 1999).

In metazoans, there exist immotile primary cilia in the anlagen of some tissues, such as nephrons of the kidney, and in the motile cilia of ciliated epithelia, such as trachea, oviduct and ependymal cells lining the ventricular system of brain and spinal cord (Doerner et al. 2015; Yano et al. 2013). See Fig. 2, 3 for comparison of primary and epithelial cilia. In this context, see discussion about TRP-type channels, below.

In ciliated epithelia, intraciliary $\left[\mathrm{Ca}^{2+}\right]_{\mathrm{i}}$ increase accelerates ciliary beat by hyperpolarization due to the opening of ATP-sensitive $\mathrm{K}^{+}$-channels (Ohba et al. 2013). With this respect, there is some similarity to hyperpolarizationinduced (although not ATP mediated) accelerated forward swimming in Paramecium (Preston et al. 1992; Van Houten 1998). Epithelial cilia of mammals are generally devoid of voltage-dependent $\mathrm{Ca}^{2+}$ channels. Only ependymal cilia contain such channels, but here they are preferably enriched in the nonciliary membrane, with only small effect of their activation on ciliary beat; therefore, they presumably serve for secretory and differentiation activities (Doerner et al. 2015; Pablo et al. 2017). Also polycystin-type channels are no more considered important for ciliary activity in animal cells-aside from the passive movement of the primary cilium (Battle et al. 2015). 

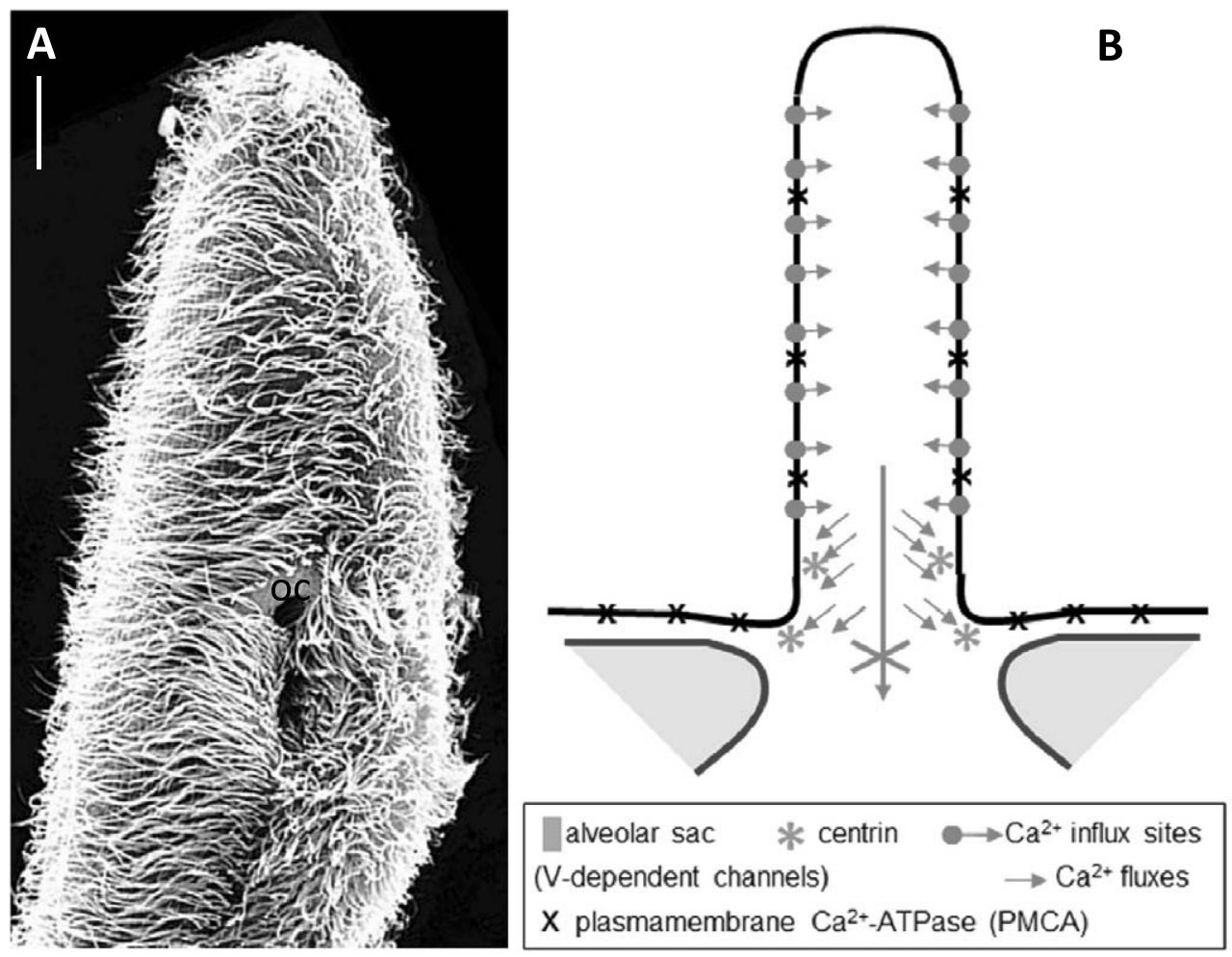

Figure 1 Cilia in Paramecium tetraurelia, scanning electron micrograph (A) and scheme (B) showing the distribution of PMCA and restriction of voltage-dependent $\mathrm{Ca}^{2+}$ channels to cilia. Upon depolarization, $\mathrm{Ca}^{2+}$ enters cilia, thus inducing ciliary beat reversal. Subsequently centrin, localized at the basis of cilia, rapidly binds $\mathrm{Ca}^{2+}$, thus inhibiting spillover into the cell soma. Also note that alveolar sacs are not involved. (A) Courtesy by J. Hentschel. Scale bar in (A), $10 \mu \mathrm{m}$.
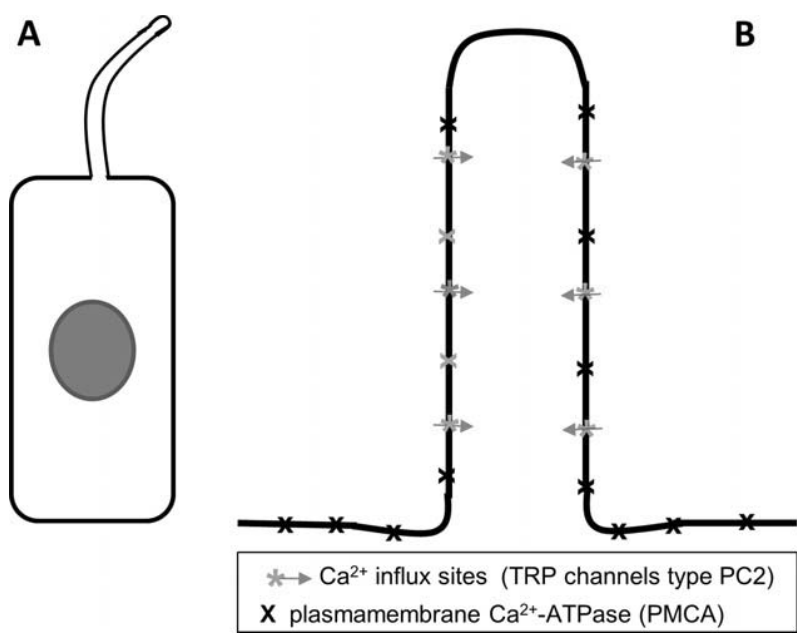

Figure 2 The primary cilium is located apically in some developing epithelia (A) and contains PMCA and TRP-type channels (B). For details, see text.

Altogether ciliary mechanosensation in mammalians remains little understood (Malicki and Johnson 2017).

During evolution, ciliary channels of ciliates have been substituted for by transient receptor potential (TRP) channels in mammalian primary cilia (Battle et al. 2015) and in epithelial cilia (Lorenzo et al. 2008) — a legacy from early unikont precursors (Cai et al. 2015). The types of cation channels regulating ciliary activity vary greatly between the different types of cilia, in protozoan and metazoan cells. Substitution of $\mathrm{Ca}^{2+}$-dependent and CaM-sensitive $\mathrm{Ca}^{2+}$ influx channels during evolution by TRP-type channels may increase responsiveness to widely different stimuli. Taken together, this is a clear case of replacement of a protein by other ones during evolution. In summary, voltage-dependent $\mathrm{Ca}^{2+}$ channels, once governing ciliary activity in protists, do occur in mammalian nerves including neurons of the central nervous system where they contribute to longterm potentiation, that is, learning (Atlas 2013; Yamashita 2012). This is quite a remarkable "career."

\section{Deviating features and functions of calmodulin and SNARES}

During evolution, CaM has acquired some additional functions. In mammalian nerve terminals, a spillover of $\mathrm{Ca}^{2+}$ during activation activates CaM in the cytosol and thereby a $\mathrm{Ca}^{2+} / \mathrm{CaM}$-activated protein kinase ("CaM-kinase"), as summarized by Swulius and Waxham (2008). Nerve terminals contain this CaM kinase (DeLorenzo et al. 1979), which facilitates the release of neurotransmitter vesicles from F-actin by phosphorylation of synapsin. This facilitates the refilling of the subplasmalemmal store of vesicles releasable by exocytosis (Chi et al. 2003; Swulius and 

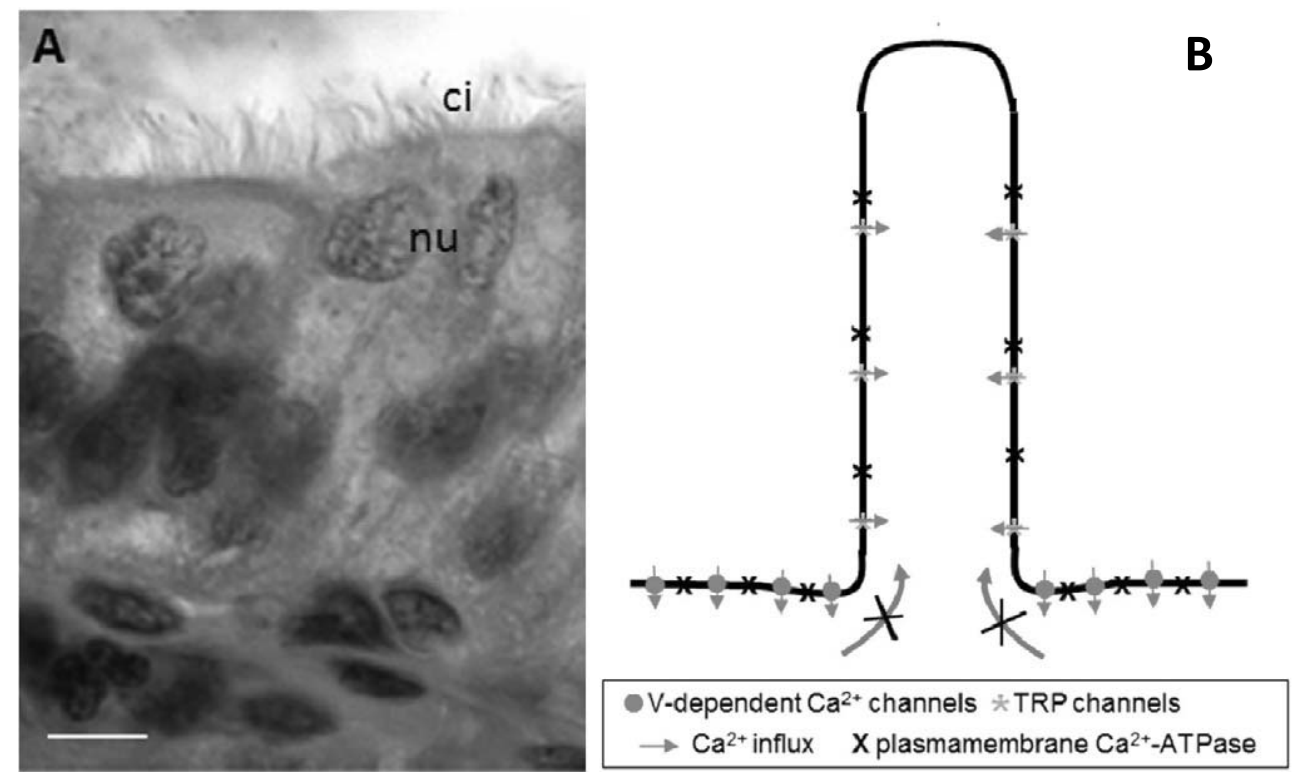

Figure 3 Ciliated epithelium (mouse oviduct, fixed and hematoxylin/eosin stained). Cilia (ci) shown in (A) are working independently (B) of any eventual voltage-dependent $\mathrm{Ca}^{2+}$ channels in the nonciliary membrane. Any $\mathrm{Ca}^{2+}$ signals eventually arising in the cell body do not remarkably affect ciliary activity. Note occurrence of TRP channels and PMCA in the ciliary membrane. nu = nuclei. (A) Courtesy by J. Hentschel. Scale bar in (A), $10 \mu \mathrm{m}$.

Waxham 2008). A comparable function is not known from other dense core-secretory vesicle systems, including protozoa. Both types of secretory systems are also (ultra) structurally quite different (Fig. 4) although they both contain fast releasable secretory vesicles.

A set of SNAREs comparable to that in protozoa and animals is also present in angiosperms (Lipka et al. 2007; Sanderfoot 2007; Uemura et al. 2004; Vedovato et al. 2009). However, R-SNAREs are preferably of the longin type. A longin domain must be an old heritage, as it is found in Lokiarchaeota, together with the transport machinery called ESCRT ("endosomal sorting complexes required for transport"), hypothetical vacuolar fusion domain protein and with BAR/IMD superfamily proteins (important for membrane deformation) (Spang et al. 2015). Thus, these archaebacteria already were prepared for vesicular traffic (which they do not have).

\section{Expansion of protein inventory by subfamily/ohnolog encoding genes}

This phenomenon is most pronounced in $P$. tetraurelia (Aury et al. 2006) and documented in some detail for actin, SNAREs, and $\mathrm{SU}-\mathrm{a}$ of the $\mathrm{H}^{+}$-ATPase.

Actin

Remarkably actin and actin-like proteins (LPS) are found already in Lokiarchaeota-type archaebacteria (Spang et al. 2015), whereas these cells contain no tubulin.

Paramecium actin genes, PtAct, include an unusual number of subfamilies (and accordingly of ohnologs), resulting in a great number of PtAct proteins and of actin- like (or actin-related) proteins (Sehring et al. 2007a). Depending on definition, representatives include 14-17 and 3-6, respectively, complementary forms. Four of the PtAct gene products encode ohnologs with differential subcellular localization, which also holds for the translation products of the other subfamilies. Numerous PtAct paralogs are situated along the cell surface. An exchange of PtAct isoforms is particularly impressive during maturation of the food vacuole, that is, phagolysosomes (Sehring et al. 2007b); see Fig. 5. PtAct4 does not only occur in the cortex but is also required for initiating formation of phagosomes and of the cleavage furrow (Sehring et al. 2010). In Paramecium, para-/ohnologs evidently may serve for vesicle fusion or budding as well as for cyclosis and to regulate access of vesicles to other membranes. Although specific effects still have to be scrutinized, differentiation of this kind appears without precedent in eukaryotic cells.

\section{A second look upon SNARES}

As mentioned, SNAREs are abundant in Paramecium. In $P$. tetraurelia, many of the R- and Q-SNAREs represent ohnologs, mostly with only $15 \%$ or less nucleotide difference between the ohnolog genes (Kissmehl et al. 2007; Schilde et al. 2006). This low difference makes it difficult, or even impossible to assign to such SNAREs specific intracellular localization by monospecific antibodies. This difficulty also holds for any attempt to assign specific functions via posttranslational silencing by competitive nucleotide sequences. In these cells, 70 SNARE-type genes have been identified by database screening (Kloepper et al. 2007) which is more than in man. Even if one disregards genes with only $\leq 15 \%$ difference, this would 

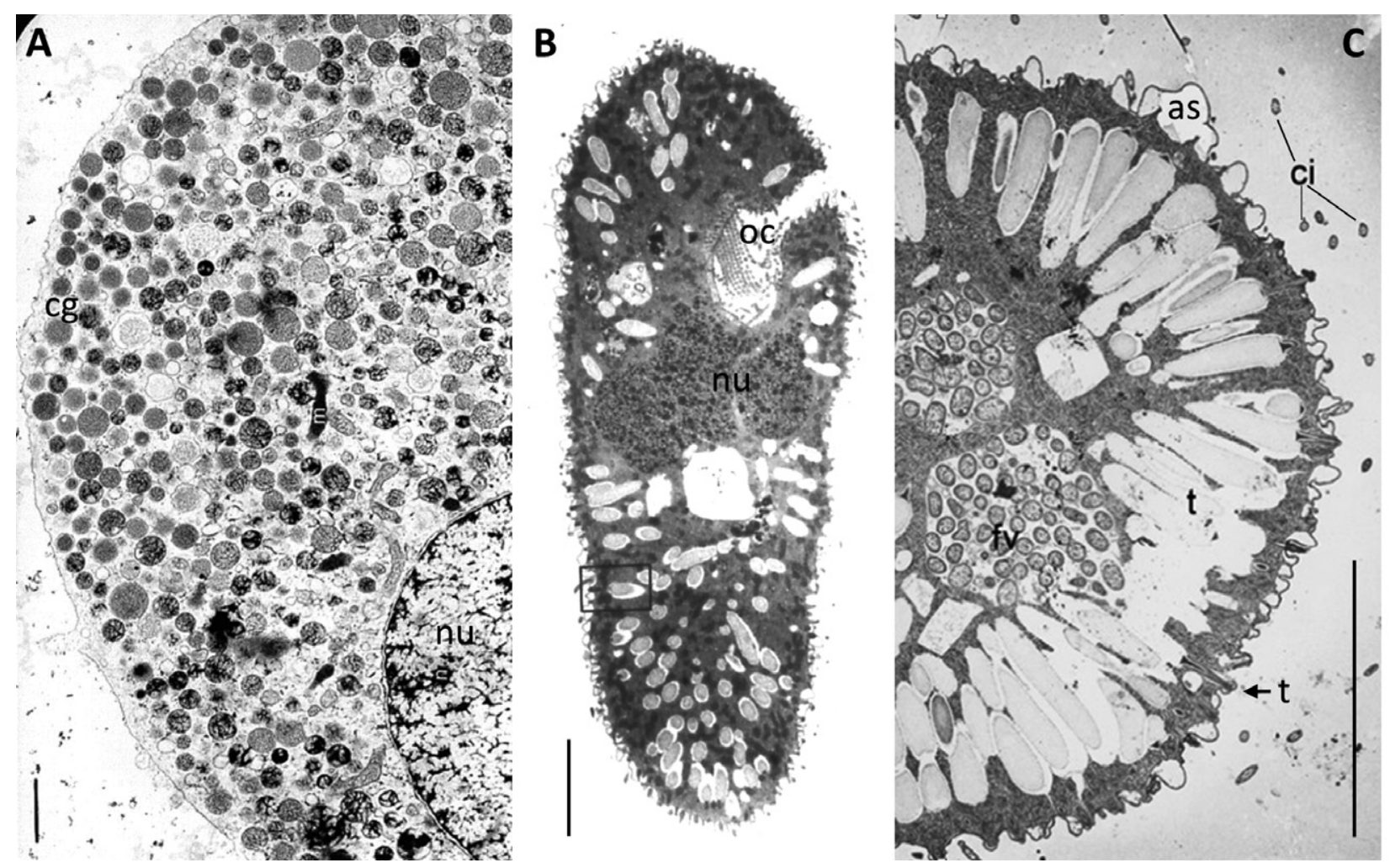

ci

Figure 4 Mammalian and protozoan dense core-secretory systems in comparison. (A) Bovine chromaffin cell in primary culture, unstimulated, containing $\sim 21,500$ chromaffin granules $(\mathrm{cg})$ of which only $\sim 440$, that is, $\sim 2 \%$ of the whole vesicle population, are attached to the cell membrane in a position potentially available for immediate release upon stimulation (Plattner et al. 1997a). (B, C) P. tetraurelia cells showing abundance of trichocysts (t). More than95\% of the whole population of up to 1,230 trichocysts are docked at the cell membrane, as can be recognized only in appropriate section planes (square in [A], arrow in [B]); of these $~ 95$ can be immediately released upon stimulation (Plattner et al. 1985). as $=$ alveolar sacs; $c i=$ cilia; $f v=$ food vacuole; $n u=$ nucleus; oc = oral cavity. (A) is from Plattner et al. (1997a), (B) from Plattner and Verkhratsky (2016), (C) H. Plattner, unpublished. Scale bars-1 $\mu \mathrm{m}(\mathrm{A}), 10 \mu \mathrm{m}(\mathrm{B}, \mathrm{C})$.

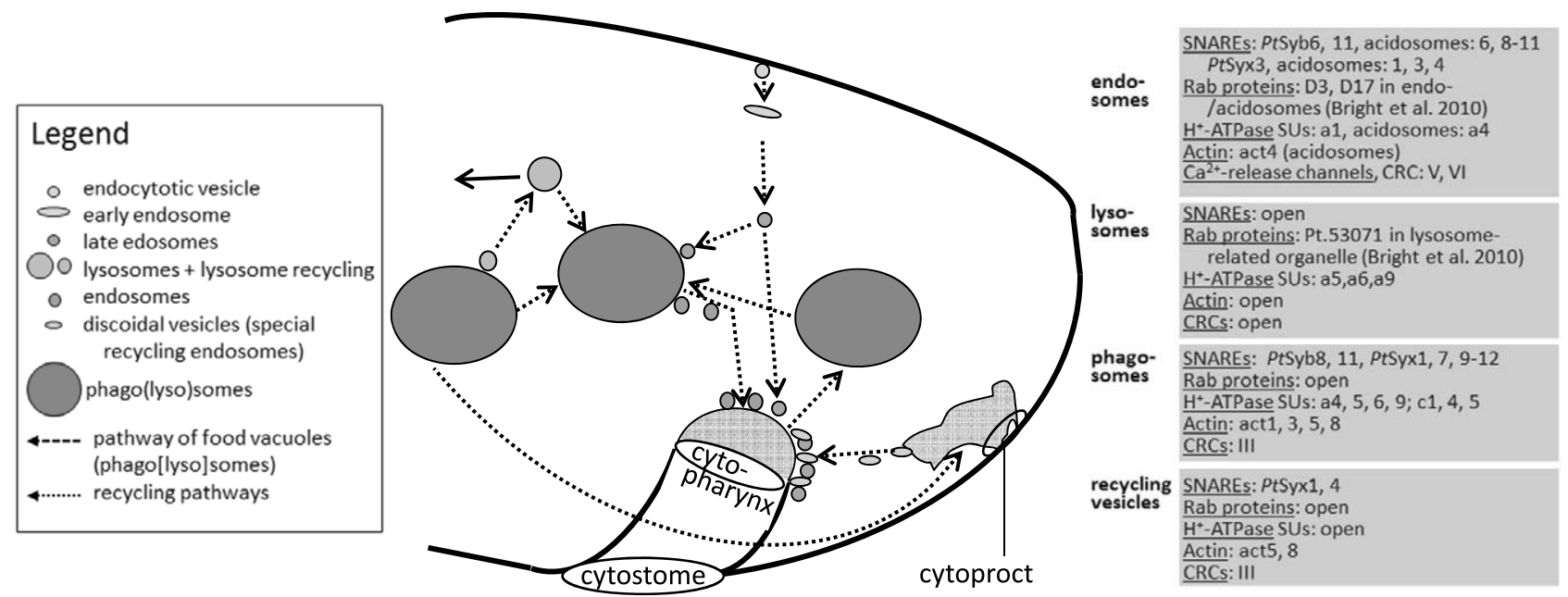

Figure 5 Trafficking of endo-/phago-/lysosomal compartments in Paramecium tetraurelia, showing multiple membrane/vesicle interactions (dotted arrows) on the way through the cell (dashed arrows). The boxes at the right side indicate the involvement of some of the numerous proteins, such as SNAREs, GTPases, $\mathrm{H}^{+}$-ATPase, actin, and $\mathrm{Ca}^{2+}$-release channels at different stages of the cycle. This complexity includes the exchange of variable isoforms on the way through the cell and, thus, looks as intriguing as comparable pathways in mammalian cells. For details, see Plattner $(2017 a, b)$. 
still yield $\sim 40$ functionally different SNAREs (Plattner 2010a). Thus, the number of functional different types of SNAREs in Paramecium is about the same as in man and far beyond values extrapolated for early eukaryotic and early metazoan cells, which is estimated as $\sim 20$ and $\sim 30$, respectively (Kloepper et al. 2008).

\section{Expansion of subunit SU-a of $\mathrm{H}^{+}$-ATPase}

The multimeric $\mathrm{H}^{+}$-ATPase/pump has precursors in bacteria (Stewart et al. 2014) and is universal to eukaryotic cells where it stands out by its multi-tasking capabilities (Maxson and Grinstein 2014). This complex molecule consists of a multimeric membrane-integrated base piece (V0), a stalk (SU-a) for connecting the V0 and the V1 part. V1 is the multimeric catalytic head part that sticks out into the cytosol. In mammals, the number of genes for each of the subunit monomers is $\leq 3$, only four are for encoding SU-a (Forgac 2007). The situation is quite similar with most plants, from mosses up to flowering plants, but with a similar number of genes for SU-a as well as for each of the monomers composing the $\mathrm{V} 0$ and the $\mathrm{V} 1$ part, respectively (Schumacher and Krebs 2010).

Usually the numbers of proteins interacting in protein assemblies have to be fine-tuned to produce a functional complex. This is generally observed in the respective expression rates also in $P$. tetraurelia (Aury et al. 2006) and-as one would expect-this should also be valid for the different SUs of multimeric proteins. However, a striking exception is $\mathrm{SU}$-a of the $\mathrm{H}^{+}$-ATPase of $P$. tetraurelia. While the number of SUs of the catalytic V1-part and of the V0-basepiece is limited as usual (Wassmer et al. 2005), these are by far outnumbered by SU-a copies, which are represented by an unprecedented number of 17 genes (Wassmer et al. 2006). In situ, the SU-a emerges from the VO part and can be reversibly connected to variable headpiece complexes, thus forming different holoenzyme variations (Forgac 2007). In Paramecium, SU-a is represented by eight doublets each of them with $>82 \%$ identity and one singlet, that is, by a total of 17 genes and 5 essentially different variants (Wassmer et al. 2006). In contrast, the number of genes for the individual V1 and V0 SUs is between 1 and 4 and between 0 and 6 , respectively. This is a clear exception to the general rule of stoichiometric expression of SUs in cooperating molecule complexes (Aury et al. 2006). This exception allows for a large number of functional $\mathrm{H}^{+}$ATPase complexes alone on the basis of SU-a variation. What may the functional implications of an increased number of SU-a, and consequently of V1/N0 complexes in Paramecium be?

In mammalian cells, tuning of luminal acidification during intracellular trafficking can cause a conformational change of the cytosolic part of the $\mathrm{H}^{+}$-complex, followed by selective binding of ARNO (ADP-ribosylation factor nucleotide site opener). ARNO is the GDP/GTP exchange factor (GEF) for GTPase Arf6, and, thus, relevant for binding to a specific SU-a of the $\mathrm{H}^{+}$-ATPase at the cytosolic side; this in turn results in GTPase-specific targeting (Hurtado-Lorenzo et al. 2006). The $\mathrm{H}^{+}$-ATPase can, thus, specify vesicle interaction partners by conformational coupling. Such a principle may be extended to different trafficking events in Paramecium where different SU-a subfamily members are distributed over specific organelles (Wassmer et al. 2006), although this still expects scrutiny.

Chlamydomonas reinhardtii possesses three genes encoding SU-a, but only one for encoding each of the monomers of the V0 and V1 complexes (Schumacher and Krebs 2010). In Entamoeba histolytica, where most $\mathrm{H}^{+}$ATPase subunit encoding genes are singlets - with high resemblance to $D$. discoideum - two genes encode SU-a (Mélendez-Hernández et al. 2008). In plants, isoforms of V0N1 coupling SU-a are differentially localized (Schumacher and Krebs 2010), just as one would expect for Paramecium. Since trafficking is also influenced by binding of actin to some of the $\mathrm{H}^{+}$-ATPase subunits (Beyenbach and Wieczorek 2006; Holliday 2014), this may entail additional variations in localization and function in Paramecium because of the large number of actin paralogs/ohnologs.

All this strongly suggests that $\mathrm{H}^{+}$-ATPase/SU-a isoforms may be important for differential targeting in all eukaryotes. In this context, Paramecium is an impressive example of selective gene expansion (Wassmer et al. 2009). This may account for the rather expansive trafficking pathways in these cells and for the involvement of a multitude of paralogs/ohnologs of SNAREs, GTPases, $\mathrm{H}^{+}$ATPase SUs, and $\mathrm{Ca}^{2+}$-release subunits during cyclosis (Fig. 5).

\section{Punctual changes in protein molecules and drug (in)sensitivity}

When compared with mammalian orthologs, the sensitivity of ciliate proteins to different drugs may be quite aberrant (Plattner et al. 2009). This has provoked quite a few errors in cell biology of protists, claiming, for instance, the alleged absence of actin from the cleavage furrow in some protists (Shimizu et al. 2013). Also sensitivity of plant microtubules differs from that of ciliates (Pape et al. 1991) and of mammalian systems. But why altogether should the interaction of a protein with specific drugs be maintained during evolution, when there is no selection pressure by a drug?

Considering drugs relevant for $\mathrm{Ca}^{2+}$ and membrane dynamics examples in Paramecium include SERCA inhibitors, such as thapsigargin, SNARE-cleaving endo-metalloproteases type Clostridium toxins, and cytoskeletal elements (Plattner et al. 2009). Some drugs reactive in mammalian cells simply do not find appropriate sites for binding to, or cleavage of target proteins.

The situation is particularly precarious with RyR-LPs in Paramecium since these CRCs do not react to the namegiving drug, ryanodine, a diterpenoide from the South American plant species Ryania speciosa (family Salicaceae). This is feasible considering the diffuse character of ryanodine-binding sites, the concentration dependence of ryanodine effects, and the irrelevance of interaction in nature. Yet, Paramecium's RyR-LPs clearly respond to 
established activators of RyRs (Ladenburger and Plattner 2011). In contrast, $I P_{3} R$ s of Paramecium are fully responsive to the metabolic activator, $I_{3}$ (Ladenburger et al. 2006).

There are little individual traits of Paramecium CaM which could entail a change of its main functions and drug sensitivity (Kink et al. 1990). Accordingly drug sensitivity is exceptionally well preserved for anti-CaM drugs (Ehrlich et al. 1988; Erxleben and Plattner 1994), in contrast to many other drugs (Plattner et al. 2009).

\section{Actin filaments}

However, universally distributed, microfilaments possess rather heterogenous properties. From myxamoebae to animals, from ciliates to angiosperms, the actin filament system contributes to cell organization and in the unikont branch, to motility. Work is abundant with Dictyostelium (and Physarum) as well as with angiosperms (Henty-Ridilla et al. 2013; Noegel and Schleicher 2000) and animals up to mammals (Gunning et al. 2015). In this sequence, the number of genes encoding different paralogs for cytoplasmic actin is 8 (D. discoideum), 10-17 (angiosperms), and 1-5 (mammals; 4 in man) (Gunning et al. 2015)

Plants use actin filaments for cytoplasmic streaming (which probably is also the case with cyclosis in ciliates), accompanied by organelle traveling, and for signaling (Henty-Ridilla et al. 2013; Shimmen 2007; Staiger et al. 2009). Just like animal cells (Bubb et al. 1994; Cooper 1987), plant actin is sensitive to the different polymerizing and depolymerizing drugs (Shimmen 2007). This is also true of Dictyostelium (see, e.g. [Parent et al. 1998]) and Chlamydomonas (Avasthi et al. 2014). In other algae, microfilaments appear incapable of binding phalloidin and, thus, to visualize the cell cleavage plane by fluorescent derivatives (Busch and Hess 2017).

The basic structure of actin appears rather conservative, but sites important for diagnostic binding of fluorescent phalloidin/jasplakinolide and cytochalasin/ latrunculin, respectively, are usually well preserved. Several defined aminoacids are critical for drug binding. These are quite variable in the large number of isoforms described in $P$. tetraurelia, together with the actin-LPs, whereas they are consistently preserved in the much smaller number of mammalian actins (Sehring et al. 2007a). Concomitantly aminoacid residues responsible for binding microfilament-stabilizing and microfilament-destabilizing drugs, shifting monomer $\rightarrow$ polymer and polymer $\rightarrow$ monomer equilibrium, that is, phalloidin or jasplakinolide and cytochalasin B or latrunculin A, respectively, are quite variable between actin isoforms of Paramecium (Sehring et al. 2007a). This is a striking example of the largely aberrant pharmacology of many established experimental and diagnostic drugs (Plattner et al. 2009).

The fact that ciliates tolerate reduction of toxin-binding sites to different degrees may again mirror the fact that drug binding is of no direct evolutionary consequence for these molecules. Importantly, localization differs for the different actin paralogs of Paramecium (Sehring et al. 2007b, 2010). It may also indicate different binding to other proteins and different polymerization kineticspredictions to be scrutinized. Remarkably, there are no consistent differences between mono- and bikonts.

\section{Microtubules}

Also microtubules are functionally and pharmacologically rather different. Several ciliate-specific epitopes of metazoan tubulins are conserved from $P$. tetraurelia to mammalians (Adoutte et al. 1985, 1991). Throughout animal evolution up to man, specific covalent modifications of microtubular tubulin can take place, such as acetylation, glycylation, and glutamylation (Song and Brady 2015) and thus determine interaction with different tubulin-binding proteins (Rosenbaum 2000). In the Paramecium cell, just as in other taxons including plants (Parrotta et al. 2014), any covalent modifications entail selective localization in specific microtubule subpopulations, located at different sites of the Paramecium cell (Adoutte et al. 1991) and apparently also different drug sensitivity.

When we tested cell division activity of $P$. tetraurelia cells in the presence of drugs with established depolymerizing effects in mammalian cells, colchicine, for example, exerted no effect in concentrations $\sim 1,000$ times above those normally applied to mammalian cells (Pape et al. 1991). In this work, we have made similar observations with drugs directed against plant microtubules (Hashimoto 2015). Thus, sensitivities do not follow a strict scheme in mono- and bikonts.

\section{Loss of a subunit}

Calcineurin $(\mathrm{CaN})$ is a dimer of the catalytic CaN-A and the regulatory $\mathrm{CaN}-\mathrm{B}$ subunit, with widely different functions from protozoa to man (Aramburu et al. 2000, 2004; Rusnak and Mertz 2000). The occurrence of CaN SU-A, together with SU-B (Fraga et al. 2010), in ciliates would suggest its occurrence also in other bikonts, such as plants. However, in plants only SU-B is maintained as CBLs (CaN-B-like [proteins]), with an increasing number or paralogs during evolution, from Bryophyta (mosses) to A. thaliana (Edel and Kudla 2015). Here, CBL is widely diversified and mainly modulates ion channel activity and $\mathrm{Ca}^{2+}$ signaling by CIPKs (CBL-interacting protein kinases) (Edel and Kudla 2015; Sanyal et al. 2015), but altogether CIPKs regulate different signaling pathways in angiosperms (Yu et al. 2014). CBLs are also known from C. reinhardtii (Mohanta et al. 2015).

In summary, the selective maintenance of only one CaN-SU is specific for plant evolution, whereas both SUs are present in both of the most intensely studied unicellular representatives of the unikont and bikont lineages, that is, Dictyostelium (Aichem and Mutzel 2001; Hellstern et al. 1997) as well as Paramecium (Fraga et al. 2010). This advocates for the occurrence of both SUs also in early times of bikont evolution and secondary loss of SU-A in plants. In parallel, CBLs have arisen during evolution of the multicellular "green representatives" of bikonts, thus making arid areas accessible. 
Proteins with variable covalently integrated extradomains

The three salient examples to be discussed are PMCA, CDPKs, and R-SNAREs.

Among PMCAs, PAT1 of Dictyostelium is exceptional insofar as it has been described as a $\mathrm{Ca}^{2+}$-ATPase most closely related with PMCAs, although it is devoid of a CaM-binding domain (Gross 2009; Moniakis et al. 1995). Plant PMCA is also aberrant insofar as its autoinhibitory $\mathrm{Ca}^{2+} / \mathrm{CaM}$-binding domain can be found at the amino-terminus (Tidow et al. 2012). Otherwise, the molecular structure is probably the same from protozoans to mammals.

Remarkably, a CaM-like sequence is attached to the carboxy-terminal end of some protein kinases, called " $\mathrm{Ca}^{2+}$ dependent protein kinases" (CDPK), in ciliates (Kim et al. 1998), Chlamydomonas (Edel and Kudla 2015), and plants (Dixit and Jayabaskaran 2015). In contrast, the myxamoeba Physarum polycephalum is reported to possess also a genuine CaM-kinase (Nakamura et al. 2005). Altogether, CDPKs are typical of the bikont lineage.

In ciliates, R-SNAREs ("synaptobrevins") have a longin domain integrated on the amino-terminal side (Schilde et al. 2006, 2010). This recalls the situation in plants (Sanderfoot 2007; Uemura et al. 2005; Vedovato et al. 2009). In plants, this domain contributes to vesicle targeting via interaction with other trafficking proteins. Occasionally, a similar effect has been reported for some mammalian R-SNAREs, for example, VAMP7, as analyzed in HeLa cells (Martinez-Arca et al. 2003). No such topology-determining effect has been scrutinized in ciliates as yet. In conclusion, a longin fold is an evolutionary criterion occurring much more frequently in bikonts than in unikonts.

\section{Proteins undergoing considerable differentiation or replacement during evolution}

\section{Plasmalemmal transporters}

This concerns a multitude of plasmalemmal transporters in plants. In plants, ion transport at the cell membrane is highly diversified - much more than in metazoan (and presumably in protozoan) cells (Edel and Kudla 2015). Together with exchangers, rather different ATPases are abundant in the cell membrane, that is, not only P-type $\mathrm{Ca}^{2+}$-ATPases/pumps but also $\mathrm{H}^{+}$-ATPases/pumps (V-type ATPases) (Duby and Boutry 2009). Not only the usual kind of V-type ATPases, composed of multimeric V0/N1 subunits and a connecting SU-a, are important as part of this inventory, but many of the transport functions can be performed by other pumps (Ratajczak 2000). Lineage-specific regulation of ion channels by CIPKs has been presented above.

A second look upon ciliary $\mathrm{Ca}^{2+}$ channels and pumps Ciliary $\mathrm{Ca}^{2+}$ channels and $\left[\mathrm{Ca}^{2+}\right]$ downregulation are connected with considerable relocalization of key proteins during evolution. As noted above, the subcellular localization of voltage-dependent $\mathrm{Ca}^{2+}$-influx channels varies during evolution: In ciliates, they are localized in cilia of
Paramecium (Dunlap 1977; Machemer and Ogura 1979; Yano et al. 2013) and of Tetrahymena (Dentler 1988) as well as in the green flagellate Chlamydomonas to the flagellar membrane (Mitchell 2007). This also holds for the flagellum of choanoflagellates (Cai et al. 2015). However, during metazoan evolution, other channels emerge in ciliary membranes.

TRP-type channels are not known in any detail from ciliates (Plattner and Verkhratsky 2015; yet see Plattner [2017a,b] for a possible equivalent), whereas they are known from unikonts, such as choanoflagellates (Cai et al. 2015). At first sight, the difference in voltage-dependent and nonvoltage-dependent channels would appear as a clear-cut difference between unikonts and bikonts. However, in contrast to what one would expect, Dictyostelium is reported to be devoid of voltage-dependent $\mathrm{Ca}^{2+}$ channels (Wilczynska et al. 2005). In Chlamydomonas, deflagellation induces upregulation of TRP1 (Fujiu et al. 2011) and electrophysiology clearly shows TRP channel characteristics (Arias-Darraz et al. 2015). While angiosperms are devoid of cilia or flagella (Moran et al. 2014), some gymnosperms, for example, Cycas palms and Gingko trees, still produce sperm cells with cilia; this still would have to be analyzed.

Why in evolution may TRP channels have been preferred by most systems over voltage-gated $\mathrm{Ca}^{2+}$ channels? TRP channels are grouped in seven subfamilies (Venkatachalam and Montell 2007), including those relevant for ciliary signaling: (i) a classical subfamily, TRPC; (ii) a vanilloid receptor subfamily, TRPV; (iii) a melastatin subfamily, TRPM; and (iv) a polycystin subfamily, TRPP (Pablo et al. 2017). TRP channels occur in, or near, motile (epithelial) as well as in immotile (primary) cilia (Kleene and Van Houten 2014). Here, in conjunction with basal bodyassociated F-actin, they serve as mechanosensors when cilia are bent (Battle et al. 2015; Venkatachalam and Montell 2007). TRP channels can form homo- or heteromeric channel complexes with variable channel properties including variable $\mathrm{Ca}^{2+}$ selectivity (Pablo et al. 2017). In the primary cilium, they can encompass, for example, TRPPs type PKD2, PKD2-1, TRPM4, and TRPV4 which are localized in the ciliary membrane (Pablo et al. 2017; Phua et al. 2015). In epithelial cells, TRPCs seem to occur, in part, in the ciliary and nonciliary cell membrane (Pablo et al. 2017). In cilia of the trachea, TRPV4 occurs, and PKD1 and PDK2 are also components of these motile cilia (Doerner et al. 2015).

So, why did this polymorphy emerge? Signal perception and also signal transmission by TRP-type channels are polymodal depending on the stimulus and the TRP channel type activated. Altogether this allows for receptor functions in response to widely different stimuli, each with a fine-tuned reaction (Bloodgood 2010; Phua et al. 2015). Functionally, the rationale of voltage-dependent $\mathrm{Ca}^{2+}$ channels is the rapid, depolarization-based ciliary reversal response for immediate avoidance of mechanical obstacles and to ward off predator attacks, for example, by paramecia, as summarized recently (Plattner 2017a,b). Closure of these channels by a forming $\mathrm{Ca}^{2+} / \mathrm{CaM}$ complex avoids $\mathrm{Ca}^{2+}$ spillover into 
the cell body and, thus, avoids the additional triggering of unwanted reactions beyond cilia.

To recall, ciliary membranes in both evolutionary branches, mono- and bikonts, contain a PMCA (Fig. 1-3), as shown with Tetrahymena (Dentler 1988), Paramecium (Yano et al. 2013), Chlamydomonas (Pazour et al. 2005), and cilia of differentiated mammalian cells (Castillo et al. 2007). However, $\mathrm{Ca}^{2+}$ downregulation by PMCA activityif present at all, for example, in the olfactory ciliary membrane-would be too sluggish (Kleene 2009). This is improved, as demonstrated with Paramecium cilia (Brehm and Eckert 1978) as well as with neuronal cell bodies of mammals (Levitan 1999), by rapid inactivation by CaM binding in a negative feedback loop. In summary, in widely different systems of different evolutionary levels, PMCA has only a minor, secondary effect on $\left[\mathrm{Ca}^{2+}\right]$ downregulation after stimulation, also in cilia.

\section{Intracellular $\mathrm{Ca}^{2+}$ channels}

To allow for locally restricted intracellular signaling by $\mathrm{Ca}^{2+}$, eukaryotic cells had to "invent" $\mathrm{Ca}^{2+}$-release channels (CRCs) (Plattner and Verkhratsky 2016). Their evolution is currently in the focus of research with different protozoan groups, for example, in ciliates (Ladenburger and Plattner 2011; Ladenburger et al. 2006, 2009) and, by preliminary genomic data mining, in choanoflagellates (Cai et al. 2015).

There are evolutionary differences in the occurrence of $\mathrm{IP}_{3}$ Rs. According to informatics analysis Dictyostelium encodes a putative $I P_{3} R$ (Traynor et al. 2000), just of the type analyzed in some detail in Paramecium (Ladenburger et al. 2006). An $I_{3} R$ is absent from Chlamydomonas (Pazour et al. 2005) and also from plant cells (Edel and Kudla 2015; Krinke et al. 2007).

The discovery of RyR-like proteins (RyR-LPs) in P. tetraurelia has a provocative effect. On one hand, the molecule has features typical of the superfamily of $I P_{3} R s$ and classical RyRs of mammalians. This includes sequence similarity, occurrence of six transmembrane domains with a characteristic selectivity filter, and the absence of an $\mathrm{IP}_{3}$-binding domain in Paramecium (Ladenburger and Plattner 2011; Ladenburger et al. 2009; Plattner 2017a,b), just like in mammalians (Efremov et al. 2015). It has to be stressed that the six transmembrane domains described for Paramecium RyR-LP (Ladenburger and Plattner 2011) are now established also for mammalian RyR (Efremov et al. 2015; Zalk et al. 2015). On the other hand, it may be designated merely as a RyR-LP, rather than as a conventional RyR, because of its unusually small molecular size. On one hand, this channel can be activated by classical activators of RyRs, such as caffeine and 4-chloro-meta-cresol, an effect inhibited by gene silencing (Ladenburger and Plattner 2011; Plattner 2017a,b). On the other hand, the large amino-terminal part found in mammalian RyRs, where it mediates functional feedback to the pore containing transmembrane segments (Efremov et al. 2015), is missing in Paramecium RyR-LPs (Ladenburger and Plattner 2011).

Remarkably, there is evidence from molecular data mining that this channel may also occur in the choanoflagellate, Salpingoeca rosetta (Cai et al. 2015). Functional substitution of $I P_{3} R /$ RyR-LPs and of TRP channels by other channels in plants has recently been broadly discussed (Edel and Kudla 2015).

All this can be summarized as follows. Concerning intracellular CRCs, there are some similarities between uni- and bikonts in lower eukaryote representatives; for instance, $\quad P_{3} R$ is present in Dictyostelium and in Paramecium. Again there are differences between the "green" and the other representatives of bikonts, considering that Chlamydomonas and angiosperms are devoid of such channels. Also the presence/absence of ciliary/flagellar channels fluctuates between representatives of the unikont and bikont branches. Altogether, loss of $I P_{3} R$ channels can be considered a characteristic of plants.

\section{Refunctionalization of proteins}

Neofunctionalization and refunctionalization mean establishment of an essentially new function for a newly evolved protein and reassignment of a new function to an already existing type of protein, respectively. What previously had been considered as pre-adaptation is now called "exaptation," that is, a shift in function of a trait/molecule during evolution (Sardar et al. 2014). Exaptation is now considered an important mechanism in evolution. Thereby, redirecting the localization of proteins (e.g. by altered targeting signals) is a mechanism of introducing new functions (Bauer et al. 2015).

A rare example of neofunctionalization is $\eta$-tubulin in Paramecium. It is an ohnolog emerging from a most recent whole genome duplication (Ruiz et al. 2000) serving for basal body biogenesis (Ruiz et al. 2000).

Refunctionalization can be exemplified as follows. The contractile vacuole complex mediates osmoregulation in some freshwater and in some parasitic protozoa. The de novo biogenesis of the organelle, as analyzed in Paramecium, precedes cell division and is regulated by proteins that are known as regulators of cytokinesis in any eukaryotic cells. Such proteins include calmodulin, centrin, $\gamma$-tubulin, and NIMA (never in mitosis A) kinase (Plattner 2015a). Formation of a centrin-based infraciliary lattice, intermingled with F-actin, as an immobile subplasmalemmal $\mathrm{Ca}^{2+}$ buffer is another example. An example of considerable interest is the dual role of some proteins, such as importin/transportin and the GTPase Ran; they regulate transport of proteins through nuclear pores as well as access to cilia (Gruss 2010). Quite recently, Shi et al. (2017) have demonstrated such dual function for IFT57A protein in Paramecium, where it serves for nuclear as well as for import of ciliary proteins. Despite the inability to produce cilia or flagella in higher plants, some axonemal proteins have been retained and used for alternative, cytoskeletal functions (Moran et al. 2014).

\section{GPI-anchored variant surface antigens (vsAGs)}

Other examples of acquirement of new functions are GPIanchored proteins, or rather of their GPI anchors. In Fig. 6, 


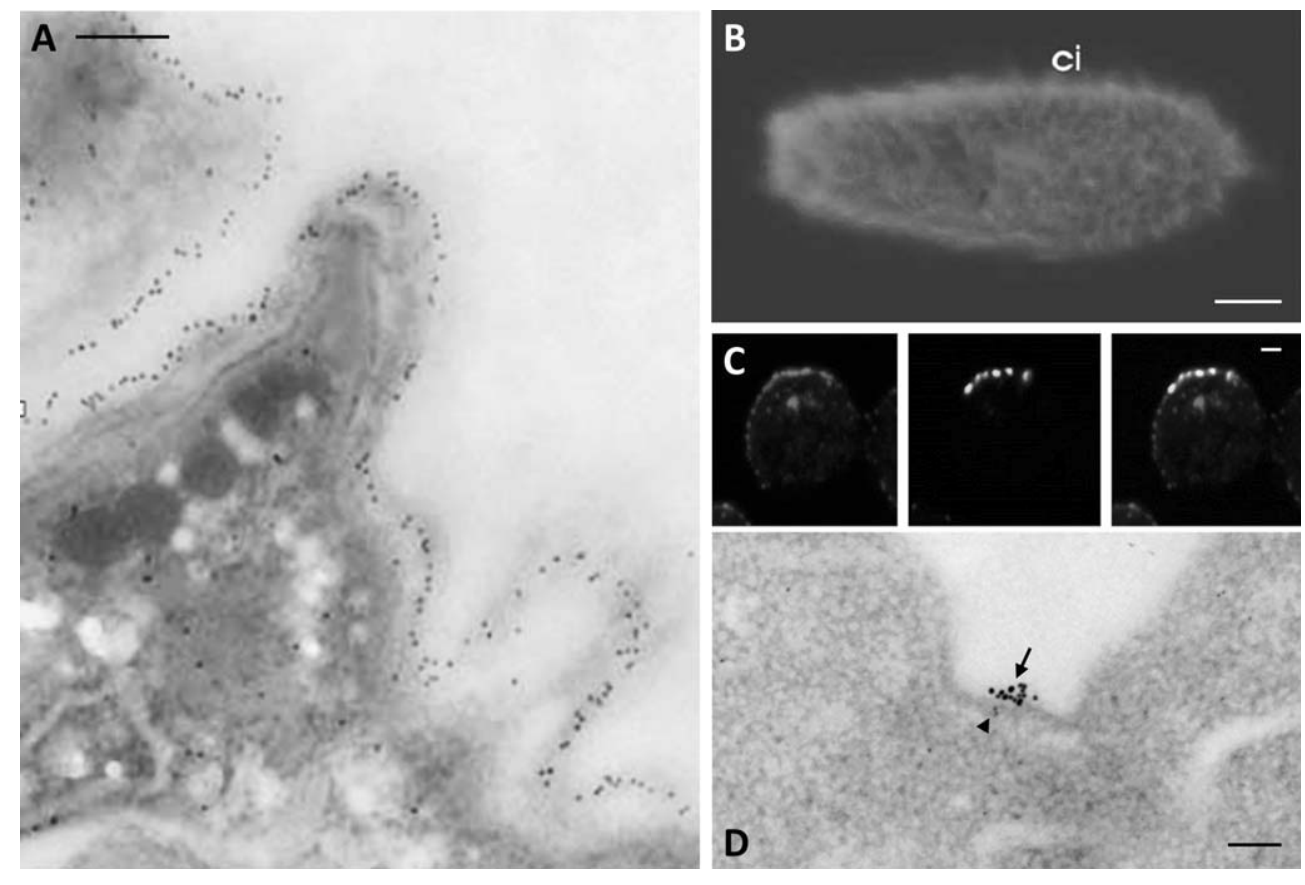

Figure 6 GPI-anchored proteins are diffusely distributed in Paramecium tetraurelia (A, B), but concentrated in microdomains in mammalian cells (C, D). (A, B) vsAGs in P. tetraurelia, (C, D) reggie/flotillin and prion protein ( $\operatorname{Pr}^{\mathrm{C}}$ ) in lymphocytes. The localization of vsAG subtype $\mathrm{G}(\mathrm{A})$ by electron microscopy using immune-gold and (B) by fluorescent antibodies is diffusely distributed over the cell surface (including cilia, ci), in the absence of any recognizable microdomain formation. (C, D) The situation is different in lymphocytes where microdomain formation is shown to involve scaffolding reggie-1/flotillin-2 proteins (red, left) and co-clustering $\mathrm{PrP}^{\mathrm{c}}$ (green, middle) shown by superposition (yellow color mix, right). Comparable co-clustering is seen in electron microscopic immunogold labeling: reggie-1/flotillin-2 labeled with $5 \mathrm{~nm}$ gold on the inner side (arrow head) and $\mathrm{PrP}^{\mathrm{C}}$ detected by $10 \mathrm{~nm}$ gold (arrow) on the outer side of the cell membrane. (A, B) is from Momayezi et al. (2004), (C, D) from Stuermer et al. (2004). Scale bars: $0.1 \mu \mathrm{m}$ (A), $10 \mu \mathrm{m}(\mathrm{B}), 1 \mu \mathrm{m}(\mathrm{C})$, and $0.1 \mu \mathrm{m}$ (D).

the localization of GPI-anchored proteins in ciliates is compared with that in mammalian cells, taking vsAGs and prion $\left(\mathrm{PrP}^{\mathrm{C}}\right)$ proteins as examples. Apicomplexa and trypanosomatids as well as free-living protists, such as ciliates, are covered by a thick layer of GPI-anchored proteins; for Paramecium, see Preer (1986), Capdeville et al. (1987), Ferguson (1999) and Simon and Schmidt (2007). These include variant surface antigens (vsAGs) which possess a GPI anchor at their carboxy-terminal part (Ferguson 1999), and which, in Paramecium, represent about two-thirds of ciliary membrane proteins by mass (Yano et al. 2013). They are called vsAGs or immobilization antigens because they can be mutually exclusively expressed and exchanged and because of the effect of antibody binding, for example, in Paramecium (Simon and Schmidt 2007). These proteins are expressed under epigenetic control ("antigenic variation") which allows for rapid exchange of isoforms that determine the different serotypes. This is enabled by RNA-mediated reprogramming of gene expression patterns (Cheaib et al. 2015; Garnier et al. 2004) and by releasing vsAGs from the cell surface by GPI-specific phospholipases (Staudt et al. 2016).

In contrast, any functional role of vsAGs in ciliates is not well established although depleting cells of vsAGs is lethal to cells. Functions discussed range from intercellular and intracellular communication (Simon and Kusch 2013) to receptors for chemoresponse (Yano et al. 2003). Could it be that vsAGs provide a kind of ionic microenvironment for the cells, for instance via $\mathrm{Ca}^{2+}$ binding, or may simply surface charges play a role? This is supported for interaction of the ciliate Pseudomicrothorax dubius with food cells (Kiersnowska et al. 1988) and for homologous interaction during conjugation in Paramecium caudatum (Kitamura and Hiwatashi 1984). Beyond this, it has not been possible so far to assign them a clear-cut function in ciliates, in contrast to the apicomplexan parasites.

The vsAGs are a rather heterogenic extended group in animals up to man where a large number of GPI-anchored proteins fulfill widely different activities. This ranges from ecto-enzymes (e.g. acetylcholine esterase, 5'-nucleotidase) to cell adhesion molecules, also in neurons and immune cells, while some serve for signal transduction (Ferguson 1999) and vesicle trafficking. Thy-1 is traditionally traded as a cell adhesion molecule, but now it is also an example of a GPI-anchored surface protein integrated into vesicle trafficking and membrane surface turnover (Stuermer 2012). Comparison of Fig. $6 A / B$ and $C / D$ reveals the rather homogenous distribution of the GPI-anchored proteins analyzed in Paramecium and the rather strict confinement of such proteins to microdomains in mammalian cells.

GPI-anchored proteins also occur in the smallest freeliving nonsymbiotic alga, Ostreococcus (Mani et al. 2011), 
in Dictyostelium (Haynes et al. 1993), and in plants (Eisenhaber et al. 2003), but-in the absence of an ER-not in bacteria (Mani et al. 2011). In eukaryotes, the GPI anchor is synthesized and attached to the carboxy terminus of selected proteins after truncation in the ER.

The GPI anchor of proteins can be released by specific phospholipase C (PL-C) forms. From bacterial precursors and from a small number of PL-C paralogs (Leondaritis et al. 2011), only two appear GPI-specific - a situation which is even less clear in mammals (Müller et al. 2012; Staudt et al. 2016). GPI proteins accompany evolution of Mono- and Bikonta from low levels on. Clearly, the principle of cutting a singlepass transmembrane protein type 1 at the carboxy-terminal side for transfer onto a GPI anchor (Ferguson 1999), followed by delivery to the cell surface via vesicle trafficking, is a principle maintained from protists up to angiosperms and mammals. Thereby, the protein moiety can be widely different.

\section{Proteins newly "invented" during evolution}

\section{Filamentous structures}

Intermediate filaments are most variable when different evolutionary lineages are compared. Intracellular keratin is paradigmatic for mammalians and extracellular cellulose fiber formation at the cell membrane by cellulose synthase is typical of plants. No genes for the prominent mammalian intermediate filament constituents have been detected in the T. thermophila genome (Eisen et al. 2006). Cellulose synthesis in tunicates (phylum Chordata) has probably been enabled by horizontal gene transfer (Sagane et al. 2010). In contrast, alveolin proteins are a true characteristic of Alveolata, specifically of ciliates and Apicomplexa, where they form subplasmalemmal filaments (Gould et al. 2008). This is different from the centrin-based "infraciliary lattice" in ciliates which is composed mainly of centrin (Beisson et al. 2001), intermingled with actin (Kissmehl et al. 2004).

\section{Cell adhesion}

"Invention" of cell adhesion molecules is another achievement. It starts with cadherins (King et al. 2003, 2008; Shalchian-Tabrizi et al. 2008), specifically with a cadherin/ $\beta$-catenin complex in choanoflagellates (Nichols et al. 2012). Cell adhesion molecules from Dictyostelium discoideum, designated DdCAD-1, display a high degree of sequence similarity with cadherin family members, including $\mathrm{Ca}^{2+}$ binding (Sesaki et al. 1997; Wong et al. 1996), yet it has some unexpected functions as it binds CaM for delivery into the contractile vacuole complex (Sriskanthadevan et al. 2013). Also in Dictyostelium, TgrB and TgrC surface proteins, dedicated to allo-recognition during transition from uni- to multicellularity (Hirose et al. 2015), are unrelated to established cell adhesion proteins. In sum, Amoebozoa are evidently devoid of cadherins (Abedin and King 2008). In the bikont lineage, the situation may be similar with fenestrins-proteins required for cell conjugation in ciliates (Cole et al. 2008)
Further evolution of intracellular signaling

GPCRs are represented by 1,000 (or more) members in mammalians where they are of paramount medical importance (Tautermann 2014). No such GPCRs are known from plants, despite the presence of trimeric G-proteins whose function, thus, differs from that in animal cells (Colaneri and Jones 2014). In protists, GPCRs are under considerable debate, except Dictyostelium. Only a few examples may be given. Of GPCRs, for instance, we know that they occur in Dictyostelium (Elzie et al. 2009), where they are coupled to folic acid-induced chemotaxis and phagocytosis (Pan et al. 2016). In contrast, we have only fragmentary information for Paramecium (as reviewed in Plattner 2017a,b).

Similarly, in protozoans, genuine Tyr phosphorylation for signal transduction (outside mitotic activity) is known only from choanoflagellates (Manning et al. 2008; Segawa et al. 2006), but not from ciliates (Plattner 2017a,b). More detailed information would be of paramount importance for a full understanding of signal transfer in these cells. Choanoflagellates are also unique in possessing receptortype Tyr-kinase molecules (King et al. 2003; Miller 2012; Shalchian-Tabrizi et al. 2008); Monosiga brevicollis and related filasterean Capsaspora owczarzaki contain even more such Tyr-kinases than man and they also possess adequate protein phosphatases (Hunter 2014). In a strict sense, receptor-type Tyr-kinases are absent from ciliates and from myxamoebae (Mayer 2008) whose genome does not encode any modern tyrosine-specific protein kinases (Lim and Pawson 2010). Ciliates possess only Tyrkinases for nuclear signaling, as summarized recently (Plattner 2017a,b). Thus, the Tyr-kinase types responsible for a large part of intracellular signal transduction, from the cell membrane on, emerge only in metazoans.

Clearly, evolution of the highest taxons entailed the development of new sensorial categories without any known structural counterpart in unicellular organisms. In vertebrates and specifically in mammals, the protein repertoire is complemented by cyclic peptide neurohormones, such as vasopressin (Baribeau and Anagnostou 2015) and oxytocin, for complex central nervous and behavioral functions (Crespi 2016; Goodson 2005). Oxytocin produces emotional effects ("love hormone") whereby vasopressin can interact, while its main function is the regulation of water balance. The latter is handled in widely different manner in lower animals, protists, and plants. In sweet water protists, it is effectuated by the mechanistic system of an osmoregulatory organelle, the contractile vacuole complex, as reviewed recently (Plattner 2015a). Both peptide neurohormones trigger intracellular signal transduction via trimeric GTP-binding proteins ("G-proteins") and GPCRs (Kobilka 2013). Whether plants dispose of GPCRs is the subject of intense discussions (Taddese et al. 2014). They use alternative mechanisms for osmoregulation, that is, by different ion transporters, as discussed recently by Edel and Kudla (2015). In summary, water balance is regulated by widely different mechanisms in protists, animals, and plants and the proteins involved are accordingly different during evolution. 


\section{Proteins lost during evolution}

There is wide variation between retention and abolition of selective proteins during evolution. Even within animals, from fish to man, only $53 \%$ of genes are shared by different species. Similarly angiosperms retain only $51 \%$ from their precursors (Gimpel et al. 2013). As mentioned, some proteins, or subunits thereof, are completely eliminated from plants, such as SU-A of CaN and RyR-LPs.

Alveolins and epiplasmins are proteins lost during evolution. Alveolins are proteins with charged repeats which are characteristic of Alveolata, such as ciliates and Apicomplexa (Plasmodium, Toxoplasma) (El-Haddad et al. 2013). In ciliates, they are essential for the formation of the regular cell surface pattern. This is paralleled by the regular arrangement of alveolar sacs which, on the side facing the cell interior, are backed up by epiplasmins (Aubusson-Fleury et al. 2013).

While the secretory machinery is largely retained during evolution, contents are quite variable. Figure 4 compares dense core-vesicle systems in mammals and in ciliates. Three facts are striking. (i) Both use a SNARE/GTPase system. (ii) Ciliates can synchronously release their contents, in contrast to mammalian systems. (iii) Importantly in the present context, there is a complete exchange of secretory proteins during evolution. This is largely the case with mucocyst and trichocyst contents in Tetrahymena and Paramecium, respectively, aside from some proteins with similar motifs and targeting mechanisms (Guerrier et al. 2017). Reports on chromogranin $A$ and pancreastatin in trichocysts could not be verified, as discussed previously (Plattner 2017b). This difference can be appreciated if one considers the engagement, for example, of some neurosecretory peptides in emotional conditioning and other systemic regulatory phenomena, whereas some other ones have lytic functions, to mention just two extremes.

Ion channels are another group of proteins exchanged or lost during evolution. Recent reviews - not to be repeated here-inform about appearance and disappearance, respectively, of different ion channels from protists on, up to mammalians and flowering plants (Edel and Kudla 2015; Plattner and Verkhratsky 2015). Examples include bacteria (Domínguez et al. 2015), ciliates (Plattner 2015b), chlorophyceae (Edel and Kudla 2015), myxamoebae (Traynor et al. 2000), trypanosomatid flagellates (Docampo et al. 2014), other pathogenic protozoa (Prole and Taylor 2011), and, finally, choanoflagellates (Cai et al. 2015). Currently, data are frequently retrieved solely by data mining, whereas only in few protozoa, some channels have been experimentally verified and, thus, made comparable to animals and plants. Many channels emerge early on in evolution; some, like $I P_{3} R s$, are maintained from ciliates, flagellates, and myxamoebae up to man (Plattner and Verkhratsky 2015), but up to now remained untraceable in plants (Edel and Kudla 2015) and apicomplexan parasites (Garcia et al.2017). Remarkably Chlamydomonas has voltage-dependent $\mathrm{Ca}^{2+}$ channels as well as TRP channels, but apparently no $I P_{3} R s$ (Edel and Kudla 2015). Thus, bikonts probably have lost
$I_{3} R$, voltage-dependent $\mathrm{Ca}^{2+}$ channels and TRP channels as soon as they became "green" (Wheeler and Brownlee 2008).

Two or more peptides/proteins from one gene and two genes for one protein

The "two or more proteins/peptides from one gene" is familiar from neuropeptides, but considerably less from protists.

In mammals, long known examples are a variety of neuropeptides released from the pituitary gland (hypophysis). One example is the cleavage of proopiomelanocortin, produced by corticotropic cells, into one dozen bioactive peptides (Dores and Baron 2011). A common prohormone is also formed for adiuretin/(Arg)vasopressin and neurophysin II (Baribeau and Anagnostou 2015). Similarly, the precursor of oxytocin is formed from a larger precursor, together with neurophysin I (Gimpl and Fahrenholz 2001). Both preprohormone genes are coupled in mammalians and transcribed in opposite directions; moreover, both vasopressin and oxytocin are nonapeptides requiring cyclization (Baribeau and Anagnostou 2015). Otherwise genes encoding two or more peptides are not frequent laside from immunoglobulins) and probably have different origin. For instance, in several holometabolic insects, a translation initiation factor can be linked to a heterochromatin-associated protein, required for chromatin condensation, by removal of a stop codon and in-frame gene fusion (Krauss and Reuter 2000).

In ciliates, an adenylyl cyclase and a $\mathrm{K}^{+}$-channel are co-expressed as a fusion protein (Schultz et al. 1992; Weber et al. 2004). This accounts for the fact that a $\mathrm{K}^{+}$ conductivity stimulates CAMP formation which regulates increased ciliary beat activity (Bonini et al. 1991). In contrast, for $\mathrm{Ca}^{2+}$ - and cGMP-mediated enhancement of ciliary reversal (Yang et al. 1997) no such connection to $\mathrm{Ca}^{2+}$ channels exists.

A "two genes for one protein" situation is seen with one of the CaN SUs in P. tetraurelia. Here, the translation products of the two CaN-B ohnolog genes-quite surprisinglyare identical (Fraga et al. 2010). Clearly this reflects permanent trial and error on the nucleotide level which results in identical proteins because of constraints. Such constraint is also observed with the highly conserved binding site of $\mathrm{CaN}-\mathrm{B}$ on the CaN-A SU. Genes encoding identical isoforms are observed more extensively with actin in E. histolytica and Dictyostelium (Gunning et al. 2015). In E. histolytica, there exists one cytoplasmic actin encoded by 7 genes, and in $D$. discoideum, eight actins are encoded by 24 genes. In such cases, one may consider a function by translational amplification effects. The numerous ohnologs of different genes/proteins in $P$. tetraurelia may be considered additional examples, considering that many of them, for example, SNAREs (Plattner 2010a,b), display only very little difference between the ohnologs (Plattner 2010a).

The requirement of only one gene for producing, by posttranslational cleavage, several proteins with different 
functions is overcompensated by the requirement of additional genes for receptors. In summary, it seems that such tandem genes do not remarkably affect the total balance of genes in different organisms. Occurrence of many ohnologs can serve an amplification effect and may also be the basis for further differentiation during evolution.

\section{Proteins under discussion}

Surprisingly, $I \mathrm{P}_{3} \mathrm{Rs}$ have been identified by mass spectroscopic analysis in the membranes of carefully purified cilia of Chlamydomonas (Pazour et al. 2005) and of Paramecium (Yano et al. 2013). However, in P. tetraurelia, molecular analyses and immuno-localization of a selection of the $I_{3} R$ s revealed restriction to vesicles participating in trafficking, whereas $I P_{3} R s$ remained undetected in cilia (Ladenburger et al. 2006). The discrepancy may be explained by different methodical sensitivities.

Also trimeric G-proteins, GPCRs, luminal CaBPs in $\mathrm{Ca}^{2+}$ stores, and annexins have been only tentatively identified in ciliates (Plattner 2010b). Other proteins identified insufficiently in ciliates are those involved in nuclear death, an apoptosis-related process involved in elimination of the old macronucleus after conjugation (Guerrier et al. 2017). There would be many more examples.

\section{SYNOPSIS OF CHANGES FROM PROTISTS TO HUMANS AND PLANTS}

Altogether, this review considers the evolutionary "career" of molecules from protists on, asking "what has become of prominent proteins during evolution?" To mediate and govern increasing complexity, evolution of eukaryotic cells has required an increasing inventory of proteins, some found already in bacteria, and many more in unicellular organisms. Essentially, this includes cytoskeletal elements, motor proteins, signaling molecules, components enabling vesicle trafficking, scaffolding proteins, and etc. Representatives of all these have been identified in different protists, although with variations. This is summarized in Tables 1, 2.

How is increasing complexity achieved? Is there an ancient core inventory transmitted during evolution? Consider that green plants are made of $\sim 70$ cell types and that our body contains $\sim 240$ cell types, to give some typical pilot values reported in the Internet and based on methodology reported by Bard et al. (2005), with nearly 100,000 proteins species, despite the only moderate increase of protein-coding genes in man (below). In principle, evolutionary differentiation of proteins can include further use of old genes, their modification by the mechanisms discussed above, by formation of new genes (and deletion of some old genes, as exemplified), formation of splice variants, posttranslational modifications, increasing numbers of transcription factors, noncoding regulatory DNA, and etc. All these mechanisms can contribute to evolution of the eukaryotic cell from unicellular to multicellular forms. The question arises whether precise numbers currently available can be accommodated as essential "core" genes/proteins of protists in metazoans and in green plants or, vice versa, which percentage this heritage may occupy in multicellular organisms.

\section{Can protistan genes and proteins potentially be accommodated in higher eukaryotes?}

The number of (protein-encoding) genes during evolution increases much less than previously assumed-quite in contrast to the enormous increase in DNA per nucleus ("C-value paradox," [Fedoroff 2012]). Numbers of predicted (protein-coding) genes are reported in the following ranges: 27,424 in T. thermophila (Eisen et al. 2006); 39,642 in P. tetraurelia (Aury et al. 2006); 8,657 in choanoflagellates (Suga et al. 2013); 14,516 in Chlamydomonas (Fritz-Laylin et al. 2010); 10,300 (Williams 2010) to 13,574 in Dictyostelium (Fritz-Laylin et al. 2010); 26,541 in A. thaliana (Fritz-Laylin et al. 2010; The Arabidopsis Genome Initiative 2000); finally an estimated number of between 20,344 (Uhlén et al. 2015), 20,700 (The ENCODE project consortium 2012) and 23,328 (Fritz-Laylin et al. 2010) are reportedly expressed in humans. The Charophyta species Klebsormidium flaccidum disposes of 16,215 (nuclear and organellar) protein-encoding genes (Hori et al. 2014).

The wide variations call for interpretation. The general line is an increase of the number of genes with increasing organizational level. But there are exceptions to this rule. The extraordinary number of genes in $P$. tetraurelia, in contrast to only 18,509 in P. caudatum (McGrath et al. 2014) reflects at least two whole genome duplications with little diversification of genes from the last two, out of probably three duplication rounds in $P$. tetraurelia (Aury et al. 2006; McGrath et al. 2014) which produced very similar paralogs called "ohnologs" (Ohno 1970). Thus, the number of subfamilies, rather of individual genes, may eventually be considered as a criterion for the real extent of differentiation, as discussed for SNAREs by Plattner (2010a). Although the number of genes published for some of the species mentioned is not precisely settled, it is clear that the number of protein-encoding genes has increased by only less than twofold in higher levels of multicellular organisms. Aside from gene transfer from other species, new genes arise from divergence of duplicated genes and by de novo formation from a non-(protein-)coding gene (Andersson et al. 2015). Nevertheless, there is ample space for maintaining quite a few genes/ proteins during evolution, and "modern genomes and proteins are also fossils in their own way, littered with evidence of genes that were useful to ancestral organism" (Hunter 2013). Among them are functionally most important genes/proteins, as mainly discussed in this review.

There is an enormous contrast between the number of genes and of nucleotides per nucleus which, during evolution, accumulates an enormous amount of "non-(protein-) coding DNA." Thus, the coding density decreases dramatically during evolution (Fritz-Laylin et al. 2010; Suga et al. 
2013). As we now know, during evolution this reflects an increasing contribution of regulatory factors, such as transcription factors and RNAs regulating transcription of protein-encoding genes, for example, during tissue differentiation.

There are still other mechanisms which have contributed to diversification of proteins. Some diversification of the protein inventory is enabled by alternative splicing of mRNA. This is considered an important aspect already for the latest eukaryotic common ancestor (Irimia and Roy 2014). The number of introns per gene in the protozoa under consideration is between 1.3 (D. discoideum), 3.6 ( $T$. thermophila), and 2.3 (P. tetraurelia), whereas the value indicated for $A$. thaliana is 4.8 (Atambaeva et al. 2008) and that for H. sapiens is 12.4 (Xiong et al. 2012). The percentage of genes with introns is $80-84 \%$ in $P$. tetraurelia (Aury et al. 2006; Zagulski et al. 2004), 68\% in D. discoideum (Zagulski et al. 2004), $79 \%$ in A. thaliana (The Arabidopsis Genome Initiative 2000), and $85 \%$ in H. sapiens (Aury et al. 2006). However, this does not reflect the low number of splice variants detected in ciliates (Jaillon et al. 2008). In P. tetraurelia, less than 0.9\% of the introns are alternatively spliced (Jaillon et al. 2008); in $T$. thermophila $\sim 5 \%$ of alternative splicing has been reported (Xiong et al. 2012). Also in angiosperms, the rate of splicing is low (The Arabidopsis Genome Initiative 2000). Proteomics analysis available so far indicates 86,771 proteins in $H$. sapiens (Wilhelm et al. 2014). When compared with the number of genes (above) this is compatible with an estimated number of splice forms per proteins which reportedly is between 4.5 (Chen et al. 2014) and 6.3 (The ENCODE Project Consortium 2012). Only among vertebrates, the number of splice variants increases with evolutionary level (Chen et al. 2014). According to RNA analysis, in A. thaliana, 23,840 transcripts (>29,000 with splice variants included) have been assigned to 22,076 genes (Liang et al. 2016). The low rate of splicing in $P$. tetraurelia explains that only $\sim 30,000$ proteins are to be expected (Zagulski et al. 2004). Here, in $P$. tetraurelia, some of the numerous ohnologs, for example, of $\mathrm{Ca}^{2+}$-release channels (Ladenburger and Plattner 2011; Ladenburger et al. 2009) and of SNAREs (Plattner 2010a), may either serve for amplification effects or they may provide similar effects as splice variants do in vertebrate cells.

Additional variation comes from covalent posttranslational modifications such as aminoacylation, for example, of tubulins from ciliates (Adoutte et al. 1991) to mammals (Wloga and Gaertig 2010), fatty acylation, isoprenylation of GTPases, and ubiquitylation (Duan and Walther 2015) phenomena, in part, known also form protozoans where this is only insufficiently analyzed so far.

The predominant mass of DNA per nucleus in mammals and higher plants is nonprotein coding; it is rather engaged in regulatory processes via regulatory RNAs (Morris and Mattick 2014) and formation of an ever increasing number of transcription factors, from $\sim 1,400$ to 1,900 (Vaquerizas et al. 2009) to several thousand estimated in man. In fact, the number of transcription factor genes steadily increases, 1,558 being reported by Wingender et al. (2013), with an additional increase to $>2,900$ when isoforms generated by alternative splicing or protein processing events are included. In a single-cell system, such as protozoa, their number will necessarily be considerably smaller. This follows from a comparative genomic analysis where the content of transcription factor-encoding genes relative to that in man was $10 \%$ in the choanoflagellate M. brevicollis, $9 \%$ in D. discoideum, $7 \%$ in T. thermophila, and $12 \%$ in C. reinhardtii (De Mendoza et al. 2013). The value was higher only in $A$. thaliana (135\%); the unexpectedly high value in $P$. tetraurelia $(42 \%)$ is probably due to the severalfold whole-genome duplications. In summary, a crucial aspect pertinent to the topic of the present review is the fact that (protein) coding density in humans is only 1.5\% (International Human Genome Sequencing Consortium 2001) or $2.8 \%$ in a selected sample (Alexander et al. 2010) and 4.5 in Arabidopsis (Arabidopsis Genome Initiative 2000), in contrast to $\sim 85 \%$ in Paramecium (Aury et al. 2006), to give an example.

In humans, widely varying expression in different tissues is required for differentiation which is enabled by epigenetically controlled transcription factors and their splice variants (Kim et al. 2014). In humans, only 44\% of the protein-encoding genes are expressed in all major tissues (Uhlén et al. 2015) which, therefore, may represent some basic equipment for basic functions. As mentioned, bacterial genes contribute by $\sim 37 \%$ to mammalian gene sequences and $28 \%$ are all-eukaryotic (McFall-Ngai et al. 2013), whereas over $50 \%$ are retained from low metazoans up to man and from low plants up to angiosperms (Gimpel et al. 2013). The percentage of protistan genes retained during evolution remains to be established. Nevertheless, there appears to be enough storage capacity to accommodate much of the basic inventory of lower eukaryotes in their highest multicellular descendants. Concomitantly, as far as analyzed so far, orthologs of functionally important genes are found throughout eukaryote evolution, although with some variations.

\section{Essential changes and innovations during evolution}

From bottom to top of organismic evolution, some proteins may display high conservation of structure and localization. Examples are calmodulin, P-type $\mathrm{Ca}^{2+}$ pumps, GTPases, and inositol 1,4,5-trisphosphate receptors in ciliates and metazoans. Most impressive changes of protein structure, function, and/or localization are as follows.

(i) The exchange of voltage-dependent $\mathrm{Ca}^{2+}$-influx channels in cilia of protozoa for transient receptor potential (TRP)-type channels in epithelia and primary cilia allows to achieve more flexibility, although with slower responses. Fast response is required, for example, to avoid obstacles and predators by swimming Paramecium cells via ciliary reversal, as summarized recently (Plattner 2017a,b). Analogously, in mammalians, voltage-gated $\mathrm{Ca}^{2+}$ channels are engaged in rapid neuronal communication. 
(ii) Some proteins are endowed with specific, but evolutionarily variable domains (e.g. R-SNAREs, type synaptobrevins, in animals vs. longins in ciliates and plants, synaptotagmin and enhanced synaptotagmins in Paramecium vs. mammalians). With R-SNAREs, targeting effects are obvious for plants.

(iii) Expansion of some protein subunit family members (ohnologs) can eventually change intracellular localization of holoenzyme combinations. In Paramecium, increased gene numbers encoding SU-a of the $\mathrm{V}$ type $\mathrm{H}^{+}$-ATPase allow to connect different $\mathrm{VO}$ and $\mathrm{V} 1$ parts and this may potentially mediate binding of different partner proteins and overall variable targeting.

(iv) Proteins with occasional incorporation of regulating sequences (e.g. a calmodulin-like domain in " $\mathrm{Ca}^{2+}$ dependent protein kinases," CDPK, of ciliates and plants). This entails strict co-localization of effector (kinase) and regulator (CaM).

(v) Loss of a subunit (e.g. of calcineurin A in plants) is connected with regulation of ion channels by $\mathrm{CBL}$ kinase.

(vi) Loss of entire proteins, alveolin, for example, can be explained by absence of alveoli outside Alveolata, although alveoli resemble structurally and functionally rather closely cortical ER sacs of some metazoan cells (Plattner 2014).

(vii) Proteins differentiating from atypical precursors during evolution, for example, from ryanodine-receptorlike $\mathrm{Ca}^{2+}$-release channels in ciliates, may be the starting point for RyRs which now requires extensive scrutiny in different taxons.

(viii) There are proteins with pharmacological characteristics varying between subfamily members (e.g. varying drug binding by actin isoforms in protists).

(ix) In some other proteins, we observe an inconsistent expression of subfamily traits, for example, flotillin/ reggie vs. stomatin characters in ciliates.

(x) Neofunctionalization (e.g. $\eta$-tubulin in Paramecium) and refunctionalization of proteins (e.g. calcineurin B in plants; centrin in centrosomes vs. plasmodesmata in plant). Such phenomena are considered a driving force in evolution.

(xi) Endowment of proteins with a GPI anchor (e.g. glycosylphosphatidylinositol-anchored "variant surface antigens" in ciliates and Apicomplexa vs. numerous GPI-anchored glycocalyx proteins in metazoans) can mediate flexibility of such proteins with regard to trafficking and signaling (Stuermer 2010, 2012). (xii) Some proteins are newly "invented" during evolution (e.g. neuronal secretory peptides; keratin-type intermediate filaments in animal cells; plant-specific proteins, such as cellulose synthase).

In this review, frequently similarities between monokonts and bikonts are mentioned, but we also see many more variability and dissimilarity when molecular structure and subcellular localization are compared (Table 2). This is compatible with the emergence of the two lineages from common ancestors, possibly already during early eukaryote evolution. Diversification can have been accompanied by loss, modification, or new formation of specific molecules. However, it should not be denied that some authors have questioned the mono-/bikont subdivision of organisms altogether, based on the analysis of a broad range of proteins (Baldauf et al. 2000) or on rare genomic changes (Rogozin et al. 2009). Similarities would be compatible with the preservation of early protein components before organisms have split into the two lineages. Beyond this, we have seen examples that "green" multicellular bikonts (plants) differ, in part, from flagellated algae and even more from ciliates, for example, with regard to centrin localization, CBL activity, and absence of $\mathrm{IP}_{3} R s$ and TPRs.

Some components occurring already in protozoans (SNAREs, GTPases, CaM, some CRCs) are retained up to highest evolutionary levels. Some become essential in man for long-term potentiation, that is learning, and for immune defense ( $\mathrm{CaN})$. Except $\mathrm{CaN}$ and CRCs, similar proteins are found in selected (archae)bacteria. This includes protein sequences related to SNAREs, GTPases, and their modulators. (However, occurrence of such protein equivalents in some pathogenic bacteria could also indicate top-to-bottom gene transfer.) Also CaM and PMCA are known from some eubacteria, and recent analysis of Lokiarchaeota-type archaebacteria was very much enlightening since it also revealed the presence of some precursors of some additional molecules under consideration here (Spang et al. 2015). In total, many proteins dedicated to most basic and complex functions in our body have been available already early on in evolution. Eventually proteins have changed intracellular position during eukaryotic evolution. A good example are voltage-dependent (depolarization-sensitive) $\mathrm{Ca}^{2+}$-influx channels which, in ciliates, are restricted to cilia, but in mammals to neurons.

In summary, from the analysis of a limited set of proteins probed so far in protists for molecular structure, function, and subcellular localization, it appears that early eukaryotes had collected most components essential for establishing a complex, dynamic intracellular structure from different types of bacteria where many putative precursors still can be found. One driving force was leakage of $\mathrm{Ca}^{2+}$ from the outside which required counter-regulation already in bacteria. Early eukaryotic cells have reverted this disadvantage to an advantage, that is, spatially and temporally restricted signaling. Thus, with increasing cell size, this principle was overriding mere 
$\mathrm{Ca}^{2+}$ downregulation. This recalls the detoxification and energetic exploitation of increasing atmospheric oxygen concentration during evolution-another innovation critical for prokaryote-to-eukaryote transformation.

Many of the basic regulatory and functional mechanisms related to $\mathrm{Ca}^{2+}$ are essentially maintained during evolution, from protozoa to man. Many details had to follow, for example, a dramatic increase of the number of effector molecules for $\mathrm{Ca}^{2+}$, that is, CaBPs, during evolution. Essential molecular features observed in protozoa and specifically in ciliates are operating in the most complicated functional capabilities of man. As outlined at the beginning, just considering size, the nuclear genome of protists could potentially have been accommodated in the genome of the most highly evolved metazoans. As mentioned, bacterial genes contribute by $\sim 37 \%$ to mammalian gene sequences (McFall-Ngai et al. 2013) and the percentage of protozoan precursors, although not known in detail, will probably be even higher. Metazoans have steadily increased their genome which is about 50\% larger than that of unicellular organisms. In addition, posttranslational processing and modification have increased the number of protein species. Considerable changes are also observed during evolution of higher plants. On several occasions, whole-genome duplications provided play material for diversification (Van de Peer et al. 2009).

In retrospect, work with different protists gives excellent examples of the evolutionary phenomena described. The kind of "evolutionary cell biology" (Lynch et al. 2014) addressed here will advance as the number of protein molecules investigated in protists will steadily increase.

\section{ACKNOWLEDGMENTS}

The author's work cited herein has been supported up to 2014 by the German Research Council (Deutsche Forschungsgemeinschaft, DFG). The author also wants to thank the many coworkers who contributed over the years, as cited, to the analysis of trafficking and signaling in Paramecium cells.

\section{ABBREVIATIONS}

$\left[\mathrm{Ca}^{2+}\right]_{\mathrm{i}}$ : intracellular free $\mathrm{Ca}^{2+}$ concentration

CaBP: $\mathrm{Ca}^{2+}$-binding protein

CaM: calmodulin

CaM-kinase: $\mathrm{Ca}^{2+} / \mathrm{CaM}$-activated protein kinase

$\mathrm{CaN}$ : calcineurin (protein phosphatase 2B, PP2B)

CBL: CaN-B-like

CDPK: $\mathrm{Ca}^{2+}$-dependent protein kinase with integrated CaM-motif

CIPKs: CBL-interacting protein kinases

COP: coatomer protein

CRC: $\mathrm{Ca}^{2+}$-release channel
GPI-: glycosylphosphatidylinositol

G-protein: trimeric GTP-binding protein

GTPase: monomeric low-molecular-weight GTP-binding/ GTP hydrolyzing proteins

$\mathrm{IP}_{3}$ : inositol 1,4,5-trisphosphate

$I P_{3} R: I P_{3}$ receptor

LP: like protein

NSF: N-ethylmaleimide sensitive factor

PL-C: phospholipase C

PMCA: plasmamembrane $\mathrm{Ca}^{2+}$-ATPase/pump

RyR: ryanodine receptor

SERCA: sarcoplasmic/endoplasmic reticulum $\mathrm{Ca}^{2+}$ ATPase/pump

SNAP-25: soluble NSF attachment protein-25

SNARE: soluble N-ethylmaleimide-sensitive factor attachment protein receptors

SPFH: stomatin/prohibitin/flotillin (reggie)/Hflk protein family

SU: subunit

TRP channel: transient receptor potential channel

vsAG: variant surface antigen

\section{LITERATURE CITED}

Abby, S. S., Tannier, E., Gouy, M. \& Daubi, V. 2012. Lateral gene transfer as a support for the tree of life. Proc. Natl Acad. Sci. USA, 109:4962-4967.

Abedin, M. \& King, N. 2008. The premetazoan ancestry of cadherins. Science, 319:946-948.

Adoutte, A., Claisse, M., Maunoury, R. \& Beisson, J. 1985. Tubulin evolution: ciliate-specific epitopes are conserved in the ciliary tubulin of metazoa. J. Mol. Evol., 22:220-229.

Adoutte, A., Delgado, P., Fleury, A., Levilliers, N., Lainé, M. C., Marty, M. C., Boisvieux-Ulrich, E. \& Sandoz, D. 1991. Microtubule diversity in ciliated cells: evidence for its generation by post-translational modification in the axonemes of Paramecium and quail oviduct cells. Biol. Cell, 71:227-245.

Aichem, A. \& Mutzel, R. 2001. Unconventional mRNA processing in the expression of two calcineurin B isoforms in Dictyostelium. J. Mol. Biol., 308:873-882.

Alegado, R. A. \& King, N. 2014. Bacterial influences on animal origins. Cold Spring Harb. Perspect. Biol., 6:a016162.

Alexander, R. P., Fang, G., Rozowsky, J., Snyder, M. \& Gerstein, M. B. 2010. Annotating non-coding regions of the genome. Nat. Rev. Genet., 11:559-571.

Ammar, R., Torti, D., Tsui, K., Gebbia, M., Durbic, T., Bader, G. D., Giaever, G. \& Nislow, C. 2012. Chromatin is an ancient innovation conserved between Archaea and Eukarya. Elife, 1: e00078.

Andersson, D. I., Jerlstrom-Hultqvist, J. \& Nasvall, J. 2015. Evolution of new functions de novo and from preexisting genes. Cold Spring Harb. Perspect. Biol., 7:a017996. 
André, B., Noegel, A. A. \& Schleicher, M. 1996. Dictyostelium discoideum contains a family of calmodulin-related EF-hand proteins that are developmentally regulated. FEBS Lett., 382:198202.

Arabidopsis Initiative. 2000. Analysis of the genome sequence of the flowering plant Arabidopsis thaliana. Nature, 408:796-815.

Aramburu, J., Heitman, J. \& Crabtree, G. R. 2004. Calcineurin: a central controller of signalling in eukaryotes. EMBO Rep., 5:343-348.

Aramburu, J., Rao, A. \& Klee, C. B. 2000. Calcineurin: from structure to function. Curr. Top. Cell. Regul., 36:237-295.

Arias-Darraz, L., Cabezas, D., Colenso, C. K., Alegria-Arcos, M., Bravo-Moraga, F., Varas-Concha, I., Almonacid, D. E., Madrid, R. \& Brauchi, S. 2015. A transient receptor potential ion channel in Chlamydomonas shares key features with sensory transduction-associated TRP channels in mammals. Plant Cell, 27:177-188.

Arnaiz, O., Cain, S., Cohen, J. \& Sperling, L. 2007. ParameciumDB: a community resource that integrates the Paramecium tetraurelia genome sequence with genetic data. Nucleic Acids Res., 35:D439-D444.

Atambaeva, S. A., Khailenko, V. A. \& Ivashchenko, A. T. 2008. Changes of introns and exons length in genes of Arabidopsis, rice, nematode and human. Mol. Biol. (Moscow), 42:352361.

Atlas, D. 2013. The voltage-gated calcium channel functions as the molecular switch of synaptic transmission. Annu. Rev. Biochem., 82:607-635.

Aubusson-Fleury, A., Bricheux, G., Damaj, R., Lemullois, M., Coffe, G., Donnadieu, F., Koll, F., Vigues, B. \& Bouchard, P. 2013. Epiplasmins and epiplasm in Paramecium: the building of a submembraneous cytoskeleton. Protist, 164:451-469.

Aury, J. M., Jaillon, O., Duret, L., Noel, B., Jubin, C., Porcel, B. M., Ségurens, B., Daubin, V., Anthouard, V., Aiach, N., Arnaiz, O., Billaut, A., Beisson, J., Blanc, I., Bouhouche, K., Camara, F., Duharcourt, S., Guigo, R., Gogendeau, D., Katinka, M., Keller, A. M., Kissmehl, R., Klotz, C., Koll, F., Le Mouël, A., Lepère, G., Malinsky, S., Nowacki, M., Nowak, J. K., Plattner, H., Poulain, J., Ruiz, F., Serrano, V., Zagulski, M., Dessen, P., Bétermier, M., Weissenbach, J., Scarpelli, C., Schachter, V., Sperling, L., Meyer, E., Cohen, J. \& Wincker, P. 2006. Global trends of whole-genome duplications revealed by the ciliate Paramecium tetraurelia. Nature, 444:171-178.

Avasthi, P., Onishi, M., Karpiak, J., Yamamoto, R., Mackinder, L., Jonikas, M. C., Sale, W. S., Shoichet, B., Pringle, J. R. \& Marshall, W. F. 2014. Actin is required for IFT regulation in Chlamydomonas reinhardtii. Curr. Biol., 24:2025-2032.

Azimzadeh, J. 2014. Exploring the evolutionary history of centrosomes. Philos. Trans. R. Soc. Lond. B Biol. Sci., 369:20130453.

Baldauf, S. L., Roger, A. J., Wenk-Siefert, I. \& Doolittle, W. F. 2000. A kingdom-level phylogeny of eukaryotes based on combined protein data. Science, 290:972-977.

Barber, C. F., Jorquera, R. A., Melom, J. E. \& Littleton, J. T. 2009. Postsynaptic regulation of synaptic plasticity by synaptotagmin 4 requires both C2 domains. J. Cell Biol., 187:295-310.

Bard, J., Rhee, S. Y. \& Ashburner, M. 2005. An ontology for cell types. Genome Biol., 6:R21.

Baribeau, D. A. \& Anagnostou, E. 2015. Oxytocin and vasopressin: linking pituitary neuropeptides and their receptors to social neurocircuits. Front. Neurosci., 9:335

Battle, C., Ott, C. M., Burnette, D. T., Lippincott-Schwartz, J. \& Schmidt, C. F. 2015. Intracellular and extracellular forces drive primary cilia movement. Proc. Natl Acad. Sci. USA, 112:14101415
Bauer, N. C., Doetsch, P. W. \& Corbett, A. H. 2015. Mechanisms regulating protein localization. Traffic, 16:1039-1061.

Beck, C. \& Uhl, R. 1994. On the localization of voltage-sensitive calcium channels in the flagella of Chlamydomonas reinhardtii. J. Cell Biol., 125:1119-1125.

Beisson, J., Clérot, J. C., Fleury-Aubusson, A., Garreau de Loubresse, N., Ruiz, F. \& Klotz, C. 2001. Basal body-associated nucleation center for the centrin-based cortical cytoskeletal network in Paramecium. Protist, 152:339-354.

Berridge, M. J. 2006. Calcium microdomains: organization and function. Cell Calcium, 40:405-412.

Berridge, M. J., Bootman, M. D. \& Roderick, H. L. 2003. Calcium signalling: dynamics, homeostasis and remodelling. Nat. Rev. Mol. Cell Biol., 4:517-529.

Beyenbach, K. W. \& Wieczorek, H. 2006. The V-type $\mathrm{H}^{+}$-ATPase: molecular structure and function, physiological roles and regulation. J. Exp. Biol., 209:577-589.

Bhattacharya, S., Bunick, C. G. \& Chazin, W. J. 2004. Target selectivity in EF-hand calcium binding proteins. Biochim. Biophys. Acta, 1742:69-79.

Bhattacharya, D., Steinkotter, J. \& Melkonian, M. 1993. Molecular cloning and evolutionary analysis of the calcium-modulated contractile protein, centrin, in green algae and land plants. Plant Mol. Biol., 23:1243-1254.

Blackman, L. M., Harper, J. D. \& Overall, R. L. 1999. Localization of a centrin-like protein to higher plant plasmodesmata. Eur. J. Cell Biol., 78:297-304.

Bloodgood, R. A. 2010. Sensory reception is an attribute of both primary cilia and motile cilia. J. Cell Sci., 123:505-509.

Bonifacino, J. S. \& Glick, B. S. 2004. The mechanisms of vesicle budding and fusion. Cell, 116:153-166.

Bonini, N. M., Evans, T. C., Miglietta, L. A. \& Nelson, D. L. 1991. The regulation of ciliary motility in Paramecium by $\mathrm{Ca}^{2+}$ and cyclic nucleotides. Adv. Second Messenger Phosphoprotein Res., 23:227-272.

Bornens, M. \& Azimzadeh, J. 2007. Origin and evolution of the centrosome. Adv. Exp. Med. Biol., 607:119-129.

Bouché, N., Yellin, A., Snedden, W. A. \& Fromm, H. 2005. Plantspecific calmodulin-binding proteins. Annu. Rev. Plant Biol., 56:435-466.

Bramkamp, M. 2012. Structure and function of bacterial dynaminlike proteins. Biol. Chem., 393:1203-1214.

Brehm, P. \& Eckert, R. 1978. Calcium entry leads to inactivation of calcium channel in Paramecium. Science, 202:1203-1206.

Bright, L. J., Kambesis, N., Nelson, S. B., Jeong, B. \& Turkewitz, A. P. 2010. Comprehensive analysis reveals dynamic and evolutionary plasticity of Rab GTPases and membrane traffic in Tetrahymena thermophila. PLoS Genet., 6:e1001155.

Briguglio, J. S., Kumar, S. \& Turkewitz, A. P. 2013. Lysosomal sorting receptors are essential for secretory granule biogenesis in Tetrahymena. J. Cell Biol., 203:537-550.

Brini, M. \& Carafoli, E. 2009. Calcium pumps in health and disease. Physiol. Rev., 89:1341-1378.

Brini, M. \& Carafoli, E. 2011. The plasma membrane Ca ${ }^{2+}$-ATPase and the plasma membrane sodium calcium exchanger cooperate in the regulation of cell calcium. Cold Spring Harb. Perspect. Biol., 3:a004168

Brooks, E. R. \& Wallingford, J. B. 2014. Multiciliated cells. Curr. Biol., 24:R973-R982.

Browman, D. T., Hoegg, M. B. \& Robbins, S. M. 2007. The SPFH domain-containing proteins: more than lipid raft markers. Trends Cell Biol., 17:394-402.

Bubb, M. R., Senderowicz, A. M., Sausville, E. A., Duncan, K. L. \& Korn, E. D. 1994. Jasplakinolide, a cytotoxic natural product, 
induces actin polymerization and competitively inhibits the binding of phalloidin to F-actin. J. Biol. Chem., 269:14869-14871.

Bublitz, M., Morth, J. P. \& Nissen, P. 2011. P-type ATPases at a glance. J. Cell Sci., 124:2515-2519.

Buhse, H. E., McCutcheon, S. M., Clamp, J. C. \& Sun, P. 2011. Vorticella. Enzyclopedia Life Sci. (ELS), https://doi.org/10.1002/ 9780470015902.a0001975.pub2

Burkhardt, P. 2015. The origin and evolution of synaptic proteins choanoflagellates lead the way. J. Exp. Biol., 218:506-514.

Burkhardt, P., Gronborg, M., McDonald, K., Sulur, T., Wang, Q. \& King, N. 2014. Evolutionary insights into premetazoan functions of the neuronal protein homer. Mol. Biol. Evol., 31:2342-2355.

Burkhardt, P., Stegmann, C. M., Cooper, B., Kloepper, T. H., Imig, C., Varoqueaux, F., Wahl, M. C. \& Fasshauer, D. 2011. Primordial neurosecretory apparatus identified in the choanoflagellate Monosiga brevicollis. Proc. Natl Acad. Sci. USA, 108:1526415269.

Busch, A. \& Hess, S. 2017. The cytoskeleton architecture of algivorous protoplast feeders (Viridiraptoridae, Rhizaria) indicates actin-guided perforation of prey cell walls. Protist, 168:12-31.

Cai, X. 2008. Unicellular $\mathrm{Ca}^{2+}$ signaling 'toolkit' at the origin of metazoa. Mol. Biol. Evol., 25:1357-1361.

Cai, X., Wang, X., Patel, S. \& Clapham, D. E. 2015. Insights into the early evolution of animal calcium signaling machinery: a unicellular point of view. Cell Calcium, 57:166-173

Capdeville, Y., Cardoso de Almeida, M. L. \& Deregnaucourt, C. 1987. The membrane-anchor of Paramecium temperature-specific surface antigens is a glycosylinositol phospholipid. Biochem. Biophys. Res. Commun., 147:1219-1225.

Carafoli, E. 1994. Biogenesis: plasma membrane calcium ATPase: 15 years of work on the purified enzyme. FASEB J., 8:9931002.

Carafoli, E. \& Krebs, J. 2016. Why calcium? How calcium became the best communicator. J. Biol. Chem., 291:20849-20857.

Carr, M., Leadbeater, B. S., Hassan, R., Nelson, M. \& Baldauf, S. L. 2008. Molecular phylogeny of choanoflagellates, the sister group to metazoa. Proc. Natl Acad. Sci. USA, 105:1664116646.

Carvalho-Santos, Z., Azimzadeh, J., Pereira-Leal, J. B. \& Bettencourt-Dias, M. 2011. Evolution: tracing the origins of centrioles, cilia, and flagella. J. Cell Biol., 194:165-175.

Castillo, K., Delgado, R. \& Bacigalupo, J. 2007. Plasma membrane $\mathrm{Ca}^{2+}$-ATPase in the cilia of olfactory receptor neurons: possible role in $\mathrm{Ca}^{2+}$ clearance. Eur. J. Neurosci., 26:2524-2531.

Catalano, A. \& O'Day, D. H. 2008. Calmodulin-binding proteins in the model organism Dictyostelium: a complete \& critical review. Cell. Signal., 20:277-291.

Chan, C. W., Saimi, Y. \& Kung, C. 1999. A new multigene family encoding calcium-dependent calmodulin-binding membrane proteins of Paramecium tetraurelia. Gene, 231:21-32.

Cheaib, M., Dehghani Amirabad, A., Nordstrom, K. J., Schulz, M. H. \& Simon, M. 2015. Epigenetic regulation of serotype expression antagonizes transcriptome dynamics in Paramecium tetraurelia. DNA Res., 22:293-305.

Chen, L., Bush, S. J., Tovar-Corona, J. M., Castillo-Morales, A. \& Urrutia, A. O. 2014. Correcting for differential transcript coverage reveals a strong relationship between alternative splicing and organism complexity. Mol. Biol. Evol., 31:14021413.

Chi, P., Greengard, P. \& Ryan, T. A. 2003. Synaptic vesicle mobilization is regulated by distinct synapsin I phosphorylation pathways at different frequencies. Neuron, 38:69-78.

Chin, D. \& Means, A. R. 2000. Calmodulin: a prototypical calcium sensor. Trends Cell Biol., 10:322-328.
Clapham, D. E. 2007. Calcium signaling. Cell, 131:1047-1058.

Colaneri, A. C. \& Jones, A. M. 2014. The wiring diagram for plant G signaling. Curr. Opin. Plant Biol., 22:56-64.

Cole, E. S., Anderson, P. C., Fulton, R. B., Majerus, M. E., Rooney, M. G., Savage, J. M., Chalker, D., Honts, J., Welch, M. E., Wentland, A. L., Zweifel, E. \& Beussman, D. 2008. A proteomics approach to cloning fenestrin from the nuclear exchange junction of Tetrahymena. J. Eukaryot. Microbiol., 55:245-256

Cooper, J. A. 1987. Effects of cytochalasin and phalloidin on actin. J. Cell Biol., 105:1473-1478.

Craxton, M. 2004. Synaptotagmin gene content of the sequenced genomes. BMC Genom., 5:43

Craxton, M. 2007. Evolutionary genomics of plant genes encoding $\mathrm{N}$-terminal-TM-C2 domain proteins and the similar FAM62 genes and synaptotagmin genes of metazoans. BMC Genom., 8:259.

Crespi, B. J. 2016. Oxytocin, testosterone, and human social cognition. Biol. Rev. Camb. Philos. Soc., 91:390-408.

Creutz, C. E., Tomsig, J. L., Snyder, S. L., Gautier, M. C., Skouri, F., Beisson, J. \& Cohen, J. 1998. The copines, a novel class of C2 domain-containing, calcium-dependent, phospholipid-binding proteins conserved from Paramecium to humans. J. Biol. Chem. 273:1393-1402.

Crisp, A., Boschetti, C., Perry, M., Tunnacliffe, A. \& Micklem, G. 2015. Expression of multiple horizontally acquired genes is a hallmark of both vertebrate and invertebrate genomes. Genome Biol., 16:50

Dacks, J. B. \& Field, M. C. 2007. Evolution of the eukaryotic membrane-trafficking system: origin, tempo and mode. J. Cell Sci., 120:2977-2985

Damer, C. K., Bayeva, M., Hahn, E. S., Rivera, J. \& Socec, C. I. 2005. Copine A, a calcium-dependent membrane-binding protein, transiently localizes to the plasma membrane and intracellular vacuoles in Dictyostelium. BMC Cell Biol., 6:46.

Damer, C. K., Bayeva, M., Kim, P. S., Ho, L. K., Eberhardt, E. S., Socec, C. I., Lee, J. S., Bruce, E. A., Goldman-Yassen, A. E. \& Naliboff, L. C. 2007. Copine A is required for cytokinesis, contractile vacuole function, and development in Dictyostelium. Eukaryot. Cell, 6:430-442.

Dammann, H., Hellstern, S., Husain, Q. \& Mutzel, R. 1996. Primary structure, expression and developmental regulation of a Dictyostelium calcineurin A homologue. Eur. J. Biochem., 238:391-399

Daněk, M., Valentová, O. \& Martinec, J. 2016. Flotillins, Erlins, and HIRs. From animal base camp to plant new horizons. Crit. Rev. Plant Sci., 35:191-214.

De Mendoza, A., Sebe-Pedros, A., Sestak, M. S., Matejcic, M., Torruella, G., Domazet-Loso, T. \& Ruiz-Trillo, I. 2013. Transcription factor evolution in eukaryotes and the assembly of the regulatory toolkit in multicellular lineages. Proc. Natl Acad. Sci. USA, 110:E4858-E4866.

Del Vecchio, A. J., Harper, J. D. I., Vaughn, K. C., Baron, A. T., Salisbury, J. L. \& Overall, R. L. 1997. Centrin homologues in higher plants are prominently associated with the developing cell plate. Protoplasma, 196:224-234.

DeLorenzo, R. J., Freedman, S. D., Yohe, W. B. \& Maurer, S. C. 1979. Stimulation of $\mathrm{Ca}^{2+}$-dependent neurotransmitter release and presynaptic nerve terminal protein phosphorylation by calmodulin and a calmodulin-like protein isolated from synaptic vesicles. Proc. Natl Acad. Sci. USA, 76:1838-1842.

Dentler, W. L. 1988. Fractionation of Tetrahymena ciliary membranes with triton X-114 and the identification of a ciliary membrane ATPase. J. Cell Biol., 107:2679-2688. 
Di Roberto, R. B. \& Peisajovich, S. G. 2014. The role of domain shuffling in the evolution of signaling networks. J. Exp. Zool. B Mol. Dev. Evol., 322:65-72.

Diekmann, Y. \& Pereira-Leal, J. B. 2013. Evolution of intracellular compartmentalization. Biochem. J., 449:319-331.

Dixit, A. K. \& Jayabaskaran, C. 2015. Calcium binding properties of calcium dependent protein kinase 1 (CaCDPK1) from Cicer arietinum. J. Plant Physiol., 179:106-112.

Docampo, R., Moreno, S. N. \& Plattner, H. 2014. Intracellular calcium channels in protozoa. Eur. J. Pharmacol., 739:4-18.

Doerner, J. F., Delling, M. \& Clapham, D. E. 2015. Ion channels and calcium signaling in motile cilia. Elife, 4:11066.

Domínguez, D. C., Guragain, M. \& Patrauchan, M. 2015. Calcium binding proteins and calcium signaling in prokaryotes. Cell Calcium, 57:151-165.

Dores, R. M. \& Baron, A. J. 2011. Evolution of POMC: origin, phylogeny, posttranslational processing, and the melanocortins. Ann. N. Y. Acad. Sci., 1220:34-48.

Duan, G. \& Walther, D. 2015. The roles of post-translational modifications in the context of protein interaction networks. PLoS Comput. Biol., 11:e1004049, https://doi.org/10.1371/journal.pcb i.1004049

Duby, G. \& Boutry, M. 2009. The plant plasma membrane proton pump ATPase: a highly regulated P-type ATPase with multiple physiological roles. Pflugers Arch., 457:645-655.

Dunlap, K. 1977. Localization of calcium channels in Paramecium caudatum. J. Physiol., 271:119-133.

Edel, K. H. \& Kudla, J. 2015. Increasing complexity and versatility: how the calcium signaling toolkit was shaped during plant land colonization. Cell Calcium, 57:231-246.

Efremov, R. G., Leitner, A., Aebersold, R. \& Raunser, S. 2015. Architectures and conformational switch mechanism of the ryanodine receptor. Nature, 517:39-43.

Ehrlich, B. E., Jacobson, A. R., Hinrichsen, R., Sayre, L. M. \& Forte, M. A. 1988. Paramecium calcium channels are blocked by a family of calmodulin antagonists. Proc. Natl Acad. Sci. USA, 85:5718-5722.

Eisen, J. A., Coyne, R. S., Wu, M., Wu, D., Thiagarajan, M., Wortman, J. R., Badger, J. H., Ren, Q., Amedeo, P., Jones, K. M., Tallon, L. J., Delcher, A. L., Salzberg, S. L., Silva, J. C., Haas, B. J., Majoros, W. H., Farzad, M., Carlton, J. M., Smith Jr, R. K., Garg, J., Pearlman, R. E., Karrer, K. M., Sun, L., Manning, G., Elde, N. C., Turkewitz, A. P., Asai, D. J., Wilkes, D. E., Wang, Y., Cai, H., Collins, K., Stewart, B. A., Lee, S. R., Wilamowska, K., Weinberg, Z., Ruzzo, W. L., Wloga, D., Gaertig, J., Frankel, J., Tsao, C. C., Gorovsky, M. A., Keeling, P. J., Waller, R. F., Patron, N. J., Cherry, J. M., Stover, N. A., Krieger, C. J., del Toro, C., Ryder, H. F., Williamson, S. C., Barbeau, R. A., Hamilton, E. P. \& Orias, E. 2006. Macronuclear genome sequence of the ciliate Tetrahymena thermophila, a model eukaryote. PLoS Biol., 4:e286.

Eisenhaber, B., Wildpaner, M., Schultz, C. J., Borner, G. H. Dupree, P. \& Eisenhaber, F. 2003. Glycosylphosphatidylinositol lipid anchoring of plant proteins. Sensitive prediction from sequence- and genome-wide studies for Arabidopsis and rice. Plant Physiol., 133:1691-1701.

Elde, N. C., Morgan, G., Winey, M., Sperling, L. \& Turkewitz, A. P. 2005. Elucidation of clathrin-mediated endocytosis in Tetrahymena reveals an evolutionarily convergent recruitment of dynamin. PLoS Genet., 1:e52.

El-Haddad, H., Przyborski, J. M., Kraft, L. G., McFadden, G. I., Waller, R. F. \& Gould, S. B. 2013. Characterization of TtALV2, an essential charged repeat motif protein of the Tetrahymena thermophila membrane skeleton. Eukaryot. Cell, 12:932-940.
Elwess, N. L. \& Van Houten, J. L. 1997. Cloning and molecular analysis of the plasma membrane $\mathrm{Ca}^{2+}$-ATPase gene in Paramecium tetraurelia. J. Eukaryot. Microbiol., 44:250-257.

Elzie, C. A., Colby, J., Sammons, M. A. \& Janetopoulos, C. 2009. Dynamic localization of $\mathrm{G}$ proteins in Dictyostelium discoideum. J. Cell Sci., 122:2597-2603.

ENCODE Project Consortium. 2012. An integrated encyclopedia of DNA elements in the human genome. Nature, 489:57-64.

Erxleben, C. \& Plattner, H. 1994. $\mathrm{Ca}^{2+}$ release from subplasmalemmal stores as a primary event during exocytosis in Paramecium cells. J. Cell Biol., 127:935-945.

Fajardo, M., Schleicher, M., Noegel, A., Bozzaro, S., Killinger, S., Heuner, K., Hacker, J. \& Steinert, M. 2004. Calnexin, calreticulin and cytoskeleton-associated proteins modulate uptake and growth of Legionella pneumophila in Dictyostelium discoideum. Microbiology, 150:2825-2835.

Fedoroff, N. V. 2012. Presidential address. Transposable elements, epigenetics, and genome evolution. Science, 338:758767.

Ferguson, M. A. 1999. The structure, biosynthesis and functions of glycosylphosphatidylinositol anchors, and the contributions of trypanosome research. J. Cell Sci., 112(Pt 17):27992809.

Fernandes, I. P. \& Oliveira-Brett, A. M. 2017. Calcium-induced calmodulin conformational change. Electrochemical evaluation. Bioelectrochemistry, 113:69-78.

Findeisen, F., Rumpf, C. H. \& Minor Jr, D. L. 2013. Apo states of calmodulin and $\mathrm{CaBP} 1$ control CaV1 voltage-gated calcium channel function through direct competition for the $\mathrm{IQ}$ domain. J. Mol. Biol., 425:3217-3234.

Firat-Karalar, E. N. \& Stearns, T. 2014. The centriole duplication cycle. Philos. Trans. R. Soc. Lond. B Biol. Sci., 369: rstb.2013.0460

Flötenmeyer, M., Momayezi, M. \& Plattner, H. 1999. Hydrophobic and hydrophilic radio-iodination, crosslinking, and differential extraction of cell surface proteins in Paramecium tetraurelia cells. J. Membr. Biol., 172:77-88.

Forgac, M. 2007. Vacuolar ATPases: rotary proton pumps in physiology and pathophysiology. Nat. Rev. Mol. Cell Biol., 8:917929

Fraga, D., Sehring, I. M., Kissmehl, R., Reiss, M., Gaines, R., Hinrichsen, R. \& Plattner, H. 2010. Protein phosphatase 2B (PP2B, calcineurin) in Paramecium: partial characterization reveals that two members of the unusually large catalytic subunit family have distinct roles in calcium-dependent processes. Eukaryot. Cell, 9:1049-1063.

Fritz-Laylin, L. K., Prochnik, S. E., Ginger, M. L., Dacks, J. B., Carpenter, M. L., Field, M. C., Kuo, A., Paredez, A., Chapman, J., Pham, J., Shu, S., Neupane, R., Cipriano, M., Mancuso, J., Tu, H., Salamov, A., Lindquist, E., Shapiro, H., Lucas, S., Grigoriev, I. V., Cande, W. Z., Fulton, C., Rokhsar, D. S. \& Dawson, S. C. 2010. The genome of Naegleria gruberi illuminates early eukaryotic versatility. Cell, 140:631-642.

Froissard, M., Kissmehl, R., Dedieu, J. C., Gulik-Krzywicki, T., Plattner, H. \& Cohen, J. 2002. N-ethylmaleimide-sensitive factor is required to organize functional exocytotic microdomains in Paramecium. Genetics, 161:643-650.

Fujiu, K., Nakayama, Y., lida, H., Sokabe, M. \& Yoshimura, K. 2011. Mechanoreception in motile flagella of Chlamydomonas. Nat. Cell Biol., 13:630-632.

Fujiu, K., Nakayama, Y., Yanagisawa, A., Sokabe, M. \& Yoshimura, K. 2009. Chlamydomonas CAV2 encodes a voltagedependent calcium channel required for the flagellar waveform conversion. Curr. Biol., 19:133-139. 
Garcia, C. R. S., Alves, E., Pereira, P. H., Bartlett, P. J., Thomas, A. P., Mikoshiba, K., Plattner, H. \& Sibley, L. D. 2017. InsP3 signaling in apicomplexan parasites. Curr. Top. Med. Chem., https://doi.org/10.2174/15680266170130121042

Garnier, O., Serrano, V., Duharcourt, S. \& Meyer, E. 2004. RNA-mediated programming of developmental genome rearrangements in Paramecium tetraurelia. Mol. Cell. Biol., 24:7370-7379.

Gimpel, J. A., Specht, E. A., Georgianna, D. R. \& Mayfield, S. P. 2013. Advances in microalgae engineering and synthetic biology applications for biofuel production. Curr. Opin. Chem. Biol., 17:489-495.

Gimpl, G. \& Fahrenholz, F. 2001. The oxytocin receptor system: structure, function, and regulation. Physiol. Rev., 81:629-683.

Gogendeau, D., Klotz, C., Arnaiz, O., Malinowska, A., Dadlez, M., de Loubresse, N. G., Ruiz, F., Koll, F. \& Beisson, J. 2008. Functional diversification of centrins and cell morphological complexity. J. Cell Sci., 121:65-74

Gonda, K., Komatsu, M. \& Numata, O. 2000. Calmodulin and $\mathrm{Ca}^{2+} /$ calmodulin-binding proteins are involved in Tetrahymena thermophila phagocytosis. Cell Struct. Funct., 25:243-251.

Goodson, J. L. 2005. The vertebrate social behavior network: evolutionary themes and variations. Horm. Behav., 48:11-22.

Gould, S. B., Tham, W. H., Cowman, A. F., McFadden, G. I. \& Waller, R. F. 2008. Alveolins, a new family of cortical proteins that define the protist infrakingdom Alveolata. Mol. Biol. Evol., 25:1219-1230

Gräf, R., Daunderer, C. \& Schultz, I. 2004. Molecular and functional analysis of the Dictyostelium centrosome. Int. Rev. Cytol., 241:156-203.

Griffiths, G. M., Tsun, A. \& Stinchcombe, J. C. 2010. The immunological synapse: a focal point for endocytosis and exocytosis. J. Cell Biol., 189:399-406.

Gross, J. D. 2009. Acidic $\mathrm{Ca}^{2+}$ stores, excitability, and cell patterning in Dictyostelium discoideum. Eukaryot. Cell, 8:696-702.

Grosshans, B. L., Ortiz, D. \& Novick, P. 2006. Rabs and their effectors: achieving specificity in membrane traffic. Proc. Natl Acad. Sci. USA, 103:11821-11827.

Gruss, O. J. 2010. Nuclear transport receptor goes moonlighting. Nat. Cell Biol., 12:640-641.

Guerini, D. 1997. Calcineurin: not just a simple protein phosphatase. Biochem. Biophys. Res. Commun., 235:271-275.

Guerrier, S., Plattner, H., Richardson, E., Dacks, J. B. \& Turkewitz, A. P. 2017. An evolutionary balance: conservation vs innovation in ciliate membrane trafficking. Traffic, 18:18-28.

Gunning, P. W., Ghoshdastider, U., Whitaker, S., Popp, D. \& Robinson, R. C. 2015. The evolution of compositionally and functionally distinct actin filaments. J. Cell Sci., 128:2009-2019.

Guy, L. \& Ettema, T. J. 2011. The archaeal 'TACK' superphylum and the origin of eukaryotes. Trends Microbiol., 19:580-587.

Ham, H., Sreelatha, A. \& Orth, K. 2011. Manipulation of host membranes by bacterial effectors. Nat. Rev. Microbiol., 9:635646.

Hardt, M. \& Plattner, H. 2000. Sub-second quenched-flow/X-ray microanalysis shows rapid $\mathrm{Ca}^{2+}$ mobilization from cortical stores paralleled by $\mathrm{Ca}^{2+}$ influx during synchronous exocytosis in Paramecium cells. Eur. J. Cell Biol., 79:642-652.

Hashimoto, T. 2015. Microtubules in plants. Arabidopsis Book, 13: e0179, https://doi.org/10.1199/tab.0179

Hauser, K., Pavlovic, N., Kissmehl, R. \& Plattner, H. 1998. Molecular characterization of a sarco(endo)plasmic reticulum $\mathrm{Ca}^{2+}$ ATPase gene from Paramecium tetraurelia and localization of its gene product to sub-plasmalemmal calcium stores. Biochem. J., 334:31-38.
Hauser, K., Pavlovic, N., Klauke, N., Geissinger, D. \& Plattner, H. 2000. Green fluorescent protein-tagged sarco(endo)plasmic reticulum $\mathrm{Ca}^{2+}$-ATPase overexpression in Paramecium cells: isoforms, subcellular localization, biogenesis of cortical calcium stores and functional aspects. Mol. Microbiol., 37:773-787.

Haynes, P. A., Gooley, A. A., Ferguson, M. A., Redmond, J. W. \& Williams, K. L. 1993. Post-translational modifications of the Dictyostelium discoideum glycoprotein PsA. Glycosylphosphatidylinositol membrane anchor and composition of O-linked oligosaccharides. Eur. J. Biochem., 216:729-737.

Hedges, S. B. 2002. The origin and evolution of model organisms. Nat. Rev. Genet., 3:838-849.

Hellstern, S., Dammann, H., Husain, Q. \& Mutzel, R. 1997. Overexpression, purification and characterization of Dictyostelium calcineurin A. Res. Microbiol., 148:335-343.

Henty-Ridilla, J. L., Li, J., Blanchoin, L. \& Staiger, C. J. 2013. Actin dynamics in the cortical array of plant cells. Curr. Opin Plant Biol., 16:678-687.

Herzig, S. \& Neumann, J. 2000. Effects of serine/threonine protein phosphatases on ion channels in excitable membranes. Physiol. Rev., 80:173-210.

Hinderhofer, M., Walker, C. A., Friemel, A., Stuermer, C. A. Möller, H. M. \& Reuter, A. 2009. Evolution of prokaryotic SPFH proteins. BMC Evol. Biol., 9:10.

Hinshaw, J. E. 2000. Dynamin and its role in membrane fission. Annu. Rev. Cell Dev. Biol., 16:483-519.

Hirose, S., Santhanam, B., Katoh-Kurosawa, M., Shaulsky, G. \& Kuspa, A. 2015. Allorecognition, via TgrB1 and $\operatorname{TgrC} 1$, mediates the transition from unicellularity to multicellularity in the social amoeba Dictyostelium discoideum. Development, 142:35613570.

Hodges, M. E., Scheumann, N., Wickstead, B., Langdale, J. A. \& Gull, K. 2010. Reconstructing the evolutionary history of the centriole from protein components. J. Cell Sci., 123:1407-1413.

Holliday, L. S. 2014. Vacuolar $\mathrm{H}^{+}$-ATPase: an essential multitasking enzyme in physiology and pathophysiology. New J. Sci., 2014:article ID 675430, https://doi.org/10.1155/2014/675430

Hori, K., Maruyama, F., Fujisawa, T., Togashi, T., Yamamoto, N., Seo, M., Sato, S., Yamada, T., Mori, H., Tajima, N., Moriyama, T., Ikeuchi, M., Watanabe, M., Wada, H., Kobayashi, K., Saito, M., Masuda, T., Sasaki-Sekimoto, Y., Mashiguchi, K., Awai, K., Shimojima, M., Masuda, S., Iwai, M., Nobusawa, T., Narise, T., Kondo, S., Saito, H., Sato, R., Murakawa, M., Ihara, Y., OshimaYamada, Y., Ohtaka, K., Satoh, M., Sonobe, K., Ishii, M., Ohtani, R., Kanamori-Sato, M., Honoki, R., Miyazaki, D., Mochizuki, H., Umetsu, J., Higashi, K., Shibata, D., Kamiya, Y., Sato, N., Nakamura, Y., Tabata, S., Ida, S., Kurokawa, K. \& Ohta, H. 2014. Klebsormidium flaccidum genome reveals primary factors for plant terrestrial adaptation. Nat. Commun., 5:3978.

Hunter, P. 2013. Molecular fossils probe life's origins. Research into molecular fossils and modern viruses is shedding light on the evolution of archaea, prokaryotes and eukaryotes. EMBO Rep., 14:964-967.

Hunter, T. 2014. The genesis of tyrosine phosphorylation. Cold Spring Harb. Perspect. Biol., 6:a020644.

Hurtado-Lorenzo, A., Skinner, M., El Annan, J., Futai, M., SunWada, G. H., Bourgoin, S., Casanova, J., Wildeman, A., Bechoua, S., Ausiello, D. A., Brown, D. \& Marshansky, V. 2006 V-ATPase interacts with ARNO and Arf6 in early endosomes and regulates the protein degradative pathway. Nat. Cell Biol., 8:124-136.

International Human Genome Sequencing Consortium. 2001. Initial sequencing and analysis of the human genome. Nature, 409:860-921. 
Irimia, M. \& Roy, S. W. 2014. Origin of spliceosomal introns and alternative splicing. Cold Spring Harb. Perspect. Biol., 6, https://doi.org/10.1101/cshperspect.a016071

Jaillon, O., Bouhouche, K., Gout, J. F., Aury, J. M., Noel, B., Saudemont, B., Nowacki, M., Serrano, V., Porcel, B. M., Ségurens, B., Le Mouël, A., Lepère, G., Schächter, V., Bétermier, M., Cohen, J., Wincker, P., Sperling, L., Duret, L. \& Meyer, E. 2008. Translational control of intron splicing in eukaryotes. Nature, 451:359-362.

Jékeley, G. 2007. Eukaryotic membranes and cytoskeleton. Origins and evolution. Springer Science+Business Media, LLC, Landes Bioscience, New York, NY.

Karpov, S. A. 2016. Flagellar apparatus structure of choanoflagellates. Cilia, 5:11.

Katz, L. A. 2012. Origin and diversification of eukaryotes. Annu. Rev. Microbiol., 66:411-427.

Kerboeuf, D., Le Berre, A., Dedieu, J. C. \& Cohen, J. 1993. Calmodulin is essential for assembling links necessary for exocytotic membrane fusion in Paramecium. EMBO J., 12:33853390.

Kienle, N., Kloepper, T. H. \& Fasshauer, D. 2009. Phylogeny of the SNARE vesicle fusion machinery yields insights into the conservation of the secretory pathway in fungi. BMC Evol. Biol., 9:19.

Kiersnowska, M., Peck, R. K. \& DeHaller, G. 1988. Cell to cell recognition between the ciliate Pseudomicrothorax dubius and its food organisms - the role of surface charges. Protoplasma, 143:93-100.

Kim, K., Messinger, L. A. \& Nelson, D. L. 1998. Ca ${ }^{2+}$-dependent protein kinases of Paramecium - cloning provides evidence of a multigene family. Eur. J. Biochem., 251:605-612.

Kim, M. S., Pinto, S. M., Getnet, D., Nirujogi, R. S., Manda, S. S., Chaerkady, R., Madugundu, A. K., Kelkar, D. S., Isserlin, R., Jain, S., Thomas, J. K., Muthusamy, B., Leal-Rojas, P., Kumar, P., Sahasrabuddhe, N. A., Balakrishnan, L., Advani, J., George, B., Renuse, S., Selvan, L. D., Patil, A. H., Nanjappa, V., Radhakrishnan, A., Prasad, S., Subbannayya, T., Raju, R., Kumar, M., Sreenivasamurthy, S. K., Marimuthu, A., Sathe, G. J., Chavan, S., Datta, K. K., Subbannayya, Y., Sahu, A., Yelamanchi, S. D., Jayaram, S., Rajagopalan, P., Sharma, J., Murthy, K. R., Syed, N., Goel, R., Khan, A. A., Ahmad, S., Dey, G., Mudga, L. K., Chatterjee, A., Huang, T. C., Zhong, J., Wu, X., Shaw, P. G., Freed, D., Zahari, M. S., Mukherjee, K. K., Shankar, S., Mahadevan, A., Lam, H., Mitchell, C. J., Shankar, S. K., Satishchandra, P. Schroeder, J. T., Sirdeshmukh, R., Maitra, A., Leach, S. D., Drake, C. G., Halushka, M. K., Prasad, T. S., Hruban, R. H., Kerr, C. L., Bader, G. D., lacobuzio-Donahue, C. A., Gowda, H. \& Pandey, A. 2014. A draft map of the human proteome. Nature, 509:575-581.

Kim, K., Son, M., Peterson, J. B. \& Nelson, D. L. 2002. Ca ${ }^{2+}$ binding proteins of cilia and infraciliary lattice of Paramecium tetraurelia: their phosphorylation by purified endogenous $\mathrm{Ca}^{2+}$ dependent protein kinases. J. Cell Sci., 115:1973-1984.

King, N., Hittinger, C. T. \& Carroll, S. B. 2003. Evolution of key cell signaling and adhesion protein families predates animal origins. Science, 301:361-363.

King, N., Westbrook, M. J., Young, S. L., Kuo, A., Abedin, M., Chapman, J., Fairclough, S., Hellsten, U., Isogai, Y., Letunic, I., Marr, M., Pincus, D., Putnam, N., Rokas, A., Wright, K. J., Zuzow, R., Dirks, W., Good, M., Goodstein, D., Lemons, D., Li, W., Lyons, J. B., Morris, A., Nichols, S., Richter, D. J., Salamov, A., Sequencing, J. G., Bork, P., Lim, W. A., Manning, G., Miller, W. T., McGinnis, W., Shapiro, H., Tjian, R., Grigoriev, I. V. \& Rokhsar, D. 2008. The genome of the choanoflagellate
Monosiga brevicollis and the origin of metazoans. Nature, 451:783-788.

Kink, J. A., Maley, M. E., Preston, R. R., Ling, K. Y., Wallen-Friedman, M. A., Saimi, Y. \& Kung, C. 1990. Mutations in Paramecium calmodulin indicate functional differences between the C-terminal and N-terminal lobes in vivo. Cell, 62:165-174.

Kint, C., Verstraeten, N., Hofkens, J., Fauvart, M. \& Michiels, J. 2014. Bacterial Obg proteins: GTPases at the nexus of protein and DNA synthesis. Crit. Rev. Microbiol., 40:207-224.

Kissmehl, R., Froissard, M., Plattner, H., Momayezi, M. \& Cohen, J. 2002. NSF regulates membrane traffic along multiple pathways in Paramecium. J. Cell Sci., 115:3935-3946.

Kissmehl, R., Huber, S., Kottwitz, B., Hauser, K. \& Plattner, H. 1998. Subplasmalemmal Ca-stores in Paramecium tetraurelia. Identification and characterisation of a sarco(endo)plasmic reticulum-like $\mathrm{Ca}^{2+}$-ATPase by phosphoenzyme intermediate formation and its inhibition by caffeine. Cell Calcium, 24:193-203.

Kissmehl, R., Schilde, C., Wassmer, T., Danzer, C., Nühse, K., Lutter, K. \& Plattner, H. 2007. Molecular identification of 26 syntaxin genes and their assignment to the different trafficking pathways in Paramecium. Traffic, 8:523-542.

Kissmehl, R., Sehring, I. M., Wagner, E. \& Plattner, H. 2004. Immunolocalization of actin in Paramecium cells. J. Histochem. Cytochem., 52:1543-1559.

Kissmehl, R., Treptau, T., Kottwitz, B. \& Plattner, H. 1997. Occurrence of a para-nitrophenyl phosphate-phosphatase with calcineurin-like characteristics in Paramecium tetraurelia. Arch. Biochem. Biophys., 344:260-270.

Kitamura, A. \& Hiwatashi, K. 1984. A possible mechanism of chemical induction of conjugation in Paramecium - importance of cationic exchange on the cell surface. J. Exp. Zool., 231:303307.

Klee, C. B., Ren, H. \& Wang, X. 1998. Regulation of the calmodulin-stimulated protein phosphatase. J. Biol. Chem., 273:1336713370.

Kleene, S. J. 2009. Limits of calcium clearance by plasma membrane calcium ATPase in olfactory cilia. PLOS ONE, 4:e5266.

Kleene, S. J. \& Van Houten, J. L. 2014. Electrical signaling in motile and primary cilia. Bioscience, 64:1092-1102.

Kloepper, T. H., Kienle, C. N. \& Fasshauer, D. 2007. An elaborate classification of SNARE proteins sheds light on the conservation of the eukaryotic endomembrane system. Mol. Biol. Cell, 18:3463-3471.

Kloepper, T. H., Kienle, C. N. \& Fasshauer, D. 2008. SNAREing the basis of multicellularity: consequences of protein family expansion during evolution. Mol. Biol. Evol., 25:2055-2068.

Klotz, C., Ruiz, F., Garreau De Loubresse, N., Wright, M., DupuisWilliams, P. \& Beisson, J. 2003. Gamma-tubulin and MTOCs in Paramecium. Protist, 154:193-209.

Kobilka, B. 2013. The structural basis of G-protein-coupled receptor signaling (Nobel Lecture). Angew. Chem. Int. Ed. Engl., 52:6380-6388

Koonin, E. V. \& Yutin, N. 2014. The dispersed archaeal eukaryome and the complex archaeal ancestor of eukaryotes. Cold Spring Harb. Perspect. Biol., 6:a016188.

Krauss, V. \& Reuter, G. 2000. Two genes become one: the genes encoding heterochromatin protein Su(var)3-9 and translation initiation factor subunit elF-2gamma are joined to a dicistronic unit in holometabolic insects. Genetics, 156:1157-1167.

Krinke, O., Novotna, Z., Valentova, O. \& Martinec, J. 2007. Inositol trisphosphate receptor in higher plants: is it real? J. Exp. Bot., 58:361-376.

Ladenburger, E. M., Korn, I., Kasielke, N., Wassmer, T. \& Plattner, H. 2006. An Ins $(1,4,5) \mathrm{P}_{3}$ receptor in Paramecium is 
associated with the osmoregulatory system. J. Cell Sci., 119:3705-3717.

Ladenburger, E.-M. \& Plattner, H. 2011. Calcium-release channels in Paramecium. Genomic expansion, differential positioning and partial transcriptional elimination. PLOS ONE, 6(11):e27111.

Ladenburger, E.-M., Sehring, I. M., Korn, I. \& Plattner, H. 2009. Novel types of $\mathrm{Ca}^{2+}$-release channels participate in the secretory cycle of Paramecium cells. Mol. Cell. Biol., 29:3605-3622.

Lai, M. M., Hong, J. J., Ruggiero, A. M., Burnett, P. E., Slepnev, V. I., De Camilli, P. \& Snyder, S. H. 1999. The calcineurin-dynamin 1 complex as a calcium sensor for synaptic vesicle endocytosis. J. Biol. Chem., 274:25963-25966.

Länge, S., Klauke, N. \& Plattner, H. 1995. Subplasmalemmal $\mathrm{Ca}^{2+}$-stores of probable relevance for exocytosis in Paramecium. Alveolar sacs share some but not all characteristics with sarcoplasmic reticulum. Cell Calcium, 17:335-344.

Langhorst, M. F., Reuter, A., Jaeger, F. A., Wippich, F. M., Luxenhofer, G., Plattner, H. \& Stuermer, C. A. 2008. Trafficking of the microdomain scaffolding protein reggie-1/flotillin-2. Eur. J. Cell Biol., 87:211-226.

Lapatsina, L., Brand, J., Poole, K., Daumke, O. \& Lewin, G. R. 2012. Stomatin-domain proteins. Eur. J. Cell Biol., 91:240-245.

Leondaritis, G., Sarri, T., Dafnis, I., Efstathiou, A. \& Galanopoulou, D. 2011. Biochemical and genetic evidence for the presence of multiple phosphatidylinositol- and phosphatidylinositol 4,5bisphosphate-specific phospholipases $\mathrm{C}$ in Tetrahymena. Eukaryot. Cell, 10:412-422.

Levitan, I. B. 1999. It is calmodulin after all! Mediator of the calcium modulation of multiple ion channels. Neuron, 22:645-648.

Levy, Y. Y., Lai, E. Y., Remillard, S. P., Heintzelman, M. B. \& Fulton, C. 1996. Centrin is a conserved protein that forms diverse associations with centrioles and MTOCs in Naegleria and other organisms. Cell Motil. Cytoskeleton, 33:298-323.

Liang, C., Cheng, S., Zhang, Y., Sun, Y., Fernie, A. R., Kang, K., Panaagiotou, G., Lo, C. \& Lim, B. L. 2016. Transcriptomic, proteomic and metabolic changes in Arabidopsis thaliana leaves after the onset of illumination. BMC Plant Biol., 16:43.

Liang, F. \& Sze, H. 1998. A high-affinity $\mathrm{Ca}^{2+}$ pump, ECA1, from the endoplasmic reticulum is inhibited by cyclopiazonic acid but not by thapsigargin. Plant Physiol., 118:817-825.

Lim, W. A. \& Pawson, T. 2010. Phosphotyrosine signaling: evolving a new cellular communication system. Cell, 142:661-667.

Lipka, V., Kwon, C. \& Panstruga, R. 2007. SNARE-ware: the role of SNARE-domain proteins in plant biology. Annu. Rev. Cell Dev. Biol., 23:147-174.

Llynch, M. \& Marinov, G. K. 2016. Mitochondria do not boost the bioenergetics capacity of eukaryotic cells. Proc. Natl Acad. Sci. USA, 113:E667-E668

Lodh, S., Yano, J., Valentine, M. S. \& Van Houten, J. L. 2016. Voltage-gated calcium channels of Paramecium cilia. J. Exp. Biol., 219:3028-3038.

Loomis, W. F. 2014. Cell signaling during development of Dictyostelium. Dev. Biol., 391:1-16.

Lopreiato, R., Giacomello, M. \& Carafoli, E. 2014. The plasma membrane calcium pump: new ways to look at an old enzyme. J. Biol. Chem., 289:10261-10268.

Lorenzo, I. M., Liedtke, W., Sanderson, M. J. \& Valverde, M. A. 2008. TRPV4 channel participates in receptor-operated calcium entry and ciliary beat frequency regulation in mouse airway epithelial cells. Proc. Natl Acad. Sci. USA, 105:12611-12616.

Lynch, M., Field, M. C., Goodson, H. V., Malik, H. S., Pereira-Leal, J. B., Roos, D. S., Turkewitz, A. P. \& Sazer, S. 2014. Evoloutionary cell biology: two origins, one objective. Proc. Natl Acad. Sci. USA, 111:16990-16994.
Machemer, H. \& Ogura, A. 1979. Ionic conductances of membranes in ciliated and deciliated Paramecium. J. Physiol., 296:49-60.

Magallón, S., Hilu, K. W. \& Quandt, D. 2013. Land plant evolutionary timeline: gene effects are secondary to fossil constraints in relaxed clock estimation of age and substitution rates. Am. J. Bot., 100:556-573.

Malicki, J. J. \& Johnson, C. A. 2017. The cilium: cellular antaenna and central processing unit. Trends Cell Biol., 27:126-140.

Mana-Capelli, S., Graf, R. \& Larochelle, D. A. 2009. Dictyostelium discoideum $\mathrm{CenB}$ is a bona fide centrin essential for nuclear architecture and centrosome stability. Eukaryot. Cell, 8:11061117.

Mani, A., Singh, S., Dwivedi, M., Tripathi, V. \& Gupta, D. K. 2011. An evolutionary account of GPI anchored proteins. Eur. J. Exp. Biol., 1:148-155.

Manning, G., Young, S. L., Miller, W. T. \& Zhai, Y. 2008. The protist, Monosiga brevicollis, has a tyrosine kinase signaling network more elaborate and diverse than found in any known metazoan. Proc. Natl Acad. Sci. USA, 105:9674-9679.

Marchadier, E., Oates, M. E., Fang, H., Donoghue, P. C., Hetherington, A. M. \& Gough, J. 2016. Evolution of the calcium-based intracellular signaling system. Genome Biol. Evol., 8:2118-2132.

Marks, B. \& McMahon, H. T. 1998. Calcium triggers calcineurindependent synaptic vesicle recycling in mammalian nerve terminals. Curr. Biol., 8:740-749.

Marsh, J. A. \& Teichmann, S. A. 2010. How do proteins gain new domains? Genome Biol., 11:126.

Martens, S. \& McMahon, H. T. 2008. Mechanisms of membrane fusion: disparate players and common principles. Nat. Rev. Mol. Cell Biol. 9:543-556.

Martijn, J. \& Ettema, T. J. 2013. From archaeon to eukaryote: the evolutionary dark ages of the eukaryotic cell. Biochem. Soc. Trans., 41:451-457.

Martin, J. A., Hu, Z., Fenz, K. M., Fernandez, J. \& Dittman, J. S. 2011. Complexin has opposite effects on two modes of synaptic vesicle fusion. Curr. Biol., 21:97-105.

Martinez-Arca, S., Rudge, R., Vacca, M., Raposo, G., Camonis, J., Proux-Gillardeaux, V., Daviet, L., Formstecher, E., Hamburger, A., Filippini, F., D’Esposito, M. \& Galli, T. 2003. A dual mechanism controlling the localization and function of exocytic vSNAREs. Proc. Natl Acad. Sci. USA, 100:9011-9016.

Martinez-Sanz, J. \& Assairi, L. 2016. New insights into the interaction of centrin with Sfi1. Biochim. Biophys. Acta, 1864: 319-330.

Maxson, M. E. \& Grinstein, S. 2014. The vacuolar-type H+-ATPase at a glance - more than a proton pump. J. Cell Sci., 127:49874993.

Mayer, B. J. 2008. Clues to the evolution of complex signaling machinery. Proc. Natl Acad. Sci. USA, 105:9453-9454.

McCourt, R. M., Delwiche, C. F. \& Karol, K. G. 2004. Charophyte algae and land plant origins. Trends Ecol. Evol., 19:661-666.

McFall-Ngai, M., Hadfield, M. G., Bosch, T. C., Carey, H. V., Domazet-Loso, T., Douglas, A. E., Dubilier, N., Eberl, G., Fukami, T., Gilbert, S. F., Hentschel, U., King, N., Kjelleberg, S. Knoll, A. H., Kremer, N., Mazmanian, S. K., Metcalf, J. L., Nealson, K., Pierce, N. E., Rawls, J. F., Reid, A., Ruby, E. G., Rumpho, M., Sanders, J. G., Tautz, D. \& Wernegreen, J. J. 2013 Animals in a bacterial world, a new imperative for the life sciences. Proc. Natl Acad. Sci. USA, 110:3229-3236.

McGrath, C. L., Gout, J. F., Doak, T. G., Yanagi, A. \& Lynch, M. 2014. Insights into three whole-genome duplications gleaned from the Paramecium caudatum genome sequence. Genetics, 197:1417-1428. 
McMahon, S. M., Chang, C. W. \& Jackson, M. B. 2016. Multiple cytosolic calcium buffers in posterior pituitary nerve terminals. J. Gen. Physiol., 147:243-254.

Mélendez-Hernández, M. G., Barrios, M. L., Orozco, E. \& LunaArias, J. P. 2008. The vacuolar ATPase from Entamoeba histolytica: molecular cloning of the gene encoding for the B subunit and subcellular localization of the protein. BMC Microbiol., 8:235.

Miller, W. T. 2012. Tyrosine kinase signaling and the emergence of multicellularity. Biochim. Biophys. Acta, 1823:1053-1057.

Min, S. W., Chang, W. P. \& Südhof, T. C. 2007. E-Syts, a family of membranous $\mathrm{Ca}^{2+}$-sensor proteins with multiple $\mathrm{C} 2$ domains. Proc. Natl Acad. Sci. USA, 104:3823-3828.

Mitchell, D. R. 2007. The evolution of eukaryotic cilia and flagella as motile and sensory organelles. Adv. Exp. Med. Biol., 607:130-140.

Mizuno-Yamasaki, E., Rivera-Molina, F. \& Novick, P. 2012. GTPase networks in membrane traffic. Annu. Rev. Biochem., 81:637-659.

Mohanta, T. K., Mohanta, N., Mohanta, Y. K., Parida, P. \& Bae, H. 2015. Genome-wide identification of Calcineurin B-Like (CBL) gene family of plants reveals novel conserved motifs and evolutionary aspects in calcium signaling events. BMC Plant Biol., 15:189.

Momayezi, M., Albrecht, P., Plattner, H. \& Schmidt, H. J. 2004 Temperature-induced change of variant surface antigen expression in Paramecium involves antigen release into the culture medium with considerable delay between transcription and surface expression. J. Membr. Biol., 200:15-23.

Momayezi, M., Kersken, H., Gras, U., Vilmart-Seuwen, J. \& Plattner, H. 1986. Calmodulin in Paramecium tetraurelia: localization from the in vivo to the ultrastructural level. J. Histochem. Cytochem., 34:1621-1638.

Momayezi, M., Kissmehl, R. \& Plattner, H. 2000. Quantitative immunogold localization of protein phosphatase 2B (calcineurin) in Paramecium cells. J. Histochem. Cytochem., 48:1269-1281

Momayezi, M., Lumpert, C. J., Kersken, H., Gras, U., Plattner, H., Krinks, M. H. \& Klee, C. B. 1987. Exocytosis induction in Paramecium tetraurelia cells by exogenous phosphoprotein phosphatase in vivo and in vitro: possible involvement of calcineurin in exocytotic membrane fusion. J. Cell Biol., 105:181189.

Moniakis, J., Coukell, M. B. \& Forer, A. 1995. Molecular cloning of an intracellular P-type ATPase from Dictyostelium that is upregulated in calcium-adapted cells. J. Biol. Chem., 270:2827628281.

Moran, J., Mckean, P. G. \& Ginger, M. L. 2014. Eukaryotic flagella: variations in form, function, and composition during evolution. Bioscience, 64:1103-1114.

Morgan, R. O., Martin-Almedina, S., Iglesias, J. M., GonzalezFlorez, M. I. \& Fernandez, M. P. 2004. Evolutionary perspective on annexin calcium-binding domains. Biochim. Biophys. Acta, 1742:133-140

Morris, K. V. \& Mattick, J. S. 2014. The rise of regulatory RNA. Nat. Rev. Genet., 15:423-437.

Müller, A., Klöppel, C., Smith-Valentine, M., Van Houten, J. \& Simon, M. 2012. Selective and programmed cleavage of GPIanchored proteins from the surface membrane by phospholipase C. Biochim. Biophys. Acta, 1818:117-124.

Müller-Taubenberger, A., Lupas, A. N., Li, H., Ecke, M., Simmeth, E. \& Gerisch, G. 2001. Calreticulin and calnexin in the endoplasmic reticulum are important for phagocytosis. EMBO J., 20:6772-6782.
Nagao, S. \& Nozawa, Y. 1985. Calmodulin-binding proteins of Tetrahymena microsomal membranes. Comp. Biochem. Physiol. B, 82:689-693.

Naitoh, Y. \& Eckert, R. 1969. Ionic mechanisms controlling behavioral responses of Paramecium to mechanical stimulation. Science, 164:963-965.

Nakamura, A., Hanyuda, Y., Okagaki, T., Takagi, T. \& Kohama, K. 2005. A calmodulin-dependent protein kinase from lower eukaryote Physarum polycephalum. Biochem. Biophys. Res. Commun., 328:838-844.

Nichols, S. A., Roberts, B. W., Richter, D. J., Fairclough, S. R. \& King, N. 2012. Origin of metazoan cadherin diversity and the antiquity of the classical cadherin/beta-catenin complex. Proc. Natl Acad. Sci. USA, 109:13046-13051.

Noegel, A. A. \& Schleicher, M. 2000. The actin cytoskeleton of Dictyostelium: a story told by mutants. J. Cell Sci., 113:759-766.

Ohba, T., Sawada, E., Suzuki, Y., Yamamura, H., Ohya, S., Tsuda, H. \& Imaizumi, Y. 2013. Enhancement of $\mathrm{Ca}^{2+}$ influx and ciliary beating by membrane hyperpolarization due to ATP-sensitive $\mathrm{K}^{+}$ channel opening in mouse airway epithelial cells. J. Pharmacol. Exp. Ther., 347:145-153.

Ohno, S. 1970. Evolution by gene duplication. George Allen and Unwin, London, UK.

Pablo, J. L., DeCaen, P. G. \& Clapham, D. E. 2017. Progress in ciliary ion channel physiology. J. Gen. Physiol., 149:37-47.

Palmgren, M. G. \& Nissen, P. 2011. P-type ATPases. Annu. Rev. Biophys., 40:243-266.

Pan, M., Xu, X., Chen, Y. \& Jin, T. 2016. Identification of a chemoattractant $\mathrm{G}$-protein-coupled receptor for folic acid that controls both chemotaxis and phagocytosis. Dev. Cell, 36:428-439.

Pape, R., Kissmehl, R., Glas-Albrecht, R. \& Plattner, H. 1991. Effects of anti-microtubule agents on Paramecium cell culture growth. Eur. J. Protistol., 27:283-289.

Parent, C. A., Blacklock, B. J., Froehlich, W. M., Murphy, D. B. \& Devreotes, P. N. 1998. G protein signaling events are activated at the leading edge of chemotactic cells. Cell, 95:81-91.

Park, H. Y., Kim, S. A., Korlach, J., Rhoades, E., Kwok, L. W., Zipfel, W. R., Waxham, M. N., Webb, W. W. \& Pollack, L. 2008. Conformational changes of calmodulin upon $\mathrm{Ca}^{2+}$ binding studied with a microfluidic mixer. Proc. Natl Acad. Sci. USA, 105:542-547.

Parrotta, L., Cresti, M. \& Cai, G. 2014. Accumulation and posttranslational modifications of plant tubulins. Plant Biol (Stuttg), 16:521-527.

Pazour, G. J., Agrin, N., Leszyk, J. \& Witman, G. B. 2005. Proteomic analysis of a eukaryotic cilium. J. Cell Biol., 170:103-113.

Pearson, C. G. \& Winey, M. 2009. Basal body assembly in ciliates: the power of numbers. Traffic, 10:461-471.

Peterson, J. B. 1991. Small GTP-binding proteins associated with secretory vesicles of Paramecium. J. Protozool., 38:495-501.

Phua, S. C., Lin, Y. C. \& Inoue, T. 2015. An intelligent nanoantenna: primary cilium harnesses TRP channels to decode polymodal stimuli. Cell Calcium, 58:415-422.

Pilhofer, M., Ladinsky, M. S., McDowall, A. W., Petroni, G. \& Jensen, G. J. 2011. Microtubules in bacteria: ancient tubulins build a five-protofilament homolog of the eukaryotic cytoskeleton. PLoS Biol., 9(12):e1001213.

Plattner, H. 2010a. How to design a highly organized cell: an unexpectedly high number of widely diversified SNARE proteins positioned at strategic sites in the ciliate, Paramecium tetraurelia. Protist, 161:497-516.

Plattner, H. 2010b. Membrane trafficking in protozoa SNARE proteins, $\mathrm{H}^{+}$-ATPase, actin, and other key players in ciliates. Int. Rev. Cell Mol. Biol., 280:79-184. 
Plattner, H. 2014. Calcium regulation in the protozoan model, Paramecium tetraurelia. J. Eukaryot. Microbiol., 61:95-114.

Plattner, H. 2015a. The contractile vacuole complex of protistsnew cues to function and biogenesis. Crit. Rev. Microbiol., 41:218-227.

Plattner, H. 2015b. Molecular aspects of calcium signalling at the crossroads of unikont and bikont eukaryote evolution-the ciliated protozoan Paramecium in focus. Cell Calcium, 57:174-185.

Plattner, H. 2017a. Signalling in ciliates: long- and short-range signals and molecular determinants for cellular dynamics. Biol. Rev. Camb. Philos. Soc., 92:60-107.

Plattner, H. 2017b. Trichocysts - Paramecium's projectile-like secretory organelles. J. Eukaryot. Microbiol., 61:95-114.

Plattner, H., Artalejo, A. R. \& Neher, E. 1997a. Ultrastructural organization of bovine chromaffin cell cortex-analysis by cryofixation and morphometry of aspects pertinent to exocytosis. $J$. Cell Biol., 139:1709-1717.

Plattner, H., Habermann, A., Kissmehl, R., Klauke, N., Majoul, I. \& Söling, H. D. 1997b. Differential distribution of calcium stores in Paramecium cells. Occurrence of a subplasmalemmal store with a calsequestrin-like protein. Eur. J. Cell Biol., 72:297-306.

Plattner, H., Sehring, I. M., Schilde, C. \& Ladenburger, E. M. 2009. Pharmacology of ciliated protozoa - drug (in)sensitivity and experimental drug (ab)use. Int. Rev. Cell Mol. Biol., 273:163-218

Plattner, H., Stürzl, R. \& Matt, H. 1985. Synchronous exocytosis in Paramecium cells. IV. Polyamino compounds as potent trigger agents for repeatable trigger-redocking cycles. Eur. J. Cell Biol., 36:32-37.

Plattner, H. \& Verkhratsky, A. 2015. The ancient roots of calcium signalling evolutionary tree. Cell Calcium, 57:123-132.

Plattner, H. \& Verkhratsky, A. 2016. Inseparable tandem: evolution chooses ATP and $\mathrm{Ca}^{2+}$ to control life, death and cellular signalling. Philos. Trans. R. Soc. Lond. B Biol. Sci., 371, https://doi.org/10.1098/rstb.2015.0419

Plattner, H., Westphal, C. \& Tiggemann, R. 1982. Cytoskeletonsecretory vesicle interactions during the docking of secretory vesicles at the cell membrane in Paramecium tetraurelia cells. J. Cell Biol., 92:368-377.

Poovaiah, B. W., Du, L., Wang, H. \& Yang, T. 2013. Recent advances in calcium/calmodulin-mediated signaling with an emphasis on plant-microbe interactions. Plant Physiol., 163:531-542.

Preer, J. R. 1986. Surface antigens of Paramecium. In: Gall, J. (ed.), Molecular Biology of the Ciliated Protozoa. Academic Press, London, NY. p. 301-339.

Preston, R. R., Kink, J. A., Hinrichsen, R. D., Saimi, Y. \& Kung, C. 1991. Calmodulin mutants and $\mathrm{Ca}^{2+}$-dependent channels in Paramecium. Annu. Rev. Physiol., 53:309-319.

Preston, R. R., Saimi, Y. \& Kung, C. 1992. Calcium current activated upon hyperpolarization of Paramecium tetraurelia. J. Gen. Physiol., 100:233-251.

Prole, D. L. \& Taylor, C. W. 2011. Identification of intracellular and plasma membrane calcium channel homologues in pathogenic parasites. PLOS ONE, 6:e26218.

Quetglas, S., Iborra, C., Sasakawa, N., De Haro, L., Kumakura, K., Sato, K., Leveque, C. \& Seagar, M. 2002. Calmodulin and lipid binding to synaptobrevin regulates calcium-dependent exocytosis. EMBO J., 21:3970-3979.

Ratajczak, R. 2000. Structure, function and regulation of the plant vacuolar $\mathrm{H}^{+}$-translocating ATPase. Biochim. Biophys. Acta, 1465:17-36.

Reuter, A. T., Stuermer, C. A. \& Plattner, H. 2013. Identification, localization, and functional implications of the microdomain- forming stomatin family in the ciliated protozoan Paramecium tetraurelia. Eukaryot. Cell, 12:529-544.

Rivera-Milla, E., Stuermer, C. A. \& Málaga-Trillo, E. 2006. Ancient origin of reggie (flotillin), reggie-like, and other lipid-raft proteins: convergent evolution of the SPFH domain. Cell. Mol. Life Sci., 63:343-357.

Rizo, J., Chen, X. \& Arac, D. 2006. Unraveling the mechanisms of synaptotagmin and SNARE function in neurotransmitter release. Trends Cell Biol., 16:339-350.

Rogozin, I. B., Basu, M. K., Csuros, M. \& Koonin, E. V. 2009 Analysis of rare genomic changes does not support the unikont-bikont phylogeny and suggests cyanobacterial symbiosis as the point of primary radiation of eukaryotes. Genome Biol. Evol., 1:99-113.

Rojas, A. M., Fuentes, G., Rausell, A. \& Valencia, A. 2012. The Ras protein superfamily: evolutionary tree and role of conserved amino acids. J. Cell Biol., 196:189-201.

Rosenbaum, J. 2000. Cytoskeleton: functions for tubulin modifications at last. Curr. Biol., 10:R801-R803.

Rothman, J. E. 2014. The principle of membrane fusion in the cell (Nobel lecture). Angew. Chem. Int. Ed. Engl., 53:12676-12694.

Ruiz, F., Krzywicka, A., Klotz, C., Keller, A., Cohen, J., Koll, F., Balavoine, G. \& Beisson, J. 2000. The SM19 gene, required for duplication of basal bodies in Paramecium, encodes a novel tubulin, eta-tubulin. Curr. Biol., 10:1451-1454.

Ruiz-Trillo, I., Burger, G., Holland, P. W., King, N., Lang, B. F., Roger, A. J. \& Gray, M. W. 2007. The origins of multicellularity: a multi-taxon genome initiative. Trends Genet., 23:113-118.

Rusnak, F. \& Mertz, P. 2000. Calcineurin: form and function Physiol. Rev., 80:1483-1521.

Sagane, Y., Zech, K., Bouquet, J. M., Schmid, M., Bal, U. \& Thompson, E. M. 2010. Functional specialization of cellulose synthase genes of prokaryotic origin in chordate larvaceans. Development, 137:1483-1492.

Saimi, Y. \& Kung, C. 2002. Calmodulin as an ion channel subunit. Annu. Rev. Physiol., 64:289-311.

Saito-Nakano, Y., Nakahara, T., Nakano, K., Nozaki, T. \& Numata, O. 2010. Marked amplification and diversification of products of ras genes from rat brain, Rab GTPases, in the ciliates Tetrahymena thermophila and Paramecium tetraurelia. J. Eukaryot. Microbiol., 57:389-399.

Sakamoto, H., Nishio, K., Tomisako, M., Kuwayama, H., Tanaka, Y., Suetake, I., Tajima, S., Ogihara, S., Coukell, B. \& Maeda, M. 2003. Identification and characterization of novel calcium-binding proteins of Dictyostelium and their spatial expression patterns during development. Dev. Growth Differ., 45:507-514.

Salathe, M. 2007. Regulation of mammalian ciliary beating. Annu. Rev. Physiol., 69:401-422.

Salisbury, J. L., Suino, K. M., Busby, R. \& Springett, M. 2002. Centrin-2 is required for centriole duplication in mammalian cells. Curr. Biol., 12:1287-1292.

Sanderfoot, A. 2007. Increases in the number of SNARE genes parallels the rise of multicellularity among the green plants. Plant Physiol., 144:6-17.

Sansebastiano, G. D. \& Piro, G. 2014. The SNARE proteins (in plants) beyond the Nobel prize. J. Plant Biochem. Physiol., 2 e122, https://doi.org/10.4172/2329-9029.1000e122

Sanyal, S. K., Pandey, A. \& Pandey, G. K. 2015. The CBL-CIPK signaling module in plants: a mechanistic perspective. Physiol. Plant., 155:89-108

Sardar, A. J., Oates, M. E., Fang, H., Forrest, A. R. R., Kawaji, H., Fantom consortium, Gough, J. \& Rackham, O. J. L. 2014. The evolution of human cells in terms of protein innovation. Mol. Biol. Evol., 31:1364-1374. 
Schilde, C., Lutter, K., Kissmehl, R. \& Plattner, H. 2008. Molecular identification of a SNAP-25-like SNARE protein in Paramecium. Eukaryot. Cell, 7:1387-1402.

Schilde, C., Schönemann, B., Sehring, I. M. \& Plattner, H. 2010. Distinct subcellular localization of a group of synaptobrevin-like SNAREs in Paramecium tetraurelia and effects of silencing SNARE-specific chaperone NSF. Eukaryot. Cell, 9:288-305.

Schilde, C., Wassmer, T., Mansfeld, J., Plattner, H. \& Kissmehl, R. 2006. A multigene family encoding R-SNAREs in the ciliate Paramecium tetraurelia. Traffic, 7:440-455.

Schlatterer, C., Happle, K., Lusche, D. F. \& Sonnemann, J. 2004. Cytosolic $\left[\mathrm{Ca}^{2+}\right]$ transients in Dictyostelium discoideum depend on the filling state of internal stores and on an active sarco/endoplasmic reticulum calcium ATPase (SERCA) $\mathrm{Ca}^{2+}$-pump. J. Biol. Chem., 279:18407-18414

Schultz, J. E., Klumpp, S., Benz, R., Schurhoff-Goeters, W. J. \& Schmid, A. 1992. Regulation of adenylyl cyclase from Paramecium by an intrinsic potassium conductance. Science, 255:600-603

Schumacher, K. \& Krebs, M. 2010. The V-ATPase: small cargo, large effects. Curr. Opin. Plant Biol., 13:724-730.

Segawa, Y., Suga, H., Iwabe, N., Oneyama, C., Akagi, T., Miyata, T. \& Okada, M. 2006. Functional development of Src tyrosine kinases during evolution from a unicellular ancestor to multicellular animals. Proc. Natl Acad. Sci. USA, 103:12021-12026.

Sehring, I. M., Klotz, C., Beisson, J. \& Plattner, H. 2009. Rapid downregulation of the $\mathrm{Ca}^{2+}$-signal after exocytosis stimulation in Paramecium cells: essential role of a centrin-rich filamentous cortical network, the infraciliary lattice. Cell Calcium, 45:89-97.

Sehring, I. M., Mansfeld, J., Reiner, C., Wagner, E., Plattner, H. \& Kissmehl, R. 2007a. The actin multigene family of Paramecium tetraurelia. BMC Genom., 8:82, https://doi.org/10.1186/14712164-8-82

Sehring, I. M., Reiner, C., Mansfeld, J., Plattner, H. \& Kissmehl, R. 2007b. A broad spectrum of actin paralogs in Paramecium tetraurelia cells display differential localization and function. $J$. Cell Sci., 120:177-190.

Sehring, I. M., Reiner, C. \& Plattner, H. 2010. The actin subfamily PtAct4, out of many subfamilies, is differentially localized for specific local functions in Paramecium tetraurelia cells. Eur. J. Cell Biol., 89:509-524.

Sesaki, H., Wong, E. F. \& Siu, C. H. 1997. The cell adhesion molecule DdCAD-1 in Dictyostelium is targeted to the cell surface by a nonclassical transport pathway involving contractile vacuoles. J. Cell Biol., 138:939-951.

Shalchian-Tabrizi, K., Minge, M. A., Espelund, M., Orr, R., Ruden, T., Jakobsen, K. S. \& Cavalier-Smith, T. 2008. Multigene phylogeny of choanozoa and the origin of animals. PLOS ONE, 3: e2098.

Shi, X., Halder, P., Yavuz, H., Jahn, R. \& Shuman, H. A. 2016. Direct targeting of membrane fusion by SNARE mimicry: Convergent evolution of Legionella effectors. Proc. Natl Acad. Sci. USA, 113:8807-8812.

Shi, L., Koll, F., Arnaiz, O. \& Cohen, J. 2017. The ciliary protein IFT57 in the macronucleus of Paramecium. J. Eukaryot. Microbiol., https://doi.org/10.1111/jeu.12423

Shimizu, Y., Kushida, Y., Kiriyama, S., Nakano, K. \& Numata, O. 2013. Formation and ingression of division furrow can progress under the inhibitory condition of actin polymerization in ciliate Tetrahymena pyriformis. Zoolog. Sci., 30:1044-1049.

Shimmen, T. 2007. The sliding theory of cytoplasmic streaming: fifty years of progress. J. Plant. Res., 120:31-43.

Sim, A. T., Baldwin, M. L., Rostas, J. A., Holst, J. \& Ludowyke, R. I. 2003. The role of serine/threonine protein phosphatases in exocytosis. Biochem. J., 373:641-659
Simon, M. C. \& Kusch, J. 2013. Communicative functions of GPIanchored surface proteins in unicellular eukaryotes. Crit. Rev. Microbiol., 39:70-78.

Simon, M. C. \& Schmidt, H. J. 2007. Antigenic variation in ciliates: antigen structure, function, expression. J. Eukaryot. Microbiol., 54:1-7.

Song, Y. \& Brady, S. T. 2015. Post-translational modifications of tubulin: pathways to functional diversity of microtubules. Trends Cell Biol., 25:125-136.

Soucy, S. M., Huang, J. \& Gogarten, J. P. 2015. Horizontal gene transfer: building the web of life. Nat. Rev. Genet., 16:472-482.

Spang, A., Saw, J. H., Jorgensen, S. L., Zaremba-Niedzwiedzka, K., Martijn, J., Lind, A. E., van Eijk, R., Schleper, C., Guy, L. \& Ettema, T. J. 2015. Complex archaea that bridge the gap between prokaryotes and eukaryotes. Nature, 521:173-179.

Sriskanthadevan, S., Brar, S. K., Manoharan, K. \& Siu, C. H. 2013. $\mathrm{Ca}{ }^{2+}$-calmodulin interacts with DdCAD-1 and promotes DdCAD-1 transport by contractile vacuoles in Dictyostelium cells. FEBS J., 280:1795-1806.

Staiger, C. J., Sheahan, M. B., Khurana, P., Wang, X., McCurdy, D. W. \& Blanchoin, L. 2009. Actin filament dynamics are dominated by rapid growth and severing activity in the Arabidopsis cortical array. J. Cell Biol., 184:269-280.

Staudt, E., Ramasamy, P., Plattner, H. \& Simon, M. 2016. Differential subcellular distribution of four phospholipase $C$ isoforms and secretion of GPI-PLC activity. Biochim. Biophys. Acta, 1858:3157-3168

Stelly, N., Mauger, J. P., Claret, M. \& Adoutte, A. 1991. Cortical alveoli of Paramecium: a vast submembranous calcium storage compartment. J. Cell Biol., 113:103-112.

Stemm-Wolf, A. J., Morgan, G., Giddings Jr, T. H., White, E. A., Marchione, R., McDonald, H. B. \& Winey, M. 2005. Basal body duplication and maintenance require one member of the Tetrahymena thermophila centrin gene family. Mol. Biol. Cell, 16:3606-3619.

Stenmark, H. 2012. The Rabs: a family at the root of metazoan evolution. BMC Biol., 10:68, https://doi.org/10.1186/1741-7007$10-68$

Stewart, A. G., Laming, E. M., Sobti, M. \& Stock, D. 2014. Rotary ATPases-dynamic molecular machines. Curr. Opin. Struct. Biol., 25:40-48.

Stuermer, C. A. 2010. The reggie/flotillin connection to growth. Trends Cell Biol., 20:6-13.

Stuermer, C. A. 2012. How reggies regulate regeneration and axon growth. Cell Tissue Res., 349:71-77.

Stuermer, C. A., Langhorst, M. F., Wiechers, M. F., Legler, D. F., Von Hanwehr, S. H., Guse, A. H. \& Plattner, H. 2004. PrP ${ }^{C}$ capping in $T$ cells promotes its association with the lipid raft proteins reggie-1 and reggie-2 and leads to signal transduction. FASEB J., 18:1731-1733.

Südhof, T. C. 2013. Neurotransmitter release: the last millisecond in the life of a synaptic vesicle. Neuron, 80:675-690.

Südhof, T. C. 2014. The molecular machinery of neurotransmitter release (Nobel lecture). Angew. Chem. Int. Ed. Engl., 53:12696-12717.

Suga, H., Chen, Z., de Mendoza, A., Sebe-Pedros, A., Brown, M. W., Kramer, E., Carr, M., Kerner, P., Vervoort, M., SanchezPons, N., Torruella, G., Derelle, R., Manning, G., Lang, B. F., Russ, C., Haas, B. J., Roger, A. J., Nusbaum, C. \& Ruiz-Trillo, I. 2013. The Capsaspora genome reveals a complex unicellular prehistory of animals. Nat. Commun., 4:2325.

Swan, D. G., Hale, R. S., Dhillon, N. \& Leadlay, P. F. 1987. A bacterial calcium-binding protein homologous to calmodulin. Nature, 329:84-85 
Swulius, M. T. \& Waxham, M. N. 2008. $\mathrm{Ca}^{2+} /$ calmodulin-dependent protein kinases. Cell. Mol. Life Sci., 65:2637-2657.

Taddese, B., Upton, G. J., Bailey, G. R., Jordan, S. R., Abdulla, N. Y., Reeves, P. J. \& Reynolds, C. A. 2014. Do plants contain g protein-coupled receptors? Plant Physiol., 164:287307.

Tamm, S. L. 2014. Cilia and the life of ctenophores. Invertebr. Biol., 133:1-46.

Tassin, A. M., Lemullois, M. \& Aubusson-Fleury, A. 2016. Paramecium tetraurelia basal body structure. Cilia, 5:6.

Tautermann, C. S. 2014. GPCR structures in drug design, emerging opportunities with new structures. Bioorg. Med. Chem. Lett., 24:4073-4079.

Tidow, H., Poulsen, L. R., Andreeva, A., Knudsen, M., Hein, K. L., Wiuf, C., Palmgren, M. G. \& Nissen, P. 2012. A bimodular mechanism of calcium control in eukaryotes. Nature, 491:468472

Tomsig, J. L. \& Creutz, C. E. 2002. Copines: a ubiquitous family of $\mathrm{Ca}^{2+}$-dependent phospholipid-binding proteins. Cell. Mol. Life Sci. 59:1467-1477.

Traynor, D., Milne, J. L., Insall, R. H. \& Kay, R. R. 2000. Ca ${ }^{2+}$ signalling is not required for chemotaxis in Dictyostelium. EMBO J., 19:4846-4854.

Uemura, T., Sato, M. H. \& Takeyasu, K. 2005. The longin domain regulates subcellular targeting of VAMP7 in Arabidopsis thaliana. FEBS Lett., 579:2842-2846.

Uemura, T., Ueda, T., Ohniwa, R. L., Nakano, A., Takeyasu, K. \& Sato, M. H. 2004. Systematic analysis of SNARE molecules in Arabidopsis: dissection of the post-Golgi network in plant cells. Cell Struct. Funct., 29:49-65.

Uhlén, M., Fagerberg, L., Hallstrom, B. M., Lindskog, C., Oksvold, P., Mardinoglu, A., Sivertsson, A., Kampf, C., Sjostedt, E., Asplund, A., Olsson, I., Edlund, K., Lundberg, E., Navani, S., Szigyarto, C. A., Odeberg, J., Djureinovic, D., Takanen, J. O., Hober, S., Alm, T., Edqvist, P. H., Berling, H., Tegel, H., Mulder, J., Rockberg, J., Nilsson, P., Schwenk, J. M., Hamsten, M., von Feilitzen, K., Forsberg, M., Persson, L., Johansson, F., Zwahlen, M., von Heijne, G., Nielsen, J. \& Ponten, F. 2015. Proteomics. Tissue-based map of the human proteome. Science, 347:1260419.

Úmen, J. G. 2014. Green algae and the origins of multicellularity in the plant kingdom. Cold Spring Harb. Perspect. Biol., 6(11): a016170.

Van de Peer, Y., Maere, S. \& Meyer, A. 2009. The evolutionary significance of ancient genome duplications. Nat. Rev. Genet., 10:725-732.

Van Houten, J. 1998. Chemosensory transduction in Paramecium. Eur. J. Protistol., 34:301-307.

Vandecaetsbeek, I., Vangheluwe, P., Raeymaekers, L., Wuytack, F. \& Vanoevelen, J. 2011. The $\mathrm{Ca}^{2+}$-pumps of the endoplasmic reticulum and Golgi apparatus. Cold Spring Harb. Perspect. Biol., 3:a004184

Vaquerizas, J. M., Kummerfeld, S. K., Teichmann, S. A. \& Luscombe, N. M. 2009. A census of human transcription factors: function, expression and evolution. Nat. Rev. Genet., 10:252-263.

Vedovato, M., Rossi, V., Dacks, J. B. \& Filippini, F. 2009. Comparative analysis of plant genomes allows the definition of the "Phytolongins": a novel non-SNARE longin domain protein family. BMC Genom., 10:510.

Veith, N. M., Plattner, H., Stuermer, C. A., Schulz-Schaeffer, W. J. \& Bürkle, A. 2009. Immunolocalisation of PrPSc in scrapieinfected N2a mouse neuroblastoma cells by light and electron microscopy. Eur. J. Cell Biol., 88:45-63.
Venkatachalam, K. \& Montell, C. 2007. TRP channels. Annu. Rev. Biochem., 76:387-417.

Vonderfecht, T., Cookson, M. W., Giddings Jr, T. H., Clarissa, C. \& Winey, M. 2012. The two human centrin homologues have similar but distinct functions at Tetrahymena basal bodies. Mol. Biol. Cell, 23:4766-4777

Wang, W. J., Soni, R. K., Uryu, K. \& Tsou, M. F. 2011. The conversion of centrioles to centrosomes: essential coupling of duplication with segregation. J. Cell Biol., 193:727-739.

Wassmer, T., Froissard, M., Plattner, H., Kissmehl, R. \& Cohen, J. 2005. The vacuolar proton-ATPase plays a major role in several membrane-bounded organelles in Paramecium. J. Cell Sci., 118:2813-2825

Wassmer, T., Kissmehl, R., Cohen, J. \& Plattner, H. 2006. Seventeen a-subunit isoforms of Paramecium V-ATPase provide high specialization in localization and function. Mol. Biol. Cell, 17:917-930

Wassmer, T., Sehring, I. M., Kissmehl, R. \& Plattner, H. 2009. The V-ATPase in Paramecium: functional specialization by multiple gene isoforms. Pflugers Arch., 457:599-607.

Weber, J. H., Vishnyakov, A., Hambach, K., Schultz, A., Schultz, J. E. \& Linder, J. U. 2004. Adenylyl cyclases from Plasmodium, Paramecium and Tetrahymena are novel ion channel/enzyme fusion proteins. Cell. Signal., 16:115-125.

Weissenmayer, B., Boeckeler, K., Lahrz, A. \& Mutzel, R. 2005. The calcineurin inhibitor gossypol impairs growth, cell signalling and development in Dictyostelium discoideum. FEMS Microbiol. Lett., 242:19-25.

Wesolowski, J. \& Paumet, F. 2010. SNARE motif: a common motif used by pathogens to manipulate membrane fusion. Virulence, 1:319-324.

Wheeler, G. L. \& Brownlee, C. 2008. $\mathrm{Ca}^{2+}$ signalling in plants and green algae-changing channels. Trends Plant Sci., 13:506-514.

Wickstead, B. \& Gull, K. 2011. The evolution of the cytoskeleton. J. Cell Biol., 194:513-525.

Wilczynska, Z., Happle, K., Müller-Taubenberger, A., Schlatterer, C., Malchow, D. \& Fisher, P. R. 2005. Release of $\mathrm{Ca}^{2+}$ from the endoplasmic reticulum contributes to $\mathrm{Ca}^{2+}$ signaling in Dictyostelium discoideum. Eukaryot. Cell, 4:1513-1525.

Wilhelm, M., Schlegl, J., Hahne, H., Gholami, A. M., Lieberenz, M., Savitski, M. M., Ziegler, E., Butzmann, L., Gessulat, S., Marx, H., Mathieson, T., Lemeer, S., Schnatbaum, K., Reimer, U., Wenschuh, H., Mollenhauer, M., Slotta-Huspenina, J., Boese, J.-H., Bantscheff, M., Gerstmair, A., Faerber, F. \& Kuster, B. 2014. Mass-spectrometry-based draft of the human proteome. Nature, 509:582-587.

Williams, R. J. 2006. The evolution of calcium biochemistry. Biochim. Biophys. Acta, 1763:1139-1146.

Williams, J. G. 2010. Dictyostelium finds new roles to model. Genetics, 185:717-726

Williams, J. G., Noegel, A. A. \& Eichinger, L. 2005. Manifestations of multicellularity: Dictyostelium reports in. Trends Genet. 21:392-398.

Wingender, E., Schoeps, T. \& Donitz, J. 2013. TFClass: an expandable hierarchical classification of human transcription factors. Nucleic Acids Res., 41:D165-D170.

Wloga, D. \& Gaertig, J. 2010. Post-translational modifications of microtubules. J. Cell Sci., 123:3447-3455

Wong, E. F., Brar, S. K., Sesaki, H., Yang, C. \& Siu, C. H. 1996. Molecular cloning and characterization of DdCAD-1, a $\mathrm{Ca}^{2+}$. dependent cell-cell adhesion molecule, in Dictyostelium discoideum. J. Biol. Chem., 271:16399-16408.

Xiong, J., Lu, X., Zhou, Z., Chang, Y., Yuan, D., Tian, M., Wang, L., Fu, C., Orias, E. \& Miao, W. 2012. Transcriptome analysis of 
the model protozoan, Tetrahymena thermophila, using Deep RNA sequencing. PLOS ONE, 7:e30630.

Yamashita, T. 2012. $\mathrm{Ca}^{2+}$-dependent regulation of synaptic vesicle endocytosis. Neurosci. Res., 73:1-7.

Yang, W. Q., Braun, C., Plattner, H., Purvee, J. \& Van Houten, J. L. 1997. Cyclic nucleotides in glutamate chemosensory signal transduction of Paramecium. J. Cell Sci., 110(Pt 20):2567-2572.

Yang, A., Miron, S., Duchambon, P., Assairi, L., Blouquit, Y. \& Craescu, C. T. 2006. The N-terminal domain of human centrin 2 has a closed structure, binds calcium with a very low affinity, and plays a role in the protein self-assembly. Biochemistry, 45:880-889.

Yang, X., Pei, J., Kaeser-Woo, Y. J., Bacaj, T., Grishin, N. V. \& Südhof, T. C. 2015. Evolutionary conservation of complexins: from choanoflagellates to mice. EMBO Rep., 16:1308-1317.

Yano, J., Rachochy, V. \& Van Houten, J. L. 2003. Glycosyl phosphatidylinositol-anchored proteins in chemosensory signaling: antisense manipulation of Paramecium tetraurelia PIG-A gene expression. Eukaryot. Cell, 2:1211-1219.

Yano, J., Rajendran, A., Valentine, M. S., Saha, M., Ballif, B. A. \& Van Houten, J. L. 2013. Proteomic analysis of the cilia membrane of Paramecium tetraurelia. J. Proteomics., 78:113-122.

Yu, O., An, L. \& Li, W. 2014. The CBL-CIPK network mediates different signaling pathways in plants. Plant Cell Rep., 33:203-214.

Yuseff, M. I., Reversat, A., Lankar, D., Diaz, J., Fanget, I., Pierobon, P., Randrian, V., Larochette, N., Vascotto, F., Desdouets,
C., Jauffred, B., Bellaiche, Y., Gasman, S., Darchen, F., Desnos, C. \& Lennon-Dumenil, A. M. 2011. Polarized secretion of lysosomes at the B cell synapse couples antigen extraction to processing and presentation. Immunity, 35:361-374.

Zagulski, M., Nowak, J. K., Le Mouel, A., Nowacki, M., Migdalski, A., Gromadka, R., Noel, B., Blanc, I., Dessen, P., Wincker, P., Keller, A. M., Cohen, J., Meyer, E. \& Sperling, L. 2004. High coding density on the largest Paramecium tetraurelia somatic chromosome. Curr. Biol., 14:1397-1404.

Zalk, R., Clarke, O. B., des Georges, A., Grassucci, R. A., Reiken, S., Mancia, F., Hendrickson, W. A., Frank, J. \& Marks, A. R. 2015. Structure of a mammalian ryanodine receptor. Nature, 517:44-49.

Zhang, Y. \& He, C. Y. 2012. Centrins in unicellular organisms: functional diversity and specialization. Protoplasma, 249:459467.

Zhang, H., Zhang, L., Gao, B., Fan, H., Jin, J., Botella, M. A., Jiang, L. \& Lin, J. 2011. Golgi apparatus-localized synaptotagmin 2 is required for unconventional secretion in Arabidopsis. PLOS ONE, 6:e26477.

Zhou, J. Z. \& Jiang, J. X. 2014. Gap junction and hemichannelindependent actions of connexins on cell and tissue functionsan update. FEBS Lett., 588:1186-1192.

Zhou, Y., Xue, S. \& Yang, J. J. 2013. Calciomics: integrative studies of and their interactomes in biological systems. Metallomics, 5:29-42. 